$$
\begin{gathered}
\text { Daniel Carmen Miguel ángel } \\
\text { Martín- } \begin{array}{c}
\text { Marta- Sobriz } \\
\text { Lena }
\end{array} \\
\text { rcoordinadores) } \\
\text { Prólogo de Xosé Soengas Pérez } \\
\text { Perspectivas y prospectivas } \\
\text { de la radio universitaria en } \\
\text { la era digital }
\end{gathered}
$$

\section{Perspectivas y prospectivas de la radio universitaria en la era digital}

Cuadernos Artesanos de Comunicación / 113

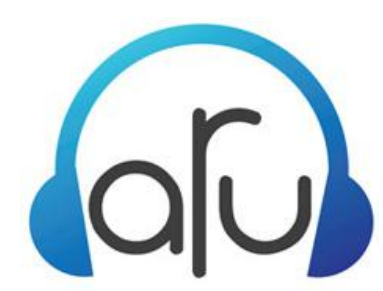




\section{Cuadernos Artesanos de Comunicación \\ Coordinador editorial: José Manuel de Pablos - jpablos@ull.edu.es \\ Comité Científico \\ Presidencia: José Luis Piñuel Raigada (UCM) \\ Secretaría: Patricia Delponti (ULL)}

- Miquel Rodrigo Alsina (Universidad Pompeu Fabra, UPF)

- Xosé Soengas (Universidad de Santiago de Compostela)

- José Luis Terrón (Universidad Autónoma de Barcelona, UAB)

- José Miguel Túñez (Universidad de Santiago, USC)

- Victoria Tur (Universidad de Alicante, UA)

- Miguel Vicente (Universidad de Valladolid, UVA)

- Ramón Zallo (Universidad del País Vasco, UPV-EHU)

- Núria Almiron (Universidad Pompeu Fabra, UPF)

- Francisco Campos Freire (Universidad de Santiago de Compostela)

- José Cisneros (Benemérita Universidad Autónoma de Puebla, BUAP)

- Bernardo Díaz Nosty (Universidad de Málaga, UMA)

- Carlos Elías (Universidad Carlos III de Madrid, UC3M)

- Paulina B. Emanuelli (Universidad Nacional de Córdoba, UNC)

- José Luis González Esteban (Universitas Miguel Hernández de Elche)

- Marisa Humanes (Universidad Rey Juan Carlos, URJC)

- Juan José Igartua (Universidad de Salamanca, USAL)

- Xosé López (Universidad de Santiago de Compostela)

- Maricela López-Ornelas (Universidad Autónoma de Baja California, AUBC)

- Javier Marzal (Universidad Jaume I, UJI)

- José Antonio Meyer (Benemérita Universidad Autónoma de Puebla, BUAP)

- Ramón Reig (Universidad de Sevilla, US)

* Queda expresamente autorizada la reproducción total o parcial de los textos publicados en este libro, en cualquier formato o soporte imaginables, salvo por explícita voluntad en contra del autor o autora o en caso de ediciones con ánimo de lucro. Las publicaciones donde se incluyan textos de esta publicación serán ediciones no comerciales y han de estar igualmente acogidas a Creative Commons.

Harán constar esta licencia y el carácter no venal de la publicación.

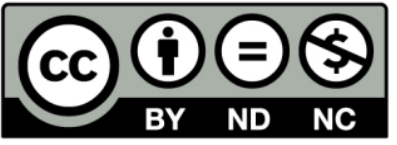

Este libro y cada uno de los capítulos que contiene, así como las imágenes incluidas, si no se indica lo contrario, se encuentran bajo una Licencia Creative Commons Atribución-No Comercial-Sin Derivadas 3.0 Unported. Puede ver una copia de esta licencia en http://creativecommons.org/licenses/by-nc-nd/3.0/ Esto significa que Ud. es libre de reproducir y distribuir esta obra, siempre que cite la autoría, que no se use con fines comerciales o lucrativos y que no haga ninguna obra derivada. Si quiere hacer alguna de las cosas que aparecen como no permitidas, contacte con los coordinadores del libro o con el autor del capítulo correspondiente.

* La responsabilidad de cada texto es de su autor o autora. 
Daniel Martín-Pena/Carmen Marta-Lazo Miguel Ángel Ortiz Sobrino

(Coordinadores)

Prólogo de Xosé Soengas Pérez

\section{Perspectivas y prospectivas de la radio universitaria en la era digital}

Cuadernos Artesanos de Comunicación / 113

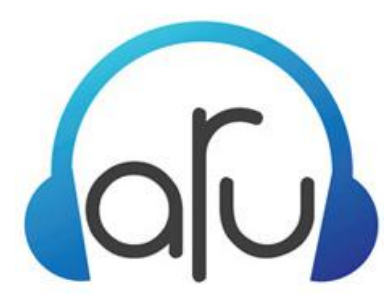


CAC $113^{\circ}$ - Perspectivas y prospectivas de la radio universitaria en la era digital

Coordinadores: Daniel Martín-Pena, Carmen Marta-Lazo y Miguel Ángel Ortiz Sobrino

Precio social: 8,50€ | Precio en librería 11,05€

Editores: Javier Herrero y Milena Trenta

Diseño: F. Drago

Ilustración de portada: Fragmento del cuadro Mujer con bernegal, de Pedro de Guezala (1958).

Imprime y distribuye: F. Drago. Andocopias S. L.

c/ La Hornera, 41. La Laguna. Tenerife.

Teléfono: 922250554 | fotocopiasdrago@,telefonica.net

Edita: Sociedad Latina de Comunicación Social - edición no venal

- La Laguna (Tenerife), 2016 - Creative Commons

http://www.revistalatinacs.org/14SLCS/portada2014.html

Descargar en pdf:

http://www.cuadernosartesanos.org/\#113

Protocolo de envío de manuscritos con destino a CAC: (la colección que corresponda)

http://www.cuadernosartesanos.org/protocolo.html

ISBN - 13: 978-84-16458-57-8

DL: TF-624-2016

DOI: $10.4185 / \operatorname{cac} 113$ 


\section{A Mariano Cebrián, el maestro de las ondas \\ y de la ciberradio universitaria.}

In memorian 


\section{Índice}

Prólogo "Las emisoras universitarias, una forma de comunicación alternativa" por

Xosé Soengas Pérez..................................................

1. Construcción colaborativa en el seno de las radios universitarias (Miguel Ángel

Ortiz Sobrino, Carmen Marta-Lazo y Daniel Martín Pena) .........................13

1. Introducción

2. Las radios universitarias: estado de la cuestión, contexto histórico, entorno educativo

3. Emisoras universitarias: un espacio, para la interactividad, la participación y la colaboración

4. Inforadio como construcción colectiva de la comunidad universitaria y la audiencia social

5. Conclusiones

2. E1 Lab experimental de 98.3 Radio para Creatividad Sonora y Radio

Especializada (Elsa Moreno)

1. Introducción

2. El proyecto de Innovación Docente

3. El caso de Creatividad Radiofónica y Sonora

4. El caso de Radio Especializada

5. Conclusión

3. Los jóvenes universitarios como productores de contenidos radiofónicos

(Nereida López Vidales, Leire Gómez-Rubio y Marta Hernando Lera) ...

1. La radio universitaria y jóvenes

2. Metodología

3. La programación de Radio UVa ¿representa realmente un elemento diferenciador en las radios universitarias?

4. Ideas para la reflexión

4. De las ondas a los bytes. La nueva era de la radio universitaria ibérica (Teresa Piñeiro Otero)....

1. Introducción

2. La Red: un nuevo espacio para un nuevo medio

3. La radio-web universitaria: una plataforma social

4. Materiales y métodos

5. Distribución de contenidos sonoros

6. Adaptación al nuevo lenguaje radiofónico

7. Interactividad

8. Conclusiones

5. La radio universitaria y su papel en la dieta mediática de los estudiantes de

Colima, México (Marina Vázquez Guerrero, Arturo García Lezama; René López Chagoya y Jorge Andrés Velasco)

1. Introducción

2. Planteamiento del problema

3. Metodología

4. Resultados y análisis

5. Discusión y recomendaciones 
6. La radio universitaria en Andalucía: experiencias y nuevos retos (Regina Pinto-

1. Introducción

2. Los albores de las futuras emisoras universitarias andaluzas

3. Emisoras de radio universitaria de Andalucía

4. Análisis de las radios universitarias andaluzas

5. Conclusiones

7. Más de diez años de experiencia formativa en OndaCampus Radio (Daniel Martín-Pena, Macarena Parejo Cuéllar y Agustín Vivas Moreno)...

1. El fenómeno de la radio universitaria en España

2. La radio de la Universidad de Extremadura, OndaCampus

3. Los datos de OndaCampus después de una década de funcionamiento

4. Conclusión

8. E1 relevo generacional en la plantilla de una radio universitaria como elemento dinamizador de su parrilla de programación y su estructura organizativa. El caso de iradioUCAM ( $\mathrm{M}^{\mathrm{a}}$ Carmen Robles Andreu, Isabel $\mathrm{M}^{\mathrm{a}}$ García González y Beatriz Correyero Ruiz).

1. Introducción

2. El relevo generacional de los miembros de una radio universitaria. El caso de iradioUCAM

3. La estructura organizativa de iradioUCAM. Innovación docente hacia la profesionalización

4. La parrilla de programación de iradioUCAM. Identidad e integración

5. Conclusiones

9. Radio universitaria, estudiantes y calidad: el podcast como instrumento de enseñanza en Radio UMH (M. Carmen Ponce López.

1. Introducción

2. Radio y Universidad: desarrollo de las radios universitarias

3. El caso de Radio UMH

4. Conclusiones

10. Análisis de las radios universitarias en el Ecuador (Juan Manuel Aguiló)

1. Inicios de la radio en Ecuador

2. Las Radios Universitarias

3. La Red de Radios Universitarias de Ecuador

4. Reflexiones sobre el papel de las radios universitarias

5. Conclusiones

11. El diseño gráfico e infografía para las radios universitarias en internet (Santiago Martínez Arias)

1. Breve apunte histórico radio en Internet

2. Web de medios audiovisuales (radio) en Internet

3. Diseño web en la enseñanza universitaria

4. Radios universitarias en España

5. Conclusiones 


\title{
Perspectivas y prospectivas de la radio universitaria en la era digital
}

\begin{abstract}
La radio universitaria ha logrado en los últimos años un amplio despliegue gracias a las posibilidades que emergen de las Tecnologías de la Información y la Comunicación y que posibilita la Red de Redes. En esta publicación colectiva se recogen investigaciones empíricas, estados de la cuestión sobre los nuevos contenidos, formatos, cibergéneros y experimentación y su aplicación en casos reales, emisoras universitarias de uno y otro lado del Atlántico. Además, de manera transversal, se realiza un acercamiento a la trayectoria histórica de los medios universitarios (radio, televisión, etc.) a nivel autonómico, estatal e internacional, que nos acerca al conocimiento de los antecedentes con los que han contado estos medios hasta encontrar en Internet su nuevo canal de comunicación y conexión con los "prosumidores". Los objetivos de este Cuaderno Artesano de la Comunicación son construir un panorama de la potencialidad de la radio como medio universitario de comunicación y plantear las posibilidades del mismo para favorecer la divulgación científica y la transferencia social del conocimiento, así como delimitar los perfiles de los oyentes y observar la diversidad de colaboradores y colectivos participantes. Asimismo, pretende servir de análisis de las dinámicas de trabajo en red, alianzas e intercambios que se vienen realizando entre diferentes emisoras universitarias en diferentes ámbitos.
\end{abstract}

\section{Keywords}

Radio Universitaria; TIC; Internet; Formatos; Programación.

\section{Forma de citar este libro}

Autor del capítulo (2016): "Título del capítulo", en Perspectivas y prospectivas de la radio universitaria en la era digital, Daniel Martín-Pena, Carmen Marta-Lazo y Miguel Ángel Ortiz Sobrino (Coords.). Cuadernos Artesanos de Comunicación, 113. La Laguna (Tenerife): Latina. 


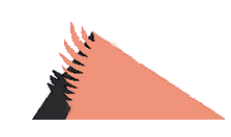

\section{Prólogo \\ Las emisoras universitarias, una forma de comunicación alternativa}

Xosé Soengas Pérez, Catedrático de Comunicación Audiovisual y Publicidad en la Universidad Santiago de Compostela

T A era digital ha modificado todos los aspectos que forman parte 1 del proceso radiofónico: los protocolos, los formatos, los contenidos, las formas de producción, de acceso y de consumo, y las emisoras universitarias no son ajenas a estos cambios. Las estructuras organizativas vigentes durante décadas ya no son válidas ahora, entre otras razones porque muchos perfiles profesionales han desaparecido, ya que sus funciones han sido asumidas por la tecnología.

Los avances actuales facilitan los cambios y contribuyen a aumentar la calidad, pero también plantean nuevas exigencias. Uno de los mayores riesgos que existen en estos momentos es la posibilidad de crear formatos novedosos sin cuidar la calidad. Este error ya se cometió en momentos claves anteriores, concretamente cuando se afrontó la informatización de las redacciones y, más tarde, cuando se inició el proceso de digitalización de los medios. La tecnología eclipsó los contenidos y ese descuido por parte de los profesionales fue uno de los factores determinantes del fracaso de muchas iniciativas, que no recibieron la aprobación de la audiencia porque no eran acordes con las expectativas, ni con las necesidades de los usuarios, ni tampoco con las posibilidades y con las características de lo recursos materiales.

La radio dispone de nuevos escenarios que facilitan su expansión, pero los retos son continuos y cada vez más complicados. Hablar de la radio del futuro implica centrarse en tres aspectos: formatos, contenidos y audiencia, tres ejes que merecen una atención especial y que, además, deben estar conectados de forma permanente para 
conseguir unos resultados óptimos. Diseñar un programa requiere pensar una estructura adecuada y luego dotarlo de temas interesantes, útiles o atractivos para un sector de la población.

La radio siempre se ha caracterizado por prestar atención a los diferentes ámbitos, pero aun así muchas instituciones han creado sus propias emisoras para canalizar propuestas que no aparecían reflejadas en la programación generalista. Estas emisoras, nacidas al amparo de instituciones públicas y organismos privados, como es el caso de las radios universitarias, han acabado siendo un referente en el ámbito de la comunicación e incluso un modelo de inspiración para algunas emisoras convencionales.

Las radios universitarias han contribuido a enriquecer el panorama radiofónico desde hace mucho tiempo. A pesar de su diversidad, tienen unos rasgos propios que son los que conforman su identidad y ahí es donde reside parte de su legado, porque suponen un contrapeso a lo establecido oficialmente. Además, es importante que se conserven sus valores esenciales, que han predominado y son los que las distinguen, sobre todo la colaboración y la participación desinteresada de muchos estudiantes para facilitar la divulgación de la cultura, el intercambio del conocimiento, la solidaridad y la creatividad. Si adoptaran los esquemas de funcionamiento e incorporaran los aspectos formales de las emisoras generalistas, inmediatamente perderían su identidad y su razón de ser. Hay que tener en cuenta que las radios universitarias emiten para un público concreto, con unos intereses específicos, y esta circunstancia también determina sus características y su finalidad.

Las emisoras universitarias constituyen un universo independiente dentro del panorama radiofónico, por varias razones. En primer lugar, el perfil del profesional que trabaja en estas radios, casi siempre un joven universitario, tiene muchas coincidencias con la mayoría de su audiencia potencial, algo que no sucede con tanta frecuencia en las demás emisoras, y esto influye en los códigos de comunicación, porque emisor y receptor comparten las mismas inquietudes, las mismas necesidades, los mismos problemas, hablan el mismo lenguaje e incluso tienen los mismos intereses personales y profesionales, que son los propios de los universitarios. Y tampoco hay que olvidar que 
muchos de estos jóvenes son prosumidores, pues producen y consumen contenidos.

En las emisoras universitarias, en la mayoría de los casos, no predominan las rutinas profesionales, ni tampoco existen presiones políticas o económicas como las que condicionan la línea editorial de las emisoras generalistas. Pero las parrillas de programación, aunque sea en una emisora alternativa y especializada, que no está sometida a los índices de audiencia, requieren una renovación periódica para adaptarse a los cambios que existen en el mundo de la comunicación y, para optimizar los resultados, las actualizaciones deben realizarse de forma integral, en los contenidos y en los demás aspectos formales y narrativos.

Internet ofrece y facilita un nuevo escenario, libre de las numerosas trabas que existían en las emisiones tradicionales, y compensa la precariedad en la que emitían algunas emisoras, un problema que impedía desarrollar y difundir muchos proyectos. El acceso a la tecnología facilita y mejora las condiciones de producción y democratiza el escenario, pero en muchos casos sólo desde el punto de vista teórico. Con Internet se eliminaron muchas dependencias, especialmente las relacionadas con la difusión, y esto supuso una modernización repentina e importante, aunque limitada por los condicionantes que caracterizan y acompañan siempre a las radios universitarias. Pero todas las posibilidades que brinda Internet pueden convertirse en trampas o en dificultades si las estrategias no son las adecuadas.

Las emisoras universitarias están cada vez más reconocidas, tanto por su consolidación como modelo de información y de comunicación, como por las investigaciones que se han realizado sobre estas radios, gracias a las cuales se han situado en prestigiosos catálogos científicos. Su importancia y sus méritos dentro del ámbito de la comunicación son esenciales porque cubren un espectro muy especializado que no estaba representado ni atendido en las parrillas de programación de las emisoras generalistas.

Xosé Soengas Pérez 



\title{
Construcción colaborativa en el seno de las radios universitarias. El caso de Info.Radio en la Universidad Complutense
}

\author{
Miguel Ángel Ortiz Sobrino (Universidad Complutense) \\ http:// orcid.org/0000-0003-0103-9524 \\ http://scholar.google.es/citations?user=3OCGQs4AAAAJ\&hl=es \\ Carmen Marta-Lazo (Universidad de Zaragoza) \\ http://orcid.org/0000-0002-0004-1094 \\ http://scholar.google.es/citations?user=vxisuH0AAAAJ\&hl=es \\ Daniel Martín-Pena (Universidad de Extremadura) \\ http://orcid.org/0000-0003-2676-5821 \\ https://scholar.google.es/citations?hl=es\&user=c3neDSYAAAAJ
}

Resumen: En España, las primeras experiencias radiofónicas universitarias se sitúan en 1974. No obstante, la gran eclosión del fenómeno se propicia en el nuevo Siglo, gracias a la irrupción de la denominada era digital que ha propiciado un importante empuje para este tipo de estaciones. Las TICs y la convergencia mediática han supuesto para la radio la ruptura del eje espacio-temporal que fue la referencia para la comunicación radiofónica durante todo el siglo XX. Se ha puesto fin a las barreras legislativas y a las fronteras geográficas impuestas por las frecuencias de emisión y la limitación de la explotación del espacio radioeléctrico. Las estaciones universitarias están sabiendo aprovechar este nuevo contexto tecnológico para emitir contenidos alternativos producidos desde el seno de la Universidad, creando un nuevo paradigma comunicativo basado en el espíritu colaborativo. A pesar de que algunas estaciones cuentan ya con un bagaje de producción y programación considerable, este tipo de emisoras tiene aún, por delante, importantes desafíos para poder 
ser consideradas medios de comunicación sostenibles. En este capítulo, se hace una aproximación al caso de la estación universitaria de la Universidad Complutense de Madrid, InfoRadio. Un medio universitario muy apegado a Internet con gran presencia en las redes sociales, como soportes de conexión con sus oyentes/usuarios.

Palabras clave: radio universitaria; InfoRadio; redes sociales; Internet; estudiantes; Información.

\section{Introducción}

T A revolución de los social media, la aparición de fenómenos como el tagging o el podcasting y las posibilidades de participación a través de Internet o la telefonía en movilidad son territorios de experimentación para la radio universitaria. Estas emisoras son consustanciales al contexto multimedia que propicia Internet, la telefonía móvil y el uso de las herramientas de la Web 2.0 y 3.0, que tienen entre sus principales exponentes a los blogs y las redes sociales. Su desarrollo se viene propiciando gracias a la convergencia mediática y las posibilidades que ofrece la tecnología digital (Marta-Lazo y Segura Anaya, 2012; Martín-Pena y Contreras Pulido, 2014). La radio universitaria en España, responde a un paradigma de radio multimedia, hipertextual e interactiva que trae consigo cambios significativos no sólo en los procesos de producción de los mensajes radiofónicos, sino también en las formas de consumo, colaboración, participación y apropiación de éstos por parte de los oyentes. Todo un empoderamiento de los oyentes que se convierten -en muchos casos- en "prosumidores" radiofónicos activos haciendo de la radio un medio interactivo, participativo y colaborativo (Ortiz Sobrino, Salgado y Cavadas, 2014a).

\section{Las radios universitarias: estado de la cuestión, contexto histórico, entorno educativo}

\subsection{Marco teórico y estado de la cuestión}

Aunque se trata un fenómeno mediático reciente en nuestro país, existe ya una considerable literatura científica que ha venido ocupándose de él. La radio universitaria española ha sido abordada 
por diferentes autores tanto españoles como latinoamericanos (Fidalgo Díez 2009; Martín-Pena, 2013; Vázquez Guerrero, 2013; Ortiz Sobrino, Rodríguez Barba y Cheval, 2014; Marta-Lazo y Martín Pena, 2014). Una de las obras más recientes, en la que se ofrece un panorama de este tipo de emisoras en América y Europa, ha sido una obra colectiva, publicada en España, en 2014, en la que han participado destacados teóricos y responsables de emisoras de estos dos continentes (Martín-Pena y Ortiz Sobrino, 2014).

En España se pueden distinguir tres tipologías de emisoras universitarias, según la implicación o no de las instituciones universitarias. En primer lugar, las emisoras gestionadas por alumnos cuya Universidad ofrece un apoyo institucional, independientemente de que los estudios que imparten estén o no relacionados directamente con el ámbito de la comunicación (estas emisoras suelen están gestionadas por alumnos de las Facultades de Comunicación, aunque bajo la supervisión de algún profesor ejerce la coordinación de los contenidos de la programación. Ese es el caso de InfoRadio, la emisora de la Universidad Complutense de Madrid objeto de este texto y también de Radio. Unizar, entre otras). En segundo lugar, pueden encontrarse emisiones de la Universidad Nacional de Educación a Distancia (UNED) a través de Radio Nacional de de España (la radio pública estatal) producidas desde un departamento de esa Universidad, con presupuesto propio y cierto grado de autonomía de gestión (Ortiz Sobrino, Rodríguez Barba y Cheval, 2014). En tercer y último lugar, existen emisoras universitarias promovidas desde asociaciones universitarias de alumnos, que cuentan con absoluta independencia -tanto económica como de orientación- de la Universidad. En este grupo se podrían incluir las emisiones realizadas desde algunos colectivos universitarios, como asociaciones de alumnos, asociaciones culturales o residentes universitarios en colegios mayores (Ortiz Sobrino, Salgado y Cavadas, 2014b).

\subsection{Las emisoras universitarias en España: origen y desarrollo}

No existe unanimidad sobre el contexto temporal en el que se puede situar el nacimiento de la radio universitaria en España. Martín-Pena (2013) lo sitúa en 1974, cuando surgen las primeras emisiones de la 
Universidad Nacional de Educación a Distancia (UNED), una vez que se crea esta institución universitaria mediante el Decreto 2310/1972, de 18 de agosto. Vázquez Guerrero (2012) y Fidalgo Díez (2009), en cambio, colocan los orígenes de la radio universitaria en 1987, cuando se registra una experiencia de emisión radiofónica en un Colegio Mayor de la Universidad de La Laguna. Otras investigaciones afirman que la Universidad de Zaragoza se adelantó a esa primera emisión canaria en dos años, según aparece en el Apéndice II de la Revista GEA, en 1985 (García Gotor, 2014). Independientemente de estas controversias el nacimiento de este tipo de radios no deben separarse de otras experiencias de programas especializados en contenidos universitarios como "Tiempo de Universidad", realizado por Fernando Segundo en Radio 3, "Ahora vosotros" en Radio Intercontinental de Madrid, o la experiencia de Radio Juventud de Madrid que, desde mediados de la década de los 70 y principios de los 80, sirvieron como canal de comunicación a los universitarios madrileños (Ortiz Sobrino, 2012). Sin embargo, el punto de inflexión para el desarrollo de este tipo de radios puede situarse al final de la primera década de este siglo, cuando empiezan a datarse los primeros encuentros de las radios universitarias españolas -a partir de 2004- en León, primero, y luego en Alcalá de Henares, que culminarían en la creación de la Asociación de Radios Universitarias Españolas en 2011.

La implementación de la radio universitaria en el resto de Europa y, sobre todo, en América ha tenido un mayor recorrido. En el caso americano, en 1922 los denominados colleges utilizaban las estaciones de radio para retransmitir lecturas y programas realizados por estudiantes, aunque fue en la década de los setenta cuando se produce el periodo de mayor desarrollo. También en América Latina el fenómeno de la radio universitaria se remonta a principio del siglo pasado. Los investigadores del medio radiofónico señalan que la primera emisora universitaria, Radio de la Universidad de la Plata (Argentina), nació en 1924. Precisamente es en este país donde existe una de las legislaciones más avanzadas para el desarrollo de la radio universitaria. En el mismo sentido, se puede hablar de la fortaleza de este tipo de radios en países como Colombia, Chile o México (Vázquez Guerrero, 2012; Martín-Pena y Ortiz Sobrino, 2014). Por su parte, en Europa, no será hasta la década de los sesenta del pasado 
siglo cuando se inicien las primeras experiencias en el Reino Unido y Francia. En el caso de Francia, la Ley Miterrand de 1981 les dio cobertura legal al incluirlas como radios asociativas, dotándolas de un canal de emisión y un fondo de ayuda para su desarrollo.

\section{Emisoras universitarias: un espacio, para la interactividad, la participación y la colaboración}

En lo que va de siglo, la denominada tecnología digital y la convergencia mediática han supuesto para la radio la ruptura del eje espacio-temporal que había sido la referencia para la comunicación radiofónica durante todo el siglo XX. En este sentido, puede decirse que se ha acabado con las barreras legales y fronteras geográficas impuestas por las licencias de emisión y las limitaciones de la explotación del espectro radioeléctrico (Marta-Lazo y Segura Anaya, 2011, 327). Las radios universitarias están aprovechando este nuevo escenario tecnológico para emitir contenidos alternativos propiciando un nuevo paradigma comunicativo. Este nuevo modelo se basa en un nuevo rol de oyente y una producción de contenidos que nace y se elabora en el seno de la comunidad universitaria con la participación de toda ella.

\subsection{Un espacio de construcción común}

Las emisoras universitarias se han convertido no sólo en un medio de comunicación y difusión universitaria, sino también en centros de entrenamiento y formación para los futuros profesionales del medio radiofónico. Se trata de auténticos laboratorios de ensayo para los estudiantes de periodismo, en los que pueden experimentar con nuevos formatos de información radiofónica y adquirir las competencias necesarias para trabajar como periodistas y realizadores radiofónicos. Algunos investigadores ya han puesto de manifiesto como Internet proporciona hoy a las radios universitarias un nuevo sistema de dinamización social y cultural para conectar mejor con los estudiantes y profesores, que encuentran en ellas más posibilidades de interactuar y tener una participación activa que va más allá de las aulas (Martín-Pena y Aguaded, 2015: 271-272). 
Comentan Ortiz Sobrino, Salgado y Cavadas que la radio universitaria puede limitarse, simplemente, a la incorporación en la web de un enlace con el campus virtual de la Universidad o, al contrario, poner a disposición de los alumnos y profesores un espacio dentro de la web que dé soporte a múltiples actividades de interacción entre docentes y discentes o entre estudiantes. Este espacio virtual se puede convertir en un lugar de intercambio de material relacionado con una determinada unidad didáctica: grabaciones de aula (lectura casting), foros de debate, etc. El acceso e intercambio de materiales en estas plataformas de webradio universitaria favorecen la relación entre alumnos formando comunidades virtuales que, con frecuencia, son utilizadas para establecer relaciones personales (Ortiz Sobrino, Salgado y Cavadas, 2014a).

\subsection{Podcasting y tagging: la personalización del consumo en tiempo, contenido y forma}

Las TIC e Internet han cambiado las rutinas productivas y el acceso a las fuentes informativas por parte de los profesionales de la radio que ya se han convertido en profesionales que buscan información no sólo en los archivos sonoros de las empresas de radio, sino también en el resto de medios colaborativos y redes sociales (Marta y Ortiz Sobrino, 2013).

La radio universitaria es hoy un medio interactivo que se apoya en el uso de las nuevas tecnologías que propicia la Red o la telefonía móvil: blogs, foros, redes sociales etc. Como afirman Casajús y Vázquez (2014), desde el surgimiento y la posterior extensión de Internet y la telefonía móvil, la Web ha ido evolucionando a pasos agigantados, pasando de ser una plataforma de información estática hasta llegar a ser una red que posibilita la interactividad y el intercambio tanto del usuario con el productor de la información, como también entre los propios usuarios. Una red que también ha sido denominada Web social o Web de la conversación y que es el contexto digital en el cual hoy se desenvuelven las emisoras universitarias (Ortiz Sobrino, Salgado y Cavadas, 201a).

La transposición de la radio a Internet y a la telefonía móvil ha provocado una mutación en el papel del receptor que ahora se puede 
conectar a los contenidos emitidos desde la web radiofónica en cualquier momento y lugar, en un acceso activo y permanente a la información. Vinculados a las radios webs se sitúa uno de los fenómenos de mayor auge en la radio universitaria española: el podcasting. Un sistema que pone a disposición de los usuarios una serie de contenidos a la carta, mediante diferentes tecnologías de streaming que le permiten configurar su propia parrilla de programación y etiquetar (tagging) los contenidos de su preferencia. Asimismo,

\subsection{La radio en construcción: del blog a los social media, en las radios universitarias}

Comentan Martínez Rodrigo y Sánchez Martín (2015) que el desarrollo de las Tecnologías de la Información y la Comunicación y, por supuesto, la implantación de Internet han favorecido la aparición de nuevas plataformas comunicativas.

Estamos inmersos en un universo global en donde los medios colaborativos y las redes sociales facilitan la relación interpersonal entre usuarios y oyentes, y la interacción de la audiencia con los medios de comunicación. Entre ellos, debemos destacar por su uso habitual en las radios universitarias españolas los audioblog y los social media.

Afirman López Vidales y González Aldea (2014) que el formato hipertextual de los blogs ha ido evolucionando hacia nuevas formas multimedia que integran contenidos audiovisuales para ser distribuidos por la Red hacia soportes móviles y portátiles como las tablets o los teléfonos inteligentes. Los blogs se han hecho más complejos al introducir el mensaje multimedia y permitir que los usuarios lo compartan mediante las redes sociales. Además de la sindicación de contenidos que facilita su distribución al público del weblog, incorporan metadatos que permiten al usuario interactuar con la web a través del etiquetado colaborativo o nube de etiquetas (tagging). Para estas dos investigadoras un audioblog puede entenderse como un blog cuyas entradas son mayoritariamente archivos de audio, bien sean éstos grabados por su creador o compartidos por sindicación o desde un agregador, para lo cual se utiliza la técnica del 
podcasting. Las entradas incluyen texto y comentarios de los oyentes o del propio bloguero que complementan la información de audio.

Por otra parta, las emisoras universitarias utilizan las redes sociales para que sus contenidos lleguen a una comunidad más amplia, no solo a las personas que escuchan sus retransmisiones en directo y se descargan sus podcast. Cuenta Asunción Ten (2015) que casi todas las radios universitarias utilizan hoy social media. En un ejercicio de observación sobre el uso de las redes sociales en las principales radios universitarias de Europa y América, Ten ha elaborado una tabla en la que se pone de manifiesto que, entre todas ellas, son Facebook y Twitter las de uso mayoritario (Tabla I).

Tabla I: Uso redes sociales en radios universitarias Europa y América

\begin{tabular}{|l|l|l|l|l|}
\hline $\begin{array}{l}\text { Redes sociales/ } \\
\text { Países }\end{array}$ & Facebook & Twitter & Facebook/Twitter & Sin Redes \\
\hline Argentina & 8 & 0 & 33 & 5 \\
\hline Chile & 1 & 0 & 7 & 9 \\
\hline Colombia & 2 & 7 & 33 & 5 \\
\hline Ecuador & 2 & 0 & 5 & 4 \\
\hline España & 0 & 1 & 21 & 1 \\
\hline Francia & 0 & 0 & 26 & 0 \\
\hline Italia & 0 & 0 & 24 & 0 \\
\hline México & 9 & 4 & 41 & 12 \\
\hline
\end{tabular}

Fuente: A. Ten, a partir de datos del libro Las Radios Universitarias en América y Europa. TFG-UCM. (2015)

La observación arroja resultados similares a los obtenidos por García Gotor (2014) en un trabajo de campo realizado sobre las web corporativas de las radios universitarias españolas (Tabla II). 
Tabla II: Utilización de redes sociales en radio universitaria española

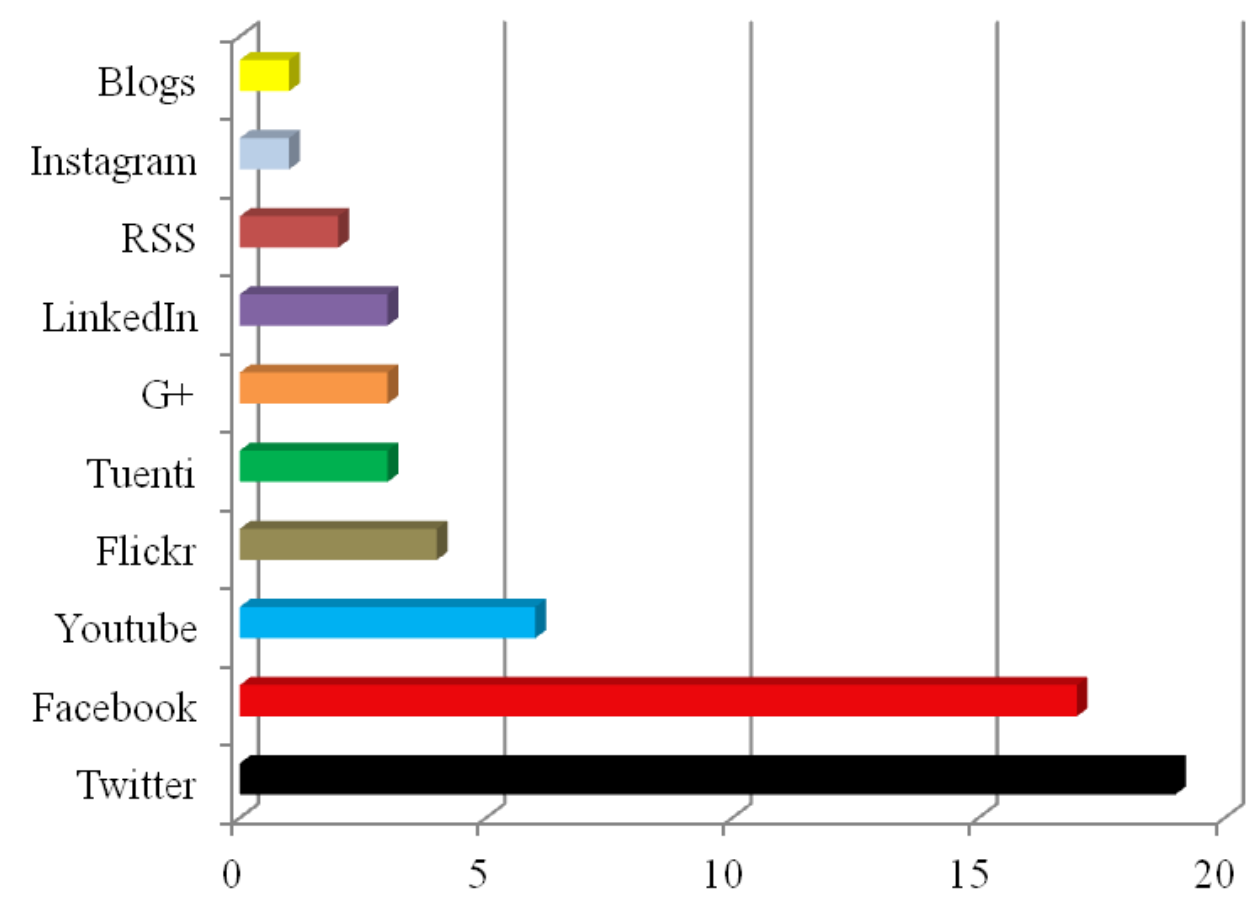

Fuente: García Gotor. TFG.UNIZAR. (2014)

A pesar del uso cada vez más frecuente y considerable de redes sociales por parte de las emisoras universitarias, en una investigación llevada a cabo por Marta-Lazo y Segura Anaya en 2014, se pudo comprobar que solo el $9,5 \%$ de los directores aseguraban que contaban en sus radios con un plan de trabajo trazado y con una línea de acción conjunta y estratégica de toda la emisora y de sus programas. Además, entre los resultados también destacaba que solo un $43 \%$ de las emisoras contaban con un Community Manager encargado específicamente de gestionar las redes sociales. En dicho análisis efectuado a 21 responsables de radios universitarias, se constató que los contenidos mayoritarios que se publican en redes sociales, en un $65 \%$ de los casos, son informativos o promoción de la radio o de programas concretos o de actividades especiales de la propia emisora. Por último, se observó que la mayoría de las emisoras cuentan con perfil institucional en las redes (solo una emisora carecía de presencia en redes), a pesar de que no posean una estrategia de comunicación en los contenidos que publican (Marta-Lazo y Segura Anaya, 2014: 360-362). 


\section{InfoRadio como construcción colectiva de la comunidad universitaria y la audiencia social}

La radio de la Universidad Complutense no puede deslindarse de su misión colectiva y colaborativa. Por ello, es absolutamente necesario referirse a ella no solo como soporte comunicativo, sino también como un medio de participación estudiantil y de colaboración de su audiencia social que se empodera como un usuario participativo que enriquece y difunde sus contenidos.

\subsection{InfoRadio: centro de participación, entrenamiento y difusión del conocimiento científico}

La puesta en funcionamiento de la emisora InfoRadio se remonta a mediados de los años 90, aunque entonces su indicativo de emisión era Radio Complutense. Los primeros pasos de la emisora se dieron en 1995 de la mano del Instituto de la Comunicación Radiofónica de la Universidad Complutense de Madrid y con el apoyo incondicional del Rector, Gustavo Villapalos, así como del Vicerrector de Extensión Universitaria y profesor de la Facultad de Ciencias de la Información, Eduardo Rodríguez Merchán. La trayectoria de la emisora ha pasado por diferentes etapas, marcadas por periodos de brillantez y momentos de funcionamiento inestable con emisiones irregulares. Incluso ha tenido que sobreponerse a cierres temporales, el último de ellos a principios de 2009.

Después de un paréntesis de poco más de un año, en 2010 surgió la nueva radio de la Universidad Complutense, esta vez, exclusivamente, en formato online, con aires renovados y ya con el nombre actual de InfoRadio. Martín-Pena (2013) señala al referirse a sus objetivos que los fines de la emisora se centran, sobre todo, en los aspectos de carácter formativo, es decir, ofrecer prácticas reales a los estudiantes de los distintos estudios impartidos en la Facultad de Ciencias de la Información: más de 200 estudiantes participan en la elaboración de contenidos para la emisora, la mayoría de ellos de la Facultad de Ciencias de la Información. El otro gran objetivo es, estrictamente comunicativo, por el cual se pretende informar a la comunidad universitaria sobre las distintas actividades investigadoras y extraacadémicas (culturales, deportivas, medioambientales, solidarias, 
etc.) que se desarrollan en el seno de esta institución educativa o en el entorno más inmediato.

Tanto la emisión a través de su sitio web en inforadioucm.es como su audioblog inforadioncm.blogspot.com/, o la utilización de kioscos/servidores en la nube digital -como Ivoox - son productos de la participación altruista de estudiantes y profesores de la Universidad y son resultado de una construcción colectiva.

\subsection{InfoRadio en las redes sociales}

La página web de InfoRadio tiene acceso a los perfiles de Facebook y Twitter. El perfil en Facebook funciona como una cuenta de cualquier persona anónima, lo que quiere decir que para poder conocer todas las actualizaciones hay que hacerse amigo de la página. Tiene 1.268 amigos a los que los contenidos les llegan con una periodicidad más regular puesto que la cuenta está bastante actualizada.

Según Ten (2015), Twitter es la red social más activa de InfoRadio. Un indicador de esta actividad es que en un fin de semana del mes de mayo de este año había publicado 5.470 tweets, seguía a 892 personas y tenía 1.529 seguidores. Comenta esta investigadora que, en el caso de Twitter, ha publicado -según datos recogidos hasta mayo de 2015más de 5.475 tuits, sigue a 893 personas y tiene algo más de 1.535 followers.

\subsection{InfoRadio en relación con otras emisoras universitarias}

A efecto de comparar la presencia en redes sociales de la radio de la Universidad Complutense con otras emisoras de tipología similar, se han tomado como referencia: Radio.Unizar, de la Universidad de Zaragoza y OndaCampus, de la Universidad de Extremadura.

Inaugurada por el actual Rector de la Universidad de Zaragoza, Manuel López Pérez, en 2011, Radio.Unizar está dirigida a la comunidad educativa pero también a una audiencia general. Según señalan Marta-Lazo y Segura Anaya (2013, 174), el reto de Radio. Unizar era doble, por un lado constituirse como instrumento docente que permitiera acercar a los alumnos del Grado de Periodismo a la 
realidad cotidiana de una redacción profesional, con las dinámicas de trabajo y responsabilidades que ello supone y, por otro, servir de escaparate a la intensa actividad docente, investigadora, social y cultural de la Universidad de Zaragoza. Su modalidad de emisión es podcast con programas de carácter temático, relacionados con la actualidad del campus, el deporte, la cultura, la ciencia o el intercambio de estudiantes con otras universidades, entre otros. En cuanto a redes sociales, esta emisora apostó desde 2012 por Twitter y, en la actualidad, cuenta ya con 1.783 seguidores. A estos hay que sumar los que poseen los diferentes programas en sus cuentas individuales. De este modo, explotan esta red para dar a conocer sus contenidos y servir como plataforma para interactuar con los oyentes, la mayoría de los espacios: Culturízate, En clave de ciencia, ¿Y tú qué opinas, Con mucha miga, Tiempo de Deporte, Agora en fase de POD, Punto de Encuentro y Crónica de Campus, que también tiene presencia en Facebook. Además, Radio.Unizar creó en 2012 la figura de un Community Manager, que se encarga de potenciar el uso de redes sociales y, en la actualidad, se está trazando un plan estratégico de acción conjunta entre la cuenta de la emisora y las de sus respectivos programas.

OndaCampus, la emisora de la Universidad de Extremadura, según apuntan Parejo y Martín-Pena (2011: 132) nace en septiembre de 2004, gracias a un acuerdo de la universidad extremeña y el gobierno autonómico que pretendía crear, en una primera instancia, un taller práctico de radio y televisión que recopilase información universitaria a través de programas de radio y TV que fuesen emitidos por emisoras locales de Extremadura. El proyecto fue evolucionando de forma dinámica a lo largo de estos más de diez años de trayectoria y se convirtió rápidamente en una radio online con firme apuesta por las TICs, de hecho fue una de las emisoras universitarias pioneras en instaurar aplicaciones para smartphones tanto bajo sistema IOS como Android. En este sentido, la interactividad está muy presente en esta estación universitaria. Cada programa tiene espacio propio en la web con el objetivo de que sea su plataforma de difusión, y en ella se encuentran enlaces a sus blogs, fotografías, podcast, etc. Además, algunos espacios, los mínimos, tienen perfil en redes sociales, ya que la estrategia de esta estación universitaria es que los programas puedan suministrar de información y contenido el perfil global de la 
emisora en Twitter y Facebook, mediante un coordinación planificada. El resultado es que tanto el perfil en Twitter como el de Facebook superan los mil seguidores (1134 y 1370, respectivamente). Además, esta emisora tiene muy potenciada su presencia en la red social del audio, iVoox, en la que cuenta con muy buena presencia con 90 podcast y más de un millón de escuchas, y determinados espacios como "Personas con historia", que cuentan con más de 100 seguidores.

\section{Conclusiones}

La conclusión más destacada es que la radio universitaria española, en general, e InfoRadio, en particular, son mayoritariamente soportes de comunicación basados en un espíritu colectivo y colaborativo, en el que la participación de la comunidad universitaria fundamentalmente de los estudiantes- y la colaboración de la audiencia a través de la redes sociales hacen de este medio un soporte dinámico, que actúa como derecho de acceso y como vehículo de participación colectiva de la comunidad universitaria. Superadas las primeras iniciativas de blogs, audioblog y otras expresiones colectivas de la red, las redes sociales están presentes, en mayor o menor medida, en las radios universitarias.

Tanto en el continente europeo como en el americano, las dos redes sociales con mayor protagonismo entre las radios y sus programas son Facebook y Twitter. En el caso de InfoRadio, la presencia de un audioblog propio y su actividad en los social media - especialmente, Facebook y Twitter- con algo más de 1.535 followers confirman la dimensión colaborativa de esta emisora, al igual que ocurre en otros casos, como hemos podido comprobar, en Radio.Unizar y Onda Campus.

De igual forma, la participación altruista de más de 200 estudiantes en la elaboración de los contenidos de su programación constituye un indicador del espíritu colectivo y participativo de la emisora. 



\title{
E1 Lab experimental de 98.3 Radio para Creatividad Sonora y Radio Especializada
}

\author{
Elsa Moreno Moreno (Universidad de Navarra) \\ https://orcid.org/0000-0003-4066-6475 \\ https://scholar.google.es/citations?user=iZB3rikAAAAJ\&hl=es
}

Resumen: El propósito de este trabajo es analizar la innovación docente en la dinámica de la emisora universitaria en la era digital. Para ello, se describe el proyecto "Revisión de las actividades formativas y metodología de la asignatura Creatividad Radiofónica y Sonora" aplicado en el Grado de Comunicación Audiovisual de la Universidad de Navarra durante 2014/2015. Este proyecto sirvió de estímulo para introducir también cambios docentes en la asignatura Radio Especializada para el Grado de Periodismo y el Grado de Comunicación Audiovisual. A modo de Lab experimental para las dos materias mencionadas, 98.3 Radio promueve el aprendizaje colaborativo alumno-profesor y la Experiential Learning (Boud, 1993) a través de la gestión de pequeños proyectos. Una media de 60 estudiantes y 4 profesores participaron en el primer caso; y 30 estudiantes y 2 profesores en el segundo. Los resultados evidencian que la especialización de la Guía Docente según las competencias específicas del Título, el diálogo del equipo de profesores para crear un material docente eficiente para 98.3 Radio y la autoevaluación del alumno contribuye a enriquecer los resultados académicos, la iniciativa y la capacidad crítica del estudiante. Asimismo, las conclusiones reflejan la valía del audio storytelling y las audiencias especializadas en lo digital.

Palabras clave: radio universitaria, innovación docente, convergencia digital. 


\section{Introducción}

S ON numerosos los estudios que realzan la potencialidad de la $\checkmark$ radio universitaria desde diferentes perspectivas (Martín-Pena, Marta-Lazo \& Ortiz Sobrino, 2015; Martín-Pena \& Ortiz Sobrino, 2014; Marta-Lazo \& Martín-Pena, 2014; y Merrill, 2008). Estos trabajos destacan tres ideas principales. En primer lugar, la oportunidad que brinda la radio universitaria para difundir la investigación y contribuir a la sociedad del conocimiento. En segundo lugar, la capacidad de este tipo de radio para estimular la vida sociocultural de la comunidad a la que se dirige a través de la colaboración con organizaciones de diversa índole. Finalmente, y derivado de lo anterior, la "voz propia" de la que dispone la radio universitaria frente a la radio pública y la radio comercial de cada localidad, región o país.

Teniendo presente todas las aportaciones realizadas desde la línea de investigación académica que estudia el desarrollo de la radio universitaria en América Latina, Estados Unidos y España, no obstante, puede decirse que la cuestión de la innovación docente en la era digital de la radio todavía es un camino por explorar. En particular, en el contexto del crecimiento de la radio universitaria española que reúne en la actualidad a 27 emisoras bajo la Asociación de Radios Universitarias de España (ARU) desde 2011.

Además, la aceptación social progresiva de Internet y las redes sociales a lo largo de las dos últimas décadas ha exigido a la docencia universitaria repensar los modos tradicionales de enseñar el medio radiofónico cuya naturaleza tradicional es sonora y temporal, como es sabido. Este proceso de reinventar también la enseñanza de la radio en la universidad se viene realizando de acuerdo a los logros investigadores obtenidos en torno al estudio de las diferentes implicaciones que conlleva el cambio del paradigma radiofónico clásico en la convergencia digital (Martínez-Costa, Moreno y Amoedo, 2012; y Moreno, Martínez-Costa y Amoedo, 2009).

Teniendo en cuenta estas dos tendencias de investigación, el objetivo general de este trabajo es analizar el aspecto concreto de la innovación docente en las actividades formativas de naturaleza 
práctica desarrollas en el ámbito de funcionamiento de la emisora universitaria en la era digital, desde la descripción y el análisis de los casos de las asignaturas de Creatividad Radiofónica y Sonora y Radio Especializada durante el curso 2014/2015, cuya docencia práctica se imparte en el seno de 98.3 Radio -la emisora de la Facultad de Comunicación de la Universidad de Navarra- ${ }^{1}$.

La asignatura de Creatividad Radiofónica y Sonora (3 ECTS) era obligatoria $^{2}$ para el alumno de $3^{\circ}$ curso del Grado de Comunicación Audiovisual en 2014/2015 y la asignatura de Radio Especializada (3 ECTS) es optativa para el alumno de $3^{\circ}$ y $4^{\circ}$ curso del Grado de Periodismo y el Grado de Comunicación Audiovisual. Por lo general, la media de estudiantes matriculados en Creatividad Radiofónica y Sonora corresponde a 60, mientras la media de estudiantes que participan en Radio Especializada atiende a 30.

Concebida a modo de Lab experimental para la enseñanza práctica de las asignaturas analizadas en este trabajo, $98.3 \mathrm{Radio}^{3}$ promueve el aprendizaje empírico-práctico o Experiential Learning (Boud, 1993) a través del diseño, ideación, producción, realización y gestión de pequeños proyectos. Se trata de un aprendizaje empírico-práctico que fomenta el método inductivo básico puesto en relación con el método deductivo de las clases teóricas. De este modo, el alumno puede abstraer lo aprendido a partir de la experiencia radiofónica real adquirida en 98.3 Radio.

\footnotetext{
${ }^{1}$ La enseñanza de radio está presente en la Universidad de Navarra desde el inicio de las actividades académicas del Instituto de Periodismo de esta universidad en el curso 1958/1959. Tal y como explica Faus, esto se producía 26 años después de que los profesores Emil Dovifat y Kurt Wagenführ dictaran el primer curso de radio en la universidad europea. En concreto, en la Universidad de Berlín (Faus, 1991: 16).

${ }^{2}$ En la actualidad esta asignatura es optativa para el Grado de Comunicación Audiovisual y el Grado de Periodismo.

${ }^{3}$ Desde su nacimiento el 29 de septiembre de 1999 bajo el nombre de Radio Universidad de Navarra, esta emisora aspiró a un planteamiento profesional (Cebrián Herreros, 2001: 192). A partir del curso 2004/2005, y bajo la marca 98.3 Radio, esta emisora evolucionó hacia una integración con la docencia.
} 


\section{El proyecto de Innovación Docente}

El Proyecto de Innovación Docente, "Revisión de las actividades formativas y metodología de la asignatura Creatividad Radiofónica y Sonora", implementado durante el curso 2014/2015 se pensó y desarrolló bajo dos premisas.

Primera. La radio universitaria se presenta como un espacio docente adecuado para renovar las actividades formativas de naturaleza práctica. En concreto, para reformular competencias de habilidades y actitudes, dinámicas metodológicas y materiales docentes de apoyo al alumno y/o profesor, así como para escuchar con más atención las valoraciones del alumno acerca del progreso de su aprendizaje.

Segunda. La radio universitaria puede ser un ámbito de trabajo de producción sonora oportuno para innovar en torno a la conceptualización, realización y gestión de formatos radiofónicos y narrativas transmedia originales ante la relevancia del mercado multiplataforma en el que participan ya todos los medios.

Teniendo en cuenta estos dos supuestos, y de manera coordinada con el Servicio de Calidad e Innovación Educativa de la Universidad de Navarra, se planificó el proyecto de innovación docente que se describe en este trabajo. Los aspectos generales de dicho proyecto también sirvieron de referencia para pensar mejoras formativas para la asignatura Radio Especializada. En este sentido, conviene señalar que el equipo docente de 4 profesores atiende ambas asignaturas y que el Servicio de Calidad e Innovación Educativa de la universidad recomienda al profesor participar en un proyecto por curso.

Bajo la cautela que conllevan las circunstancias formales de ambas iniciativas, las preguntas principales de innovación docente de las que partió el proyecto específico para Creatividad Radiofónica y Sonora fueron las dos siguientes: a) cómo especializar las competencias de la asignatura de acuerdo a las competencias propias del Título en el que se imparte; y b) cómo renovar las actividades formativas, en concreto las de naturaleza práctica, para favorecer la madurez intelectual y la capacidad creativa del alumno. Respecto de esta segunda pregunta, se avanzó además sobre los dos asuntos siguientes: a) qué materiales 
docentes de orientación personal y grupal podrían aplicarse para favorecer la autonomía del alumno; y b) qué tecnologías de apoyo docente podrían emplearse.

Como puede apreciarse, estos aspectos revisaban los principios que sustentan a la actividad de cualquier asignatura universitaria y que se reflejan en los apartados del documento de planificación de la Guía Docente (variables). La tabla 1 que se presenta a continuación refleja que se decidió especializar las competencias y el programa de la asignatura, y en consecuencia, adecuar la formación del equipo de profesores y renovar el material docente de apoyo a las clases prácticas impartidas en 98.3 Radio.

Tabla 1: Apartados revisados en el Proyecto de Innovación Docente

\begin{tabular}{|c|c|}
\hline \multicolumn{2}{|l|}{ Competencias } \\
\hline $\begin{array}{l}\text { Asignatura: conocimientos y habilidades- } \\
\text { actitudes. }\end{array}$ & $\begin{array}{l}\text { Mayor especialización de la } \\
\text { asignatura. }\end{array}$ \\
\hline Título: generales y específicas. & Mayor adecuación al Título. \\
\hline \multicolumn{2}{|l|}{ Equipo docente } \\
\hline $\begin{array}{l}\text { Profesores: número, cumplimiento ratio } \\
\text { alumno-profesor, categoría y perfil } \\
\text { profesional, y años de experiencia } \\
\text { docente y profesional. }\end{array}$ & $\begin{array}{l}\text { Mayor adecuación al perfil de } \\
\text { alumno que cursa el Título. }\end{array}$ \\
\hline \multicolumn{2}{|l|}{ Tipología de actividades formativas } \\
\hline $\begin{array}{l}\text { Clases magistrales, clases prácticas, } \\
\text { seminarios, trabajos en grupo, tutorías, } \\
\text { etc. }\end{array}$ & $\begin{array}{l}\text { Adecuación de la estrategia } \\
\text { docente y mayor sinergia con } \\
\text { 98.3 Radio. }\end{array}$ \\
\hline \multicolumn{2}{|l|}{ Material docente } \\
\hline \multirow{3}{*}{$\begin{array}{l}\text { Manuales, guías de trabajo, ejercicios de } \\
\text { autoevaluación, etc. }\end{array}$} & Guías de trabajo para el alumno. \\
\hline & Guías de trabajo para el profesor. \\
\hline & aluación. \\
\hline \multicolumn{2}{|l|}{ Tecnologías educativas } \\
\hline \multirow{4}{*}{$\begin{array}{l}\text { Ordenador fijo/aula, ordenador } \\
\text { portátil/alumno, disponibilidad de wifi, } \\
\text { plataformas docentes de docencia virtual, } \\
\text { equipamiento de los estudios de radio, } \\
\text { salas de producción y edición sonora, } \\
\text { material de grabación y edición sonora,... }\end{array}$} & Audacity. \\
\hline & Pro-Tools. \\
\hline & Teléfono móvil/alumno. \\
\hline & Materiales de 98.3 Radio. \\
\hline
\end{tabular}

Fuente: elaboración propia 
Respecto al último factor que recoge la tabla anterior, tecnologías educativas, cabe destacar la utilidad de la plataforma de gestión de la enseñanza y el aprendizaje "Aula Virtual ADI" de la Universidad de Navarra, la disponibilidad de un ordenador personal (portátil) y teléfono móvil por cada alumno, la conexión en red (wifi) de los edificios del campus, el uso del editor de audio libre Audacity o el empleo de materiales de grabación de 98.3 Radio.

Asimismo, la implementación del marco del Espacio Europeo de Educación Superior (EEES) o Proceso de Bolonia promovió en los casos de las asignaturas analizadas la oportunidad de consolidar uno de los adelantos de innovación educativa ya iniciado anteriormente en 98.3 Radio como es la creación de equipos docentes (Michavila, 2009: 6) ${ }^{4}$.

Los procesos de innovación docente para los casos de estudio en este trabajo se detallan a continuación.

\section{El caso de Creatividad Radiofónica y Sonora}

La creatividad radiofónica puede definirse como la actividad profesional que busca tener ideas sonoras nuevas para comunicarlas al oyente con cierto grado de originalidad radiofónica y eficiencia, ajustándolas al tipo de exigencias planteadas en la emisora, sin descuidar la expresividad sonora y la estética radiofónica. Puede observarse que, este concepto engloba a todo el proceso de elaboración del contenido radiofónico. Es decir, a la fase de ideación del producto (originalidad temática y singularidad narrativa), y a la etapa de narración y realización del mismo (expresividad sonora y estética radiofónica).

Partiendo de esta definición, y bajo el propósito de promover en el alumno las competencias (conocimientos y habilidades-actitudes)

\footnotetext{
${ }^{4}$ La "Declaración de Bolonia" de 1999 tuvo como propósito introducir un sistema universitario más compatible y coherente para la educación superior europea. Uno de los objetivos principales durante los primeros diez años del proceso consistió en establecer el Espacio Europeo de Educación Superior (EEES) que comenzó en 2010 con la "Declaración de Budapest-Viena". Hasta 2020, los objetivos se establecieron en torno a la consolidación del EEES. Véase http:/ / eur-lex.europa.eu/legalcontent/ES/TXT/?uri=URISERV:c11088 [Fecha de consulta: 20/11/15].
} 
apropiadas que le permitan encontrar ideas y formas originales de trabajar el sonido, el tiempo y la imaginación en la radio, se pensó en cómo mejorar la docencia práctica en 98.3 Radio para una asignatura que se desarrolla sobre 10 semanas de clases prácticas presenciales (30 horas) de acuerdo a una dedicación total de 75 horas por parte del alumno (3 ECTS $)^{5}$.

Tal y como se ha avanzado, las conclusiones esperadas del proyecto se planificaron en torno a la revisión de los tres aspectos siguientes: a) impulsar las competencias generales-transversales del Título (Graduado en Comunicación Audiovisual) desde el programa de la asignatura; b) generar un material docente específico de apoyo al alumno y profesor para las clases prácticas impartidas en 98.3 Radio; y c) estudiar modos de evaluación innovadores.

Se consideró que el logro positivo de estos tres aspectos incrementaría los resultados académicos del estudiante favoreciendo la especialidad del Grado interesado en explorar los modos narrativos de la vida cotidiana, el entretenimiento y la ficción. Es decir, en contar historias.

Las acciones concretas para desarrollar el proyecto de innovación docente se organizaron en torno a cuatro reuniones de trabajo presencial de los 4 profesores que conforman el equipo de la asignatura a lo largo de los meses previos del inicio del curso y durante el desarrollo de las clases. Asimismo, se mantuvo un continuado diálogo semanal no presencial (vía correo electrónico) ${ }^{6}$ durante el desarrollo de las clases para ir ajustando los objetivos.

\footnotetext{
${ }^{5}$ La dedicación total del alumno en la asignatura se distribuía del modo siguiente en el curso 2014/2015: 13 horas de clases teóricas presenciales, 20 horas de clases prácticas presenciales en la redacción, 10 horas de talleres, seminarios y reuniones de grupo en los estudios de radio, 1 hora de tutoría con el profesor de las clases prácticas, 9 horas de apoyo al desarrollo y la producción de las clases prácticas, 20 horas de estudio personal del alumno y de preparación del examen y 2 horas de evaluación del examen.

${ }^{6}$ Las reuniones presenciales del equipo docente de profesores tuvieron lugar las semanas del 25 al 29 de agosto de 2014, del 13 al 17 de octubre de 2014, del 24 al 28 de noviembre de 2014 y del 9 al 12 de diciembre de 2014 .
} 
En esta línea, y respecto a las reuniones presenciales, fue clave ponderar la especialización de la Guía Docente, adecuar la escritura de las Guías de Trabajo de base a las clases prácticas, apostar por tecnologías educativas de apoyo a la producción sonora y realizar una sesión de audición pública del trabajo radiofónico realizado como cierre final de la asignatura. Por su parte, y respecto del diálogo no presencial (vía correo electrónico), fue efectivo ir determinando sólo una acción de mejora semanal de acuerdo a la progresión real del aprendizaje teórico-práctico del alumno.

Las decisiones tomadas introdujeron los tres cambios metodológicos siguientes:

El primer cambio metodológico consistió en reformular la dinámica del inicio de las clases presenciales -en particular, el planteamiento de la Práctica 1- para aprovechar mejor el tiempo del alumno en el aula durante el primer mes de trabajo. Algo que obligó a replantear el comienzo del programa de la asignatura. Se apostó porque la Práctica 1 estableciera como objetivo principal idear y planificar a la par dos proyectos de narración de historias bajo los principios de la creatividad sonora. El primero de ellos centrado en "los sonidos escondidos" de la realidad cotidiana y el segundo en la ficción sonora.

La tabla 2 muestra los objetivos, la dinámica y los criterios de evaluación de esta práctica.

Tabla 2: Material docente: Guía de Trabajo de la Práctica 1

Proyecto 1: La ideación y el diseño de una historia inspirada en los sonidos cotidianos. Duración: entre 5 y 7 minutos.

Proyecto 2: La ideación y el diseño de una ficción sonora. Duración: entre 5 y 7 minutos.

\section{Los objetivos}

- Que el alumno aprenda a pensar creativamente sobre el sonido para idear, diseñar y planificar la apuesta narrativa de una historia inspirada en la realidad de cada día; y una ficción sonora.

- Que el alumno sepa planificar la búsqueda de los elementos esenciales de la radio creativa a lo largo del proceso de realización de ambos proyectos.

- Que el alumno sea capaz de elaborar una breve memoria de cada 
proyecto en la que se resalte el concepto creativo de la historia y el modo original de procesar el sonido.

\section{La dinámica}

- El profesor recuerda los objetivos de la práctica y constituye los equipos de trabajo de entre seis y ocho alumnos.

- El profesor establece la coordinación de la ideación y la estrategia de producción y realización del total de espacios radiofónicos a realizar.

- El alumno dispone de una semana para elaborar las memorias de los dos proyectos. En la medida de lo posible, ambas memorias deben incluir una primera pauta sobre las fuentes documentales y sonoras a emplear.

\section{Los criterios de evaluación}

- La actitud y el interés del alumno en la clase.

- La capacidad retórica proponiendo las ideas radiofónicas al profesor.

- La claridad expositiva y descriptiva de las memorias.

- La originalidad del enfoque y la perspectiva temática.

- La planificación singular de la producción y la realización sonora.

Fuente: elaboración propia

El cambio metodológico que acaba de describirse evidenció que esta fórmula de ideación conjunta de los dos proyectos radiofónicos a desarrollar resultó ser la adecuada para conseguir los resultados de aprendizaje creativo iniciales y previstos en la asignatura.

Por su parte, el segundo cambio metodológico consistió en propulsar el análisis de la creatividad sonora de referentes de la producción audiovisual (cine y televisión) en las clases teóricas bajo el propósito de despertar la sensibilidad sonora del alumno. Precisamente, estos visionados estimularon el interés y la capacidad analítica del alumno respecto del montaje sonoro en la producción audiovisual.

Finalmente, el tercer cambio metodológico se basó en realizar una sesión de audición presencial (voluntaria para el alumno) de la totalidad de las historias radiofónicas creadas en las clases prácticas de 98.3 Radio. Profesores y alumnos evaluaron los resultados de aprendizaje teórico-práctico conseguidos. 
Tanto las decisiones tomadas, como los cambios metodológicos que acaban de exponerse, lograron las tres conclusiones esperadas en la planificación del proyecto de innovación docente para la asignatura. Asimismo, este proceso de revisión pedagógica arrojó luz sobre nuevas oportunidades formativas para la asignatura.

En primer lugar, aumentaron los resultados académicos (calificaciones) obtenidas por los alumnos en el curso 2014/2015 frente a cursos anteriores. Puede decirse que la calificación media obtenida por la clase atiende a un notable alto ( 8 '5 sobre 10$)$. No obstante, se considera pertinente planear sistemas de evaluación más innovadores que permitan al perfil de alumno excelente obtener la máxima calificación (Matrícula de Honor).

En segundo lugar, se comprobó que el fortalecimiento del diálogo docente entre los profesores enriqueció dos aspectos clave del desarrollo de la asignatura. Por un lado, contribuyó a la validez del programa teórico y las Guías de Trabajo semanales (material docente) para planificar y organizar el trabajo práctico de aprendizaje colaborativo alumno-profesor en el espacio de 98.3 Radio. Por otro lado, motivó que la gestión del tiempo de aprendizaje teórico-práctico semanal del alumno fuera más eficiente. Sin embargo, todavía puede meditarse sobre la necesidad de la presencialidad del alumno en algunas actividades formativas de carácter práctico ya que se ha constatado que tecnologías de producción y edición sonora, como Audacity, ayudan a optimizar el tiempo del aprendizaje del alumno.

En tercer lugar, se favoreció el significado de la asignatura en la especialidad del Grado de Comunicación Audiovisual impartido en la Universidad de Navarra. En particular, y respecto del Plan Docente de $3^{\circ}$ curso del Grado, se establecieron sinergias teóricas con las asignaturas de Dirección-Realización, Sonido y Música en el Cine y la Televisión o Dirección de Actores. Esta reorientación teóricopráctica de la asignatura en el Grado aportó una valoración más positiva por parte del estudiante en los resultados de la Encuesta de Valoración Docente del curso 2014/2015. Además de las tres conclusiones esperadas tras la aplicación del proyecto de innovación docente, también se percibió una mejoría de la calidad creativa de las historias radiofónicas realizadas en el espacio docente de 98.3 Radio. 
A lo largo del curso 2014/2015, la asignatura cooperó con la creación de 31 piezas (23 inspiradas en los sonidos de la realidad cotidiana y 8 de ficción sonora) que se difundieron a través de la antena de FM (98.3), el sitio web de la emisora (http://www.unav.edu/web/vidauniversitaria/983radio) y su cuenta en la red social Twitter (@983Radio). En la actualidad, están disponibles vía podcasts a través de http://ow.ly/UYOSw. En el momento de realizar este trabajo, 98.3 Radio dispone de una audiencia media de 2.000 oyentes diarios en la antena y el conjunto de piezas realizadas desde la asignatura han experimentado 1.458 descargas.

La tabla que se recoge a continuación (tabla 3) sintetiza el elenco de las historias radiofónicas realizadas desde Creatividad Sonora y Radiofónica para el formato "Contando Historias" en 98.3 Radio.

Tabla 3: Piezas realizadas desde Creatividad Radiofónica y Sonora para “Contando Historias" en 98.3 Radio, curso 2014/2015

\section{Sonidos escondidos de la vida cotidiana}

Kendo (05:53), Ecuavoley (04:36), Campeón de judo (04:24), Fútbol femenino, Lagunak (06:27), Dentro de Shockwave (05:46), Partido histórico de Osasuna ante el Mallorca (06:06), Autoescuela (05:23), Ruidos que molestan (04:42), Las tribus universitarias (04:31), La banda de música de Burlada (05:04), Una clase de ballet (05:40), El piano del Edificio Central de UNA (05:40), Ensayo de teatro (04:16), Fotografías de Pamplona (04:57), Los sonidos de San Fermin Txikito (05:10), El festival de cine de San Sebastián (03:57), Perchas Films (04:42), Zorokiain (05:09), De paseo por el Arga (03:51), El señor del BBVA (04:44), La cola del paro (04:57), El Banco de Sangre (06:11) y La máquina de café (06:01).

\section{Ficción sonora}

Bomba en el maratón de Nueva York (04:30), El "asesinato" de Kurt Cobain (07:03), Novecento (11:37), El monte de las ánimas (06:42), El avión de la bella durmiente (07:06), La historia del hombre del saco (08:47), Patrulla navideña (08:07) y Hannah Arendt (07:32).

Una vez descrito el caso de Creatividad Radiofónica y Sonora, se expone el caso de la asignatura Radio Especializada. 


\section{E1 caso de Radio Especializada}

La asignatura Radio Especializada enseña al alumno las competencias (conocimientos y habilidades-actitudes) esenciales para gestionar las cuestiones clave que toda acción radiofónica enfrenta en el mercado multiplataforma de la convergencia digital. Entre ellas, las tres siguientes: a) cómo diseñar y realizar "productos radiofónicos exclusivos" para llegar a un target de público definido a través de la antena, el sitio web y las redes sociales; b) cómo fidelizar a los oyentes y a los anunciantes desde el liderazgo de una marca radiofónica; y c) cómo mejorar la estrategia radiofónica realizada desde el progreso de la calidad, la creatividad y la innovación.

La dinámica docente de la asignatura promueve la capacidad de autonomía del alumno para proponer ideas y llevarlas a la práctica en el ámbito de trabajo práctico de 98.3 Radio. También, fomenta la disposición del estudiante hacia la autoevaluación constante del aprendizaje adquirido. Esta fundamentación pedagógica permite emprender un plan de 10 clases presenciales de aplicación teóricopráctica (30 horas) sobre las 75 horas totales de dedicación del alumno a la asignatura (3 ECTS $)^{7}$.

Durante el curso 2014/2015, se decidió introducir cambios docentes para impulsar las competencias de autonomía y autoevaluación del perfil del estudiante de $3^{\circ}$ y $4^{\circ}$ curso del Grado de Periodismo y Grado de Comunicación Audiovisual de tal modo que pudieran asumir las responsabilidades de edición-presentación, realizacióncontrol de sonido, producción-redacción y producción-redacción multimedia de productos radiofónicos que aspiren a la innovación.

Tras realizar un análisis previo de las oportunidades existentes en la radio española, la radio europea y la radio americana, el equipo de alumnos de la asignatura ideó y realizó “Kill the Dj 98.3". Un programa especializado en los diferentes géneros y estilos de la

\footnotetext{
${ }^{7}$ El resto del tiempo de dedicación del alumno a la asignatura consiste en 30 horas de apoyo a la producción, 8 horas de trabajos y ensayos (trabajo de campo sobre los mercados de la radio), 1 hora de tutoría con el profesor y 6 horas de preparación y realización del ejercicio final de autoevaluación.
} 
música popular, que se emitió cada jueves de entre el 5 de febrero y 12 de marzo de 2015 a través de la antena de 98.3 Radio (de 10am a 12am); killthedj983.wordpress.com; @KilltheDj983; y la cuenta Directos 98.3 Radio en YouTube. Tras cada emisión semanal, el aprendizaje colaborativo alumno-profesor aplicó un breve análisis DAFO (Debilidades, Amenazas, Fortalezas y Oportunidades) del trabajo radiofónico realizado para seguir promoviendo la autoevaluación personal y grupal. Esta sesión de treinta minutos de duración sirvió de rumbo para determinar mejoras a incorporar en las próximas emisiones (clases). Asimismo, y durante 2014/2015, se confió al alumno la realización de un ejercicio de autoevaluación final para confrontar las competencias adquiridas a lo largo del aprendizaje práctico en 98.3 Radio, con las expectativas puestas en la asignatura y los objetivos profesionales. Se decidió otorgar a este ejercicio la valoración del $30 \%$ de la nota final de la asignatura ${ }^{8}$ y prescindir del examen tradicional. Es significativo señalar que esta novedad de evaluación docente aportó una información valiosa sobre el interés de la asignatura. En este sentido, un alumno sugiere lo siguiente?

“En conclusión, 'Kill the Dj 98.3' es un buen programa original (...). Se escucha y analiza buena música pasando por una presentación del género o estilo, curiosidades, influencias y propuestas en las que se habla de las letras o de representantes nacionales, un contenido musical muy completo y culto. Además hemos ido más allá con la moda, cultura, deporte (...) alrededor del género de la semana y el vivo que le da al programa mucha vida. Ha sido una muy buena experiencia”.

Además, la valoración del estudiante también propone algunas mejoras organizativas futuras tal y como sugiere la alumna siguiente:

“(...) creo que al inicio había demasiadas personas en la asignatura creando un equipo muy extenso y resultaba difícil la comunicación, a al final encontramos el modo de solucionarlo".

\footnotetext{
${ }^{8} \mathrm{El} \mathrm{70 \%}$ restante de la nota final alcanzada por el alumno en la asignatura corresponde al trabajo teórico-práctico realizado de manera presencial en 98.3 Radio y no presencial.

${ }^{9}$ Se omiten los nombres de los alumnos para guardar la confidencialidad.
} 
Finalmente, puede decirse que las acciones de innovación docente incorporadas al caso de la asignatura Radio Especializada durante el curso 2014/2015 también acrecentaron los resultados académicos del alumno (media de 9,5 sobre 10), así como el interés del estudiante hacia una asignatura que ganó en significado propio al desplegarse hacia la ideación y realización de "servicios radiofónicos exclusivos" para la distribución multiplataforma.

\section{Conclusión}

En el marco de evolución hacia un nuevo modelo de universidad que favorezca la participación, la iniciativa, el espíritu crítico y, en definitiva, el aprendizaje 2.0 (Esteve, 2009: 65); puede afirmarse que el aprendizaje empírico-práctico o Experiential Learning (Boud, 1993) desarrollado en el seno de la emisora universitaria 98.3 Radio ha sido una oportunidad excepcional de innovación docente. Prueba de ello son los resultados de innovación docente obtenidos tras la aplicación del proyecto descrito y analizado en este trabajo para los casos de las asignaturas Creatividad Radiofónica y Sonora y Radio Especializada. El análisis de estas consecuencias comprueba un enriquecimiento de los resultados académicos del alumno, del significado específico de cada asignatura en el Plan Docente del Grado de Comunicación Audiovisual y Grado de Periodismo y, por tanto, del interés del estudiante por el valor del audio storytelling y la propuesta de "productos radiofónicos exclusivos" para llegar a audiencias especializadas o niche audiences (Coffey, 2012) en el mercado multiplataforma de la convergencia digital.

En síntesis, las acciones de innovación docente ligadas a la gestión de pequeños proyectos desde el Lab experimental de 98.3 Radio revelan que las emisoras universitarias pueden promover una experiencia de aprendizaje atractiva e integrada de lo radiofónico desde la creatividad y la innovación. Asimismo, la dinámica del aprendizaje colaborativo alumno-profesor en el ámbito universitario favorece la iniciativa personal del estudiante, así como su competencia intelectual y capacidad crítica respecto del progreso de sus resultados de aprendizaje. 


\title{
Los jóvenes universitarios como productores de contenidos radiofónicos
}

\author{
Nereida López Vidales (Universidad de Valladolid) \\ http://orcid.org/0000-0002-6960-6129 \\ http:// scholar.google.es/citations?user $=\mathrm{d}-\mathrm{h}$-uasAAAAJ\&hl=es \\ Leire Gómez-Rubio (Universidad de Valladolid) \\ http:// orcid.org/0000-0002-6436-0297 \\ http://scholar.google.es/citations?user=dufyKbUAAAAJ\&hl=es \\ Marta Hernando Lera (Universidad de Valladolid) \\ http:// orcid.org/0000-0001-5326-4868 \\ http://scholar.google.es/citations?user=uthE9KYAAAAJ\&hl=es
}

Resumen: En la presente aportación se exponen los resultados del análisis, durante el curso académico 2014/2015, de la parrilla radiofónica de la emisora de la Universidad de Valladolid, Radio UVa. Entre los aspectos analizados se encuentran los géneros y formatos elegidos por los estudiantes para sus creaciones, número de roles y funciones asignadas ante los micrófonos, duración de los programas y horario de emisión preferido para sus espacios. Se muestra, en definitiva, si sus creaciones radiofónicas difieren, en contenido y forma, con las ofrecidas por la radio generalista de hoy o si, a pesar de sus reivindicaciones, cuando son creadores se decantan por contenidos similares a los ya existentes. Entre los principales resultados obtenidos, nos encontramos con que a pesar de ser una emisora de radio universitaria en la que se permite a los alumnos idear, crear y realizar un proyecto de radio de principio a fin, estos optan por trasladar a la emisora los mismos formatos actualmente existentes en las cadenas de radio generalista, resultando, de este modo, el magazine el formato dominante.

Palabras clave: radio, jóvenes, magazine, universidad. 


\section{La radio universitaria y los jóvenes}

T A radio siempre ha ido muy unida a la educación, entre otros 1 motivos porque "el alcance de la radiodifusión, su amplio grado de cobertura y los bajos costes que supone en relación con otros medios, la convierten en un vehículo especialmente idóneo para la transmisión de la cultura y educación" (Rivera, 1993). Con el desarrollo, en los últimos años, de la radio online surge el podcast con función educativa en el que pueden intervenir tanto los docentes como los propios alumnos; la radio añade a su ubicuidad y sencillez de uso un enorme potencial educativo representando una fuente de recursos didácticos para el aula en diferentes formatos, bien sean audio solo o con otros elementos mediáticos, y se convierte en una nueva forma de aprender y profundizar sobre cualquier tema que se trabaje (Gutiérrez y Rodríguez, 2010). Su integración en el aula puede realizarse, entre otros, desde una triple perspectiva: como herramienta didáctica complementaria, como objeto de estudio y como instrumento de expresión a disposición de los alumnos (Blanco, 2007: 35).

Pero además, hay que tener en cuenta que en la radio el oyente adopta siempre un papel activo, "desde el momento en que tiene que deducir del referente exclusivamente sonoro la significación conceptual y las características icónicas que permiten entender el sentido global del estímulo" y que aporta la ventaja intrínseca del lenguaje auditivo que facilita la comprensión de conceptos abstractos, debido al procesamiento lineal-secuencial que se realiza de la información de referencia (Rodero, 2008). Todas estas características convierten al medio en un exponente didáctico de primer orden en la formación de los jóvenes.

Entre los principales objetivos de las radios universitarias destacan los de "servir de plataforma a las prácticas de los alumnos de titulaciones vinculadas al mundo de la comunicación, a aquellas que pretenden ser un altavoz de la propia universidad e incluso vía de comunicación con la sociedad en general" (Martín Pena y Segura Anaya, 2015:73); apoyar la difusión de la cultura y ofrecer "contenidos de tipo social, institucional y cultural” (Vázquez Guerrero, 2015:23); divulgar las actividades del campus y ser una vía de comunicación entre la 
comunidad universitaria que dé más visibilidad a sus actividades (Segura Anaya, 2014:50). Para dar respuesta a estos objetivos, entre las funciones tradicionalmente adscritas a este tipo de emisoras, tenemos:

- La difusión de contenidos vinculados con las materias de estudio para motivar, apoyar y facilitar su comprensión, aportando otros puntos de vista y una proyección social que potencie el valor de esos contenidos.

- La actualización de información sobre actividades vinculadas con la docencia y la investigación.

- La extensión universitaria con un amplio abanico de temas de interés para la sociedad en general" (Baeza Fernández y Busón Buesa, 2012: 170).

Y todo ello sin que esto signifique que "la radio universitaria deba dirigirse a un público minoritario", para lo que estas emisoras deberán implicar en su programación a toda la sociedad para que ésta se vea representada en esa programación (Martín-Pena y Espino Narváez, 2014: 29).

En las siguientes páginas se muestran los resultados de un estudio de caso a este respecto, el de la radio universitaria de la Universidad de Valladolid -Radio UVa- con el propósito de observar, tras el análisis de la parrilla del curso 2014/15, si realmente los jóvenes ponen en marcha nuevas iniciativas radiofónicas cuando son creadores de sus propios contenidos.

\subsection{La radio universitaria en España}

La Universidad de La Laguna (Tenerife) fue la primera ${ }^{10}$ en poner en marcha una emisora de radio universitaria en 1987, de la mano de un grupo de alumnos del Colegio Mayor Universitario de San Fernando.

\footnotetext{
${ }^{10}$ Hay autores que señalan Radio UNED como la primera experiencia radiofónica universitaria en España, puesto que "realiza las primeras transmisiones formativas radiofónicas procedentes de una institución educativa superior". No obstante, "nos encontramos ante un caso ciertamente particular, ya que no es una estación universitaria al uso que cuente con frecuencia propia" (Martín Pena y Contreras Pulido, 2014:91).
} 
A la experiencia canaria le siguieron las de Salamanca, León, A Coruña, Navarra, Complutense y Autónoma de Madrid, entre otras, siendo a partir del año 2000 cuando comienzan sus emisiones la mayor parte de las radios universitarias existentes actualmente (Fidalgo Diez, 2009). De hecho, en la primera década del tercer milenio, son cerca de treinta "las experiencias radiofónicas universitarias que están funcionando de forma más o menos regular", lo que "significa que existe radio en un tanto por cierto aproximado de una de cada tres universidades españolas, ya sean públicas o privadas" (Martín-Pena y Contreras, 2014: 94).

La notoria presencia de este tipo de experiencias radiofónicas contribuye a que, en noviembre de 2011, se constituya en la Universidad Complutense de Madrid la Asociación de Radios Universitarias de España (ARU) entre cuyos objetivos figuran: promover el desarrollo de nuevos formatos radiofónicos de contenidos culturales y educativos; contribuir al desarrollo de la educación, la cultura, la ciencia, la creación, la producción y la difusión de contenidos; y potenciar el desarrollo de la coproducción, de programas educativos y formativos, culturales, artísticos, científicos, tecnológicos, de salud, deporte, medio ambiente y bienestar social ${ }^{11}$.

En cuanto a su actividad en la actualidad, un estudio sobre la radio universitaria en España realizado en junio de 2014 señala que más de la mitad de las emisoras analizadas poseen dos sistemas de emisión FM e Internet-, que un 40\% emite de manera exclusiva a través de la Red -de las que un $68 \%$ posibilitan la escucha tanto en streaming como en podcast-, siendo "la parrilla clásica de tipo mosaico, con programas temáticos de una hora de duración” (Marta-Lazo y Segura Anaya, 2014:105-108).

Los contenidos que conforman habitualmente estas emisoras son diversos aunque pueden concentrase, en su mayoría, en la siguiente lista temática elaborada por las profesoras Marta-Lazo y Segura Anaya (2012:117): magazines de actualidad culturales y sociales, programas

${ }^{11}$ Objetivos detallados por la asociación en su página web: http://www.asociacionderadiosuniversitarias.es/objetivos.html (consultado el 5 de junio de 2015). 
musicales, información universitaria, deportes, ciencia, tecnología e informática y programas de salud

Por último, y según los datos que arroja el estudio de Perona (2012:44), los temas que más abordan los jóvenes estudiantes en sus programas son los relacionados con aspectos sociales, seguido de la investigación científica, el cine, las nuevas tecnologías, el empleo, los viajes, la literatura y los libros, con porcentajes que oscilan entre el $64 \%$ y el $29 \%$.

\subsection{La Universidad de Valladolid y Radio UVa}

Radio UVa se pone en marcha como proyecto piloto en la Universidad de Valladolid durante el curso académico 2011/12. Lo hace en el marco de la Facultad de Filosofía y Letras del campus de Valladolid, dentro del Grado en Periodismo -perteneciente al Departamento de Historia Moderna, Contemporánea, de América, Periodismo, Comunicación Audiovisual y Publicidad-, y su objetivo principal es convertirse en una herramienta que permita llevar a la práctica los conocimientos teóricos impartidos en clase en la asignatura "Radio Informativa", materia contemplada como obligatoria en el primer cuatrimestre del segundo curso del Grado.

Radio UVa nace, de este modo, dentro de categoría de radio universitaria que Fidalgo Diez (2009) clasifica como emisora gestionada por un Departamento o una Facultad en la que los alumnos pueden participar, apostando, sobre todo, por el "uso pedagógico de la radio como instrumento de prácticas de los futuros periodistas" (citado en Segura Anaya, 2014:52).

Tras el primer periodo de prueba, la emisora entra a formar parte de un Proyecto de Innovación Docente financiado por el Área de Formación e Innovación de la universidad, que permanece en desarrollo desde 2013 hasta el momento actual. A través del planteamiento constructivista de este proyecto se posibilita el trabajo colaborativo conjunto de docentes y alumnos en la configuración de un espacio de trabajo y formación, especialmente, en comunicación, que anima al trabajo en equipo mediante la actitud de compartir ideas y la libertad de no sentirse presionados por razones comerciales, 
institucionales, de elección de temas, expresión e incluso de forma (horarios, periodicidad, composición grupos, etc.).

Esta emisora favorece, además, la simulación de la realidad del medio, aunque a escala relativa como todas las del modelo: "Gracias a la experiencia de Radio UVa, los alumnos no sólo pueden llevar a la práctica los conocimientos teóricos adquiridos en el aula, sino que también adquieren otras competencias -como trabajo en equipo, liderazgo de un grupo, selección de contenidos, problemas técnicos y del directo, posibilidades reales de realizar un programa etc.-, imposibles de transmitir si no es a través de la simulación de situaciones reales." (PID-UVa, 04-2013/2014). La emisora cuenta también, desde 2014-2015, con la experiencia de "Radio AULA", un nuevo Proyecto de Innovación Docente avalado por la Universidad de Valladolid, que se une de este modo a la radio, y donde los alumnos elaboran en podcast didácticos - píldoras de conocimiento- los contenidos teóricos de la asignatura de "Radio Informativa" que se publican a través de la misma web (PID-UVa, 20-2014/2015).

Radio UVa elabora su primera parrilla de programación en el curso 2013/2014. La emisión es exclusivamente online, por ahora, y todos los programas están alojados en un servidor gratuito alojado en la nube, a los que se puede acceder a través de la web oficial de la radio. Cada programa es autónomo y está elaborado por varios alumnos que deciden unirse para presentar el proyecto al equipo que coordina y dirige la emisora. Durante el curso 2013/14 pudieron seguirse 11 programas de forma periódica y en $2014 / 2015$ son ya 16 los espacios que figuran en la parrilla de la radio.

\section{Metodología}

Para nuestro estudio analizaremos los 16 programas radiofónicos que han compuesto la parrilla de Radio UVa en el curso 2014/2015, concretamente en el periodo de marzo a mayo de 2015. Estos programas han sido ejecutados por otros tantos grupos de alumnos de la Universidad de Valladolid, pertenecientes la mayoría de ellos al segundo y tercer curso del Grado en Periodismo (2013/2017), aunque también forman parte de algunos de estos proyectos radiofónicos alumnos de otras disciplinas -Lengua, Filología o 
Literatura, por ejemplo- y doctorandos del Programa de Doctorado en Español: Lingüística, Literatura y Comunicación (ELLCom) ${ }^{12}$, así como varios licenciados en Periodismo de la promoción de 2014.

En el análisis se han seguido dos fases: una primera, en la que se han recogido los datos principales de cada espacio radiofónico relativos a su idea, estructura interna y secciones, formato y género; y una segunda, donde el aspecto central era observar el estilo, el discurso, las intervenciones de colaboradores e invitados, el empleo de la música, el tono predominante y los temas tratados. La recogida de información se ha llevado a cabo a partir de los datos consignados en los respectivos proyectos de programas presentados por cada uno de los equipos para su admisión en la parrilla radiofónica, donde se encontraba todo lo relativo a la idea inicial, la duración y periodicidad del espacio, la división por tareas o rutinas de cada miembro en la grabación de los contenidos, el tema fundamental elegido, el género correspondiente, el logo y fotografía de sus miembros, secciones fijas, colaboraciones y día y horario de emisión.

La metodología del estudio es fundamentalmente cualitativa -análisis de contenido y observación directa- y se lleva a cabo mediante el diseño de una ficha en la que se tienen en cuenta la forma y el contenido de los programas seleccionados como muestra, para observar si reproducen los esquemas y contenidos de programas radiofónicos ya existentes en el mercado audiovisual.

\section{La programación de Radio UVa ¿̇representa realmente un elemento diferenciador en las radios universitarias?}

Los contenidos de las emisoras universitarias deben ser uno de los principales elementos diferenciadores de este tipo de radios con respecto al resto de cadenas. No obstante, los análisis realizados hasta ahora ponen de manifiesto que, al menos en lo que a géneros $y$ formatos se refiere, las parrillas de estas emisoras no difieren demasiado de las grandes emisoras de la mano, fundamentalmente, del "formato minimagazine, es decir, aquel en el que se combinan diferentes subgéneros informativos (entrevistas, tertulias, entrevistas, debates, etc.) en espacios de tiempo relativamente breves", siendo

${ }^{12}$ Página web oficial del programa de Doctorado: http://ellcom.blogs.uva.es/ 
este formato "el que aglutina la mayor diversidad en cuanto a temáticas se refiere, y en él tienen especial incidencia los programas sobre aspectos sociales (exclusión, igualdad, solidaridad, derechos humano) en tanto que están presentes en el 64\% de las redes" (Perona, 2012:44).

\subsection{Principales objetivos, formatos y temática de los programas}

Las clásicas funciones informar, formar y entretener, tradicionalmente atribuidas a los medios de comunicación son los pilares sobre los que los alumnos de la Facultad de Filosofía y Letras de la Universidad de Valladolid construyen la parrilla de Radio UVa, con un claro predominio de la información y el entretenimiento sobre la formación. De hecho, de los 16 espacios analizados, la función formativa sólo está presente de manera combinada con alguna de las otras dos. Tal y como puede verse en el gráfico 1, los programas favoritos son aquellos que apuestan por la información y el entretenimiento, mientras que la información de forma exclusiva sólo está presente en dos espacios.

Gráfico 1: Objetivos de los programas de la parrilla de Radio UVa

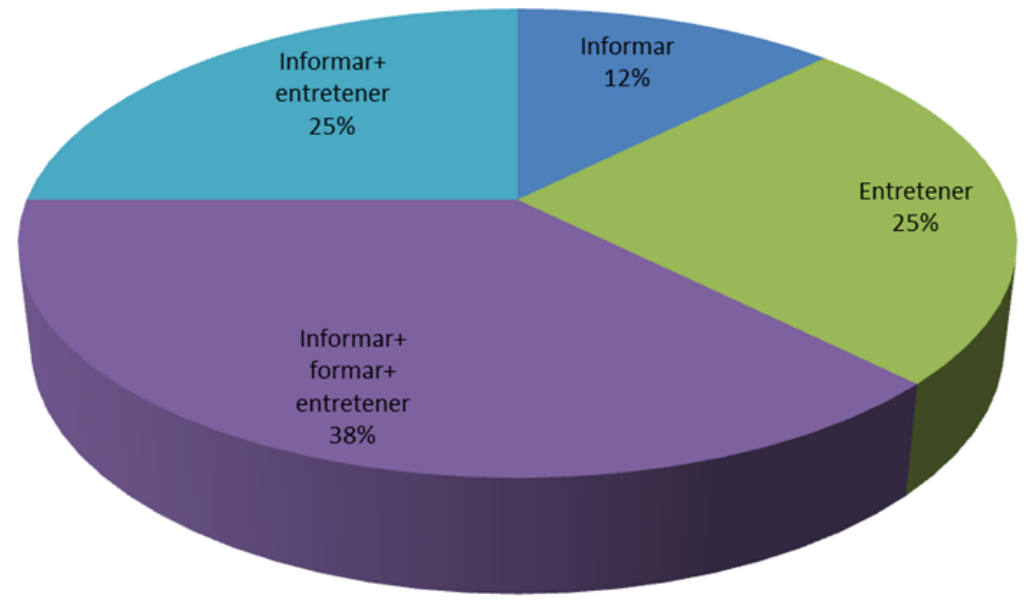

Fuente: Elaboración propia

De este modo, la parrilla de Radio UVa cuenta con un alto componente de infoentretenimiento en su programación. Se trata de un estilo que, según los propios alumnos que participan en esta experiencia radiofónica, "copian" directamente de la televisión, fundamentalmente de la mano de aquellos espacios que se sirven de 
la sátira y la ironía para ofrecer al espectador la actualidad del momento. En estos casos, así como en aquellos en los que además de informar y entretener también quieren formar, el formato dominante es el magazine, entendido como programa contenedor en el que tienen cabida distintos géneros y expresiones periodísticas y comunicativas para trasladar los contenidos a la audiencia. En este sentido, nos encontramos con que más de la mitad de los programas analizados, 11 concretamente, optan por este formato, a los que se suman tres Info-show y un magazine con tintes de Info-show, siendo el informativo semanal el único espacio que cuenta con un formato totalmente diferente al programa contenedor por excelencia.

Esta similitud en los formatos se mantiene si nos centramos en las temáticas elegidas para cada uno de los programas, especialmente en el magazine, donde vemos que las preferencias se reparten, en mayor medida, entre los espacios deportivos y los de actualidad informativa -que copan la mitad de los programas-, mientras que el resto dedica su tiempo a contenidos musicales, culturales y de ocio, donde priman los relacionados con el cine y la televisión. En el caso de los Info-show existentes, sin embargo, la actualidad informativa no es la temática dominante, sino los temas sociales, culturales, cine y televisión.

Tabla 1: Temáticas dominantes en la parrilla de Radio UVa

\begin{tabular}{l|l|l|l|l|l|}
\cline { 2 - 6 } Temática/Formato & Magazine & Info-show & Informativo & $\begin{array}{l}\text { Magazine/ } \\
\text { Info-show }\end{array}$ & Total \\
\hline Deportes & 3 & 0 & 0 & 0 & 3 \\
\hline Actualidad & 4 & 1 & 1 & 1 & 7 \\
\hline Música & 1 & 0 & 0 & & 1 \\
\hline Cultura & 1 & 1 & 0 & 0 & 2 \\
\hline Ocio & 2 & 0 & 0 & 0 & 2 \\
\hline Temas sociales & 0 & 1 & 0 & 0 & 1 \\
\hline Total & $\mathbf{1 1}$ & $\mathbf{3}$ & $\mathbf{1}$ & $\mathbf{1}$ & $\mathbf{1 6}$ \\
\hline
\end{tabular}

Fuente: Elaboración propia

\subsection{Estructura interna, géneros y estilo de los programas}

La noticia es el género más empleado en la emisora vallisoletana. No en vano, el alumnado que participa en todos los programas que conforman la parrilla se decantan de forma mayoritaria por esta 
unidad básica de información. La duración de los programas -en torno a los treinta minutos- y las diferentes secciones en las que se divide cada uno de ellos - la mayoría estructura sus espacios en cuatro secciones- son dos de las razones que contribuyen a que este género sea el más empleado, ya que su apego a la actualidad, corta duración y escasa necesidad de postproducción contribuyen a que su realización les resulte más fácil y rápida que la de otros géneros. A la noticia le sigue en presencia el reportaje -en un $13 \%$ de los programas- y la crónica -en el 11\%-bytes.

Gráfico 2: Géneros usados en los programas de Radio Uva

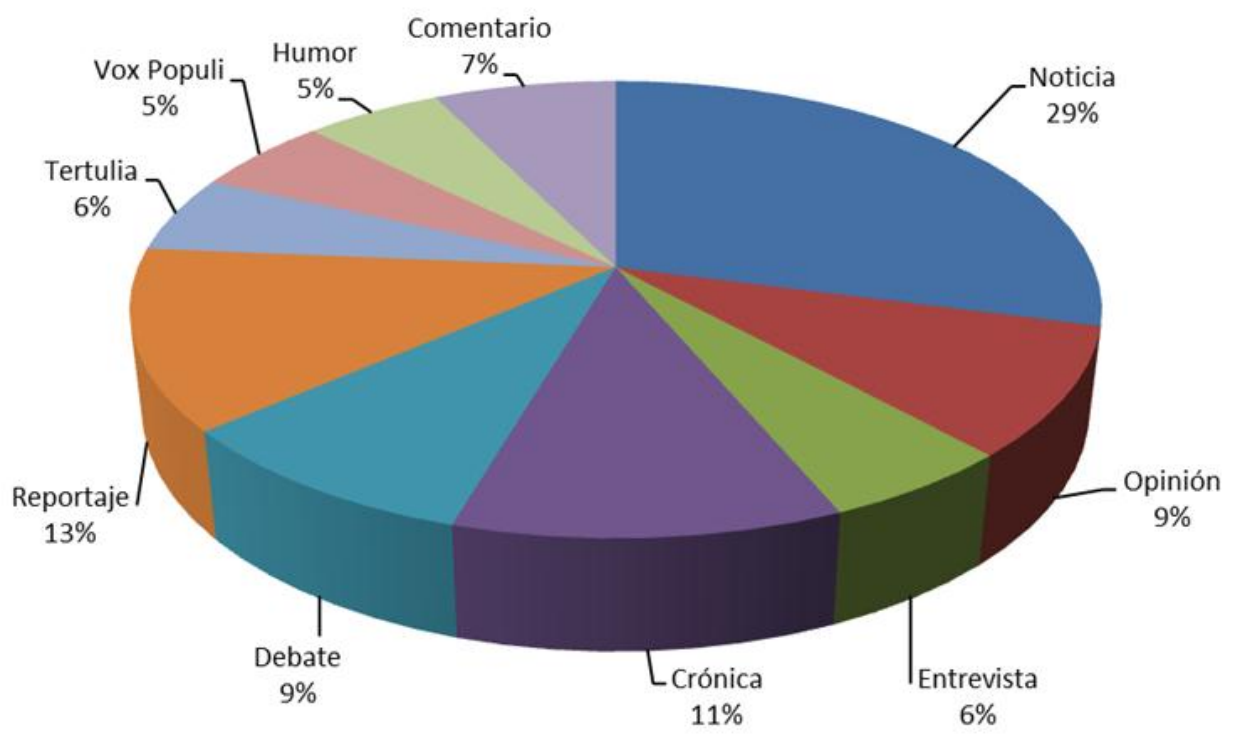

Fuente: Elaboración propia

Estos datos ponen de manifiesto la escasa apuesta que hacen los jóvenes, por ejemplo, por el humor, cuando es, precisamente, "el carácter excesivamente serio" de la radio una de la principales críticas que realizan al medio y uno de sus "géneros" preferidos cuando se les pregunta por la televisión. Del mismo modo, llama la atención que no aboguen por dar mayor presencia a la opinión ciudadana de la mano de un recurso tan económico y fácil de obtener como son las encuestas a los ciudadanos a pie de calle (vox populi). En estos casos, los alumnos optan de forma mayoritaria por incluir en sus espacios las opiniones que les llegan de los oyentes a través de las redes sociales -sobre todo de Facebook y Twitter, que son las redes en las que están presentes los programas analizados. 
Al margen del formato y de los géneros por los que se decantan para dotar de contenido a sus programas, todos se organizan de forma similar. De hecho, en los 16 programas que conforman la parrilla de Radio UVa, todos, a excepción de uno, están divididos de secciones generalmente cuatro o cinco-, a las que dan paso y van desarrollando una vez que han hecho la presentación del espacio ante los micrófonos y han adelantado sus principales contenidos mediante un sumario o titulares. Tan sólo hay un espacio en la programación -un magazine cultural especialmente centrado en Latinoamérica- que tras la presentación pasa directamente a exponer sus contenidos a través de la noticia y la entrevista, que son los géneros con mayor presencia en el programa.

Nos encontramos que, aunque en todos los espacios haya una temática dominante, tal y como se recoge en la tabla 2, a lo largo de cada uno de los programa, sus conductores y demás participantes abordan contenidos de otros temas, a excepción de los espacios deportivos, que están dedicados, de principio a fin, de forma exclusiva al deporte, bien con una o varias disciplinas. Estos programas siguen un esquema tradicional, que importan de los programas deportivos de éxito en las grandes cadenas generalistas comerciales, donde tras repasar y analizar los resultados de la jornada, promueven debates sobre los principales eventos deportivos que les ocupan.

\subsection{Estilo y tono ante los micrófonos}

En los programas analizados se produce de forma mayoritaria una alternancia de estilos formal e informal, que lleva aparejado un tono más serio o desenfado a cada espacio. La tendencia general es la apuesta por realizar programas desenfadados. De hecho, casi la mitad de la parrilla está compuesta por espacios en este tono, mientras que un $37 \%$ opta por un estilo más formal y un 19\% elige la combinación de ambos tonos, dependiendo de la sección que aborde el programa, una tendencia actualmente muy presente en los magazines de las cadenas generalistas españolas, con espacios divididos en dos partes claramente diferenciadas: una destinada a la exposición y análisis de la información del día y otra dedica al entretenimiento, y donde, 
además, cada parte cuenta con un presentador diferente (López Vidales y Gómez Rubio. 2015).

Ese estilo formal o informal, sin embargo, no depende tanto de la temática abordada como del carácter conferido a cada uno de los programas y/o secciones, es decir, que asuntos "serios" pueden ser tratados de forma irónica, entre los que destacan todos aquellos relacionados con el ámbito educativo. No obstante, a pesar de esa preferencia mayoritaria por los programas desenfadados, los jóvenes no incluyen en sus programas espacios de humor: tan sólo tres de los programas de Radio UVa cuentan con secciones de humor como tales: se trata de dos de los Info-show realizados, así como del magazines con tintes de Info-show. En el resto de programas el carácter desenfadado y formal de los espacios viene de la mano del tono empleado por el conductor o conductores del espacio. Por norma general, los programas analizados no cuentan con invitados y si lo hacen es de una manera muy esporádica. Por otra parte, cabe destacar que el trabajo realizado por los alumnos se lleva a cabo principalmente en el estudio de radio y se realizan pocas aportaciones procedentes de fuera de este espacio.

\section{Ideas para la reflexión}

Tras el análisis de la parrilla de Radio UVa se concluye que los jóvenes que participan en la emisora no innovan ni en contenidos ni en forma. A pesar de ser una emisora de radio universitaria en la que, además de poner en práctica los conocimientos necesarios para introducirse en la producción radiofónica, se permite a los alumnos idear, crear y realizar un proyecto de radio de principio a fin, estos optan por trasladar a la emisora los mismos formatos actualmente existentes en las cadenas de radio generalista. Concretamente, eligen de forma mayoritaria el magazine, configurando dentro del mismo los contenidos en diferentes secciones pero al amparo de un tema dominante, que, generalmente, gira en torno a la actualidad, la cultura, la música, el ocio y los deportes. Esto hace que la innovación no sólo esté ausente por lo que a formatos se refiere, sino también en la temática y en los géneros escogidos por sus artífices para confeccionar los contenidos, donde la noticia, el reportaje y la crónica son los favoritos, frente a otros minoritarios como el humor, la 
entrevista, la tertulia y las encuestas de calle. Teniendo todos los programas analizados como punto de partida obligatorio la actividad de la Universidad de Valladolid en sus diferentes ámbitos, cada uno de ellos completa su tiempo de emisión dando cobertura a otros ámbitos que exceden el universitario. No obstante, no se observa una apuesta por la búsqueda de temas que den voz y presencia a temas y colectivos que la encuentran en las grandes cadenas, sino que se basan en los temas de máxima actualidad y cobertura en las emisoras generalistas, reproduciendo los mismo esquemas y patrones. En este sentido, la falta de humor en estos espacios universitarios llama especialmente la atención, puesto que cuando se les ha preguntado por la opinión que tienen de la radio actual, sus respuestas han dejado de manifiesto que consideran a ésta como un medio serio, con poca variedad temática y con contenidos alejados a sus intereses e inquietudes. Por lo tanto, aunque estos jóvenes se decantan en su mayoría por la puesta ante las ondas de programas desenfadados, la temática, las secciones y los géneros que emplean para ello son los mismos que rechazan en las grandes cadenas. Es más, ese tono informal que confieren a sus espacios viene dado por los propios presentadores y colaboradores, cuyos comentarios en torno a los temas sobre los que giran sus espacios son desenfadados, mientras que la presencia de espacios de humor propiamente dichos, como los sketches realizados ex profeso para los programas, son prácticamente nulos. Ante esta imitación en la reproducción de contenidos y roles radiofónicos, cabe preguntarse si los jóvenes de hoy lo que buscan en las ondas no es tanto una renovación de contenidos, sino una renovación de voces protagonistas, sustituyendo a esos comunicadores "estrella" con una larga trayectoria profesional que pueblan el dial por otros con menos aval profesional pero a los que ellos ven más cercanos en intereses e inquietudes y con los que se sienten más identificados. Se trata, en definitiva, de un "lavado de cara" donde la esencia radiofónica seguiría siendo la misma de hoy. 



\title{
De las ondas a los bytes. La nueva era de la radio universitaria ibérica
}

\author{
Teresa Piñeiro-Otero (Universidade da Coruña) \\ Ohttp://orcid.org/0000-0001-6414-2700 \\ Ghttps://scholar.google.es/citations?user=4hOLIbUAAAAJ\&hl=es
}

Resumen: La radiofonía universitaria está viviendo una nueva expansión con la irrupción de Internet y las nuevas Tecnologías de la Información y la Comunicación. En la Red las emisoras universitarias pueden integrar las potencialidades del medio digital para la creación y distribución de contenidos así como su interactividad y multimedialidad.

En esta línea el presente trabajo efectúa un análisis de los websites de las emisoras universitarias de España y Portugal para conocer el grado de adaptación al medio digital desde la perspectiva de los géneros (lenguaje y distribución de contenidos) como de la interacción y participación de los oyentes-usuarios.

Palabras clave: Radio univesitaria; radiomorfosis; géneros; interacción; España; Portugal.

\section{Introducción}

T A radio universitaria comenzó su singladura en 1919 con la $\mathcal{L}$ puesta en marcha de la primera emisora en la Universidad de Wisconsin (Faus, 1973). La $W H A$, como se denominó dicha iniciativa, constituyó la primera radio al servicio de la comunidad académica tras años de experimentación con el medio en el ámbito de la institución universitaria. 
En 1933, en pleno desarrollo de la radiodifusión universitaria en el continente americano, inició sus emisiones la Rádio Universitária de Coimbra. "Este proyecto duró poco tiempo y, en la década de los 40, surge el Centro Experimental de Rádio, en aquel entonces una de las secciones de la Associaçao Académica de Coimbra que comenzaba a formar técnicos e locutores iniciando emisiones regulares" (Duarte, 2014: 137).

Pese a su pronta aparición la radiodifusión universitaria en Portugal y, en general, en el continente europeo no se desarrolló hasta la segunda mitad del siglo XX. Un retraso que marcó el discurrir histórico de este tipo de emisoras también en el contexto ibérico (Martín Pena, Marta-Lazo y Ortiz Sobrino, 2015: 83).

A partir de los años 50 la radio generalista portuguesa acogió algunas iniciativas creadas por y para la universidad. Siguiendo a Duarte (2014: 137) estaciones como RDP Emissora Nacional, desde su delegación regional Coimbra, u Onda Média da Lisboa emitieron programas orientados a las comunidades de estas instituciones académicas.

En España la primera experiencia de radio en el ámbito universitario fue Radio UNED, en la década de los 70. Esta iniciativa suele fijar el inicio de la radiofonía universitaria española aunque, señalan Martín Pena y Contreras (2014), por sus particularidades no puede considerarse una emisora de este tipo propiamente dicha.

En cualquier caso, el despegue de la radiofonía universitaria en el contexto ibérico se sitúa en la década de los 80 , momento en el que aparecen la Rádio Universidade de Coimbra. RUC (1986) y la Radio San Fernando en la Universidad de La Laguna (Duarte, 2014; Martín Pena y Contreras, 2014).

El desarrollo de la radio universitaria en España y Portugal no sólo ha sido tardío, también se ha caracterizado por su limitada penetración en las instituciones académicas. Esta situación ha comenzado a cambiar con la incorporación de las TIC al proceso de producción/transmisión radiofónico y la aparición de nuevas formas de distribución de contenidos (Teixeira et al, 2010). 
Internet también ha permitido a las emisoras universitarias hacerse un nuevo en el complejo contexto de la radiodifusión, más allá del espectro electromagnético.

La radio-web ha dotado de una mayor proyección al fenómeno de la radiofonía universitaria en España, tras un período de desaparición de emisoras por problemas legales (Espino Narváez y Martín Pena, 2012: 22). La última década se ha caracterizado "por una clara expansión del mapa universitario radiofónico español, con la irrupción de nuevas emisoras que, mayoritariamente, emiten solo a través de la Red -ya sea de manera continua o mediante podcast y repositorios (...)" (Perona, 2012: 38).

E el contexto luso desde finales de los 90 se pueden reseñar diversas experiencias de radio universitaria en la Red, de las que hoy pocas permanecen activas (Teixeira y Silva, 2009). De hecho, frente a la creciente entidad de las internet-only-radios en las instituciones académicas españolas, la mayoría de las radios-web portuguesas constituyen la huella digital de emisoras convencionales.

Pero, ¿se puede decir lo mismo de su adaptación al medio? En esta línea el presente trabajo analiza la adaptación de la radio universitaria de España y Portugal a la plataforma web poniendo especial atención a su lenguaje, la distribución del sonido y la interacción-participación de sus públicos.

\section{La Red: un nuevo espacio para un nuevo medio}

El traspaso de la radiofonía hertziana a la Web supuso un revulsivo para el desarrollo y expansión de las emisoras universitarias. Este proceso de 'radiomorfosis' (Prata, 2008) conllevó una profunda renovación del producto sonoro con la incorporación de otros elementos inherentes al medio digital como textos, hipertextos, imágenes o formatos audiovisuales.

Ya en su nueva esencia multimedia la radio ha experimentado diversas estrategias comunicativas con el sonido como elemento catalizador. Dichas estrategias están marcadas por la aparición de diversos modos de distribución bajo demanda que, además de acabar 
con la fugacidad característica del medio, posibilitaron la aparición de una radio a medida del usuario.

La creación de fonotecas con archivos disponibles previa descarga y, posteriormente, la penetración del podcasting permitieron flexibilizar el consumo radiofónico para una experiencia personal y móvil, también en entornos offline (Gallego 2012; Sellas 2012). Hoy el desarrollo de la banda ancha y la conectividad de los dispositivos portátiles han situado al streaming como nuevo motor de la radiofonía online (Cordeiro 2012).

Más allá de la diversificación en los modos de emisión y distribución del sonido, el salto a la Red ha permitido a la radio la adopción de sus potencialidades interactivas tanto en sus mensajes como en la relación que se establece con los oyentes-usuarios (Perona 2012).

La emergencia de diferentes servicios y plataformas sociales 2.0 ha provisto a la radio de un contexto idóneo para generar nuevas dinámicas con sus radioescuchas.

En la Red "la gente anteriormente conocida como audiencia" (Rosen, 2005) puede asumir un papel activo en la creación de los contenidos del medio (User Generated Content) como en su distribución a través de sus redes personales (Used Distributed Content). Este papel del usuario exige una transformación en las estrategias de producción, distribución y comercialización radiofónica que -siguiendo a Ortiz Sobrino (2011)- tiene un recorrido pendiente.

Internet ha alumbrado un nuevo concepto de radio -la R@dio- que conjuga "sonido e imagen, es [más] interactiva, [más] participativa, compartible, asíncrona, repetible, reproducible, inspeccionable, personalizable, discontinua, hipertextual, no linear, convergente y bajo demanda" (Cordeiro, 2012: 503).

\section{La radio-web universitaria: una plataforma social}

En el caso concreto de la radiofonía universitaria Espino Narváez y Martín Pena (2012, 23) señalan tres fórmulas de integración de Internet en la práctica diaria de esta tipología de emisoras: 
- Internet como soporte de la emisión en tiempo real o simulcast.

- Internet como radio a la carta con la distribución de sus contenidos en archivos descargables (habitualmente MP3), podcast o streaming. Si bien todos estos formatos exigen una respuesta activa del usuario es probablemente el podcasting el que más se aproxima al concepto de radio personal dado que su posibilidad de suscripción permite un consumo a la carta sin volver a acceder al medio (Piñeiro Otero, 2012).

- Internet como plataforma de interacción con el oyente/usuario. La Web 2.0 y las plataformas sociales han propiciado nuevas formas de relación entre el público, los productores del medio y sus contenidos, con los que puede interactuar y participar de diversos modos.

Estas tres fórmulas no son excluyentes sino que pueden aparecer integradas de diversos modos en las emisoras universitarias con presencia en la Red. Lo más relevante es que estas radios "desarrollen todas las posibilidades que ofrece Internet y hagan de la interactividad un principio activo" (Espino Narváez y Martín Pena, 2012: 23).

Si, como señalan Calvo y Padilla (2010) la radio 3.0. cuenta con tres pilares: radio, internet y usuario; es éste último el que cobra una entidad especial en el ámbito la radiofonía universitaria.

Por una parte, la función de servicio público va a llevar a estas emisoras a habilitar diversas fórmulas para la participación, intercambio e interacción de la comunidad universitaria en la Red.

Por otra, condicionantes como la limitada profesionalización de la plantilla, la vertiente formativa del medio o las políticas de inclusión y participación universitaria han llevado a dichas emisoras a alimentar sus parrillas con contenidos de los propios radioescuchas (Casajús y Vázquez, 2014: 90).

En su expansión a la plataforma web las emisoras universitarias presentan múltiples puntos de conexión con su público principal -los estudiantes- dadas sus tendencias de uso y consumo audiovisual, 
Los jóvenes han hecho de la web 2.0 sus dominios. En efecto este colectivo se erige como principal usuario de las redes sociales, produce más contenido que otros emisores clásicos, desarrolla nuevas formas de acceso y consumo de información que han convertido la pantalla del móvil en una expansión de su vida dando lugar a un usuario permanentemente conectado.

En resumen, estos jóvenes presentan las características precisas para "estar y participar" en la radio universitaria 2.0 (Casajús y Vázquez, 2014). En este proceso las redes sociales se han convertido en un aliado esencial para la radio universitaria dado que permiten "un tráfico fluido, bidireccional, multipunto y nodal entre personas que intercambian sus papeles" (Caldevilla Domínguez, 2011: 301). Asimismo la importante penetración de las redes sociales entre los jóvenes las convierten en un espacio privilegiado para estas emisoras (Casajús, 2012),

La expansión a las redes sociales, en su mayoría Facebook y Twitter, constituye un paso más en la evolución de la radio universitaria. Un proceso iterativo que está marcado por el imperativo de la radio universitaria de abrirse a la comunidad académica; de permitir a sus radioescuchas la partición en y a través del medio, el acceso a la radio y la intervención en los contenidos.

\section{Materiales y métodos}

Para determinar el grado de adaptación de las radios universitarias de España y Portugal a la Red se ha efectuado un estudio de sus websites utilizando el análisis de contenido como método de investigación. Se parte de la hipótesis de que las radios universitarias presentan una importante adaptación a la web para incrementar la accesibilidad de sus contenidos y conectar con sus oyentes-usuarios, en su mayoría estudiantes universitarios.

La selección de emisoras universitarias estuvo marcada por la complejidad del fenómeno en el que se integran multiplicidad de estructuras, objetivos y tipos de gestión (Sauls, 2000).

En esta línea se tomó como referencia el catálogo de emisoras recogido por la Asociación de Radios Universitarias de España 
(ARU) y el listado de radios portuguesas de Teixeira y Silva (2009). Esta acotación conllevó una muestra final de 29 emisoras universitarias -23 españolas y 6 lusas- con presencia en la Red.

Tabla 1: Emisoras universitarias de la muestra de estudio.

\begin{tabular}{|c|c|}
\hline \multicolumn{2}{|c|}{ EMSORAS UNIVERSITARIAS ESPAÑOLAS } \\
\hline Radio CEU Valencia & Cardenal Herrera-CEU \\
\hline Radio UNED & UNED \\
\hline RUAH Radio Universitaria de Alcalá de Henares & Universidad de Alcalá \\
\hline iRadio UCAM & Universidad Católica San Antonio \\
\hline ONCeu & Universidad CEU San Pablo \\
\hline InfoRadio UCM & Universidad Complutense de Madrid \\
\hline RadioUniversidad.es & Universidad de Almería \\
\hline Onda Campus & Universidad de Extremadura \\
\hline UniRadio* & Universidad de Huelva \\
\hline UniRadio Jaen & Universidad de Jaén \\
\hline Radio Universitaria & Universidad de Léon \\
\hline 98.3 Radio & Universidad de Navarra \\
\hline Radio Universidad & Universidad de Salamanca \\
\hline Radio Unizar & Universidad de Zaragoza \\
\hline Europea Radio & Universidad Europea de Madrid \\
\hline Radio Campus & Universidad La Laguna \\
\hline Radio Universitaria UMH & Universidad Miguel Hernández \\
\hline Radio URJC & Universidad Rey Juan Carlos \\
\hline Radio Universidad San Jorge & Universidad San Jorge \\
\hline Radio Universitat & Universitat de València \\
\hline Vox UJI & Universitat Jaume I \\
\hline UPV Radio & Universitat Politècnica de València \\
\hline UPF Ràdio & Universitat Pompeu Fabra \\
\hline \multicolumn{2}{|c|}{ EMSORAS UNIVERSITARIAS PORTUGUESAS } \\
\hline RUM. Rádio Universitária do Minho & Universidade do Minho \\
\hline RUBI. Radio Universitaria da Beira Interior & Universidade da Beira Interior \\
\hline RUA.Radio Universitaria do Algarve & Universidade do Algarve \\
\hline RUC. Radio Universidade de Coimbra & Universidade de Coimbra \\
\hline Universidade FM & Universidade de Trás-os-Montes e Alto Douro \\
\hline Radio Zero & Instituto Superior Técnico de Lisboa \\
\hline
\end{tabular}

Fuente: Elaboración propia ${ }^{13}$

El análisis de contenido se enfocó en los dos aspectos clave de la radiofonía web: géneros (difusión de contenidos sonoros, tipos de lenguajes empleados, expansión a otras plataformas, etc.) e interactividad (posibilidades de interacción en contenido, mecanismos de participación, integración de redes sociales, etc.).

${ }^{13}$ En el momento de recogida de la información, en la primera semana de noviembre de 2015, UniRadio Huelva se encontraba actualizando su web. 


\section{Distribución de contenidos sonoros}

El sonido constituye el elemento esencial en la radiofonía universitaria ibérica. Todas las radio-web analizadas, con independencia de su forma o complejidad, han incorporado contenidos de audio en streaming ya se trate de la emisión en directo (72,41\% de la muestra), ya de un acceso bajo demanda (83\% de las radios). En esta línea se puede señalar divergencias entre las emisoras universitarias de España y Portugal. Si la radiofonía lusa se centra en la retransmisión en directo $(100 \%$ de la muestra), las emisoras españolas presentan una mayor orientación hacia el consumo bajo demanda (87\% de las radios).

Esta divergencia puede relacionarse con la propia esencia de las radios universitarias como emisoras FM (39\% españolas y $83 \%$ lusas) o webradios propiamente dichas (61\% españolas y 17 lusas).

Gráfico 1: Fórmulas de distribución de contenidos sonoros en las radio-webs universitarias españolas y lusas (expresado en porcentaje).

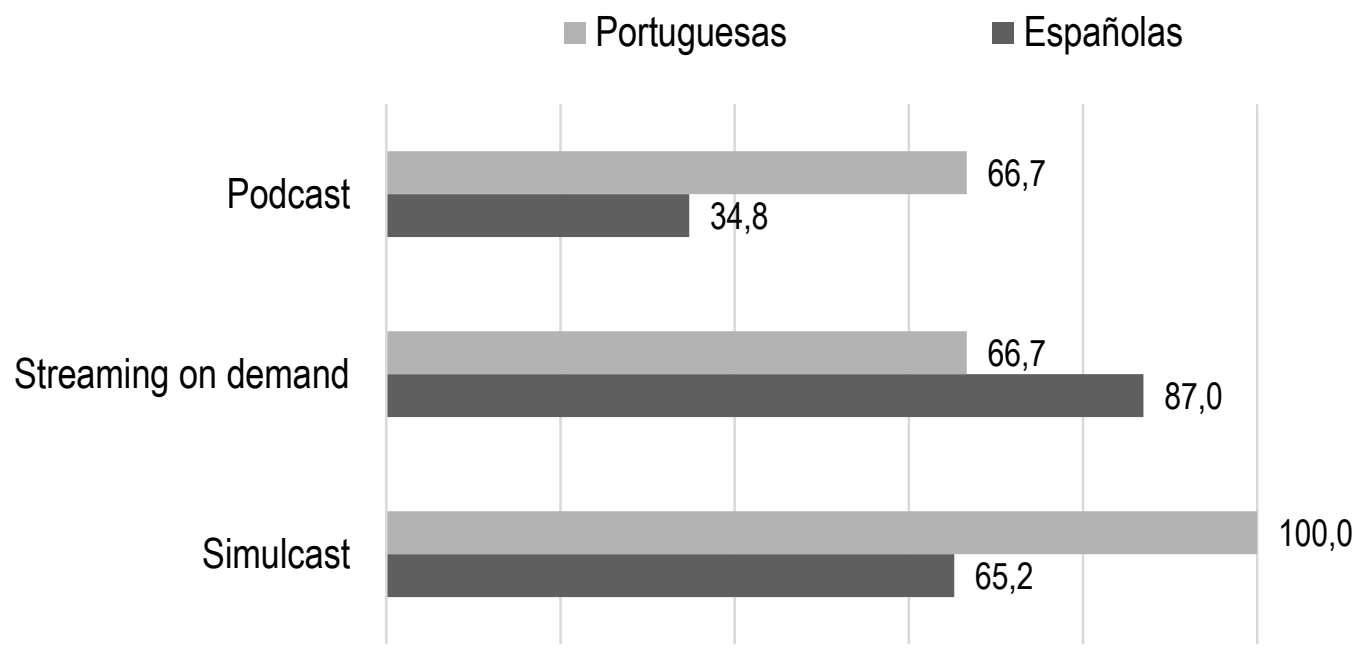

Fuente: Elaboración propia

El streaming se refrenda también como el modo más habitual de distribución de contenidos, llegando a duplicar en su penetración al podcasting. No obstante, la asociación del consumo no-lineal con el podcasting ha llevado a algunas radios universitarias a identificar como tal otra tipología de archivos sonoros. 
En cualquier caso la fórmula más habitual de presentación de los contenidos on demand es la integración de estos archivos en la página web de la emisora, bien a través del plugin de reproductor de otras plataformas de audio (23\% de las emisoras).

Servicios como iVox, TuneIn, o Souncloud han facilitado a las emisoras universitarias replicar su emisión en la Red, generar una biblioteca para su consumo en streaming, su descarga, o la automatización del proceso a través de podcast.

La gratuidad de estas plataformas, la facilidad que presentan para la integración en un determinado sitio web (como icono, plugin del reproductor de audio u otros complementos) y su compartibilidad (shareability), las convierten en una oportunidad para las radio-webs universitarias, tanto desde la perspectiva de los contenidos como de la interactividad de sus públicos.

\section{Adaptación al nuevo lenguaje radiofónico}

En su nueva esencia multimedia las radios universitarias integran con frecuencia textos e imágenes pero dejan relegados otros formatos audiovisuales.

Con la excepción de Universidade FM (Universidade de Trás-osMontes e Alto Douro) cuyo site vehicula únicamente la emisión de la radio en directo, todas las emisoras incorporan contenidos en formato texto. Estos textos pueden introducir audios (83\% y 82\% de emisoras españolas y portuguesas respectivamente), complementarlos (26\% y $17 \%$ de emisoras españolas y portuguesas), o contar por sí mismos con sentido completo (52\% y $33 \%$ de emisoras españolas y portuguesas respectivamente).

Asimismo algunas de las radio-web analizadas presentan un uso interesante de los textos al crear artículos sugerentes para introducir los últimos audios publicados. Este uso permite llamar la atención de los oyentes-usuarios de la emisora sobre el contenido sonoro y mejorar su posicionamiento web, cuestión que facilita la atracción de nuevos públicos. 
En boga con el visual thinking que impera en la Red son diversas las radios que han desarrollado sus sites con un importante peso de la maquetación y contenido gráfico.

Un ejemplo de esta tendencia es el empleo de imágenes en miniatura con un título o sumario que, con la interacción del usuario, se amplían e integran dentro del contenido.

Más allá de estas imágenes, presentes en la mitad de los sites analizados, los contenidos gráficos con mayor penetración en la radio universitaria son los iconos $(70 \%$ y $67 \%$ de emisoras españolas y portuguesas), seguidos por aquellas fotografías que acompañan a un texto o audio determinado ( $74 \%$ y $50 \%$ radios españolas y lusas).

Textos e imágenes, por tanto, establecen en las radio-webs universitarias una relación de interdependencia similar a la señalada por Piñeiro Otero (2015) para las emisoras locales. Los titulares o sumarios suelen acompañarse por imágenes con valor de icono, mientras que las noticias o contenidos textuales de mayor entidad integran fotografías que complementan dichas informaciones.

En este aspecto se puede señalar una mayor relevancia de los contenidos de carácter textual y visual en el contexto de la radio universitaria española frente su homóloga lusa; cuestión que puede remitir a una mayor adaptación a la radiofonía web. Sin embargo una emisora portuguesa, la RUM. Rádio Universitária do Minho, se sitúa entre las emisoras que han logrado una mayor adaptación a la plataforma web tanto en lo que respecta a la distribución de sus contenidos, lenguajes utilizados (conjuga texto, audio, imagen, vídeo e hipervínculos), universo de servicios online, o sus posibilidades de interacción y participación dentro de la propia web.

\section{Interactividad}

En lo que se refiere a la interactividad se debe señalar un empleo limitado de las posibilidades de interacción y participación de las radio-webs universitarias. 
Gráfico 2: Fórmulas de interacción y participación previstas por las radio-webs universitarias ibéricas (expresado en porcentaje).

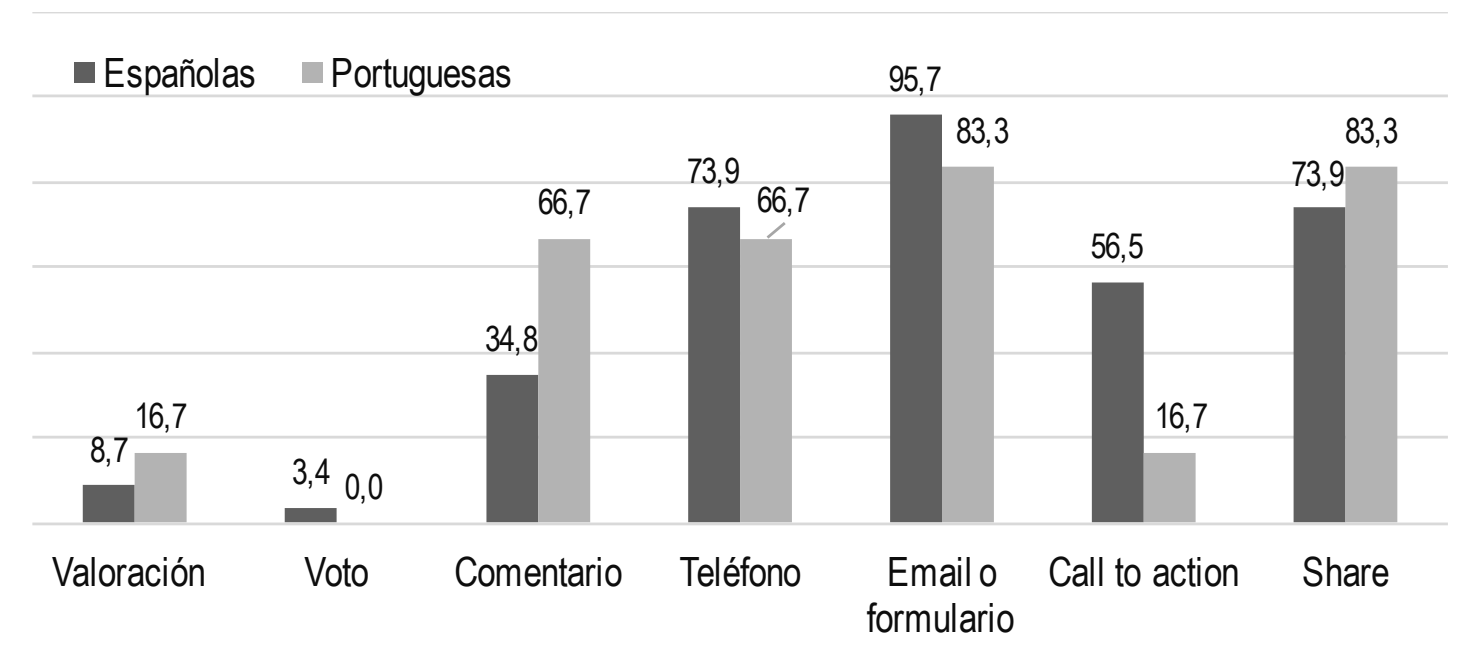

Fuente: Elaboración propia

Menos de la mitad de las emisoras universitarias analizadas prevén alguna opción de interacción con sus contenidos, siendo más frecuentes los comentarios que las opciones automatizadas (valorar, votar, me gusta). Estos comentarios pueden efectuarse a través de funcionalidades de la propia web o de un complemento específico de Facebook, siempre identificándose con una cuenta de correo electrónico o red social válidas.

UPF Ràdio restringe los comentarios a los miembros de la Universitat Pompeu Fabra (con un e-mail de la universidad). Una medida que puede señalar una concepción más limitada de los públicos de una radio universitaria.

Además de las fórmulas automatizadas y los comentarios la RUAH, Radio Universitaria de Alcalá de Henares integra una sala de chat en su reproductor de sonido. Esta funcionalidad permite la interacción en tiempo real de los oyentes-usuarios de la radio de modo que se fomenta, de forma más directa, la sensación de comunidad.

La incorporación de las redes sociales a la radiofonía online ha permitido complementar las posibilidades de interacción de los websites con plugins sociales o iconos que facilitan el acceso del oyenteusuario a la conversación social. En este sentido, ocho de cada diez radio-webs analizadas integran un acceso directo a sus perfiles 
sociales destacándose una mayor penetración de Twitter entre las emisoras españolas y de Facebook entre las lusas.

Gráfico 3: Presencia de las emisoras universitarias y lusas en Redes Sociales (expresado en porcentajes) Elaboración propia.

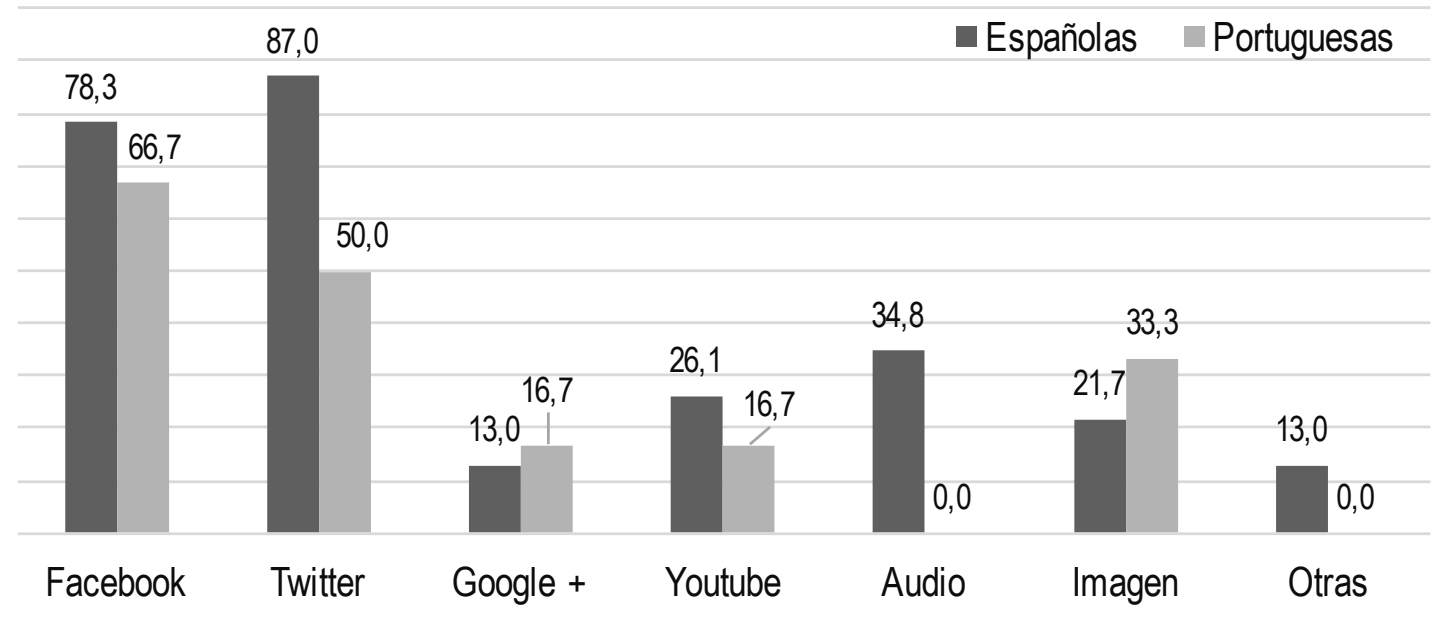

Fuente: Elaboración propia

Además de la interacción con los contenidos, el 75\% de las emisoras universitarias incorporan en sus sites opciones de 'compartibilidad' que automatizan la distribución de los contenidos en los espacios sociales de los oyentes-usuarios. Dichas posibilidades para el User Distributed Content son bastante básicas, permitiendo la redifusión de los contenidos textuales y -en menor medida- sonoros a través del correo electrónico y de las principales plataformas sociales.

Las opciones de compartibilidad se multiplican con el acceso o integración en el site radiofónico de plataformas de audio como iVox o Soundcloud, que presentan una esencia eminentemente social.

En cuanto a las estrategias de participación, el número de emisoras universitarias que integran los oyentes-usuarios en los contenidos del medio se reduce de forma notable.

Solo cuatro de cada diez emisoras desarrollan call to actions para facilitar y estimular el User Generated Content. Una participación que se puede articular de múltiples modos con diversos niveles de compromiso que van desde el envío de noticias hasta que van desde 
el envío de informaciones a la integración en el equipo de producción.

El 34\% de las emisoras (todas ellas españolas) apelan a la participación de los estudiantes y, en general, de toda la comunidad universitaria en la producción del medio. La integración en el equipo de producción puede efectuarse en el marco de un convenio de prácticas-beca o fuera de éste.

Por su parte el $28 \%$ de las radios universitarias solicitan la colaboración oyentes-usuarios a través de la propuesta y desarrollo de programas. En estos casos las emisoras suelen anclar este tipo de participación con la distribución de una plantilla, escaleta u otra documentación que facilite a los oyentes-usuarios el desarrollo de la idea y sistematice el envío de propuestas para su valoración.

Ambas posibilidades de participación no sólo se imponen a otras fórmulas de User Generated Content en cuanto a su penetración en las radio-webs universitarias ibéricas y al grado de compromiso de sus oyentes-usuarios, también los inviste como -verdareros-prosumers.

\section{Conclusiones}

La radio universitaria ha logrado una mayor proyección a través de Internet, sus plataformas y servicios, que le ha llevado a una nueva era. En su expansión a la Web las emisoras universitarias ibéricas han combinado fórmulas de emisión y lenguajes que permiten flexibilizar el consumo del medio y configurar una radio a medida del usuario. En este sentido se puede señalar el predominio del streaming frente otras fórmulas de distribución de audio; un resultado que converge con el estudio de Marta-Lazo y Segura Anaya (2014) sobre la adaptación de la radio universitaria española a Internet. Sin embargo frente a dicho estudio se ha podido señalar una evolución positiva de las emisoras universitarias hacia una radio a la carta.

La posibilidad de un consumo bajo demanda supone una oportunidad para unas estructuras radiofónicas que:

- No suelen contar con un horario de programación extenso, facilitando el acceso a la comunidad académica y su entorno. 
- Presentan un público acotado pero heterogéneo, con diversos perfiles e intereses. La programación a la carta les permite orientar su escucha y, a las emisoras, crear perfiles de acceso.

- Carecen de licencias de emisión o presentan frecuencias limitadas que dificultan el acceso fuera de su radio de alcance. La Red elimina las barreras espaciales y temporales en la configuración de la comunidad de radioescuchas, pudiendo acompañar a los oyentes durante sus estancias en otros centros/lugares e -inclusomantener el vínculo una vez que éstos dejan de formar parte de la institución académica.

- Cuentan con una función de servicio público que les exige la atención a diversos colectivos de oyentes-usuarios. En este sentido la Web permite una fragmentación de contenidos y los hace más accesibles con la incorporación de textos e imágenes.

Respecto a la interactividad-participación si bien las emisoras universitarias ibéricas integran fórmulas de interacción en sus sites, han derivado esta función mayoritariamente a las redes sociales. No obstante han sido los servicios de audio 2.0 los que han multiplicado las posibilidades de interacción de la radiofonía universitaria ibérica. Estas plataformas, usadas para paliar carencias funcionales de las páginas web en la distribución de audio, facilitan la conversación social y la redifusión de los contenidos sonoros entre los espacios personales del oyente-usuario. Finalmente, en cuanto a la participación, se han podido constatar fórmulas de User Generated Conent en las radios universitarias ibéricas. La llamada a los oyentesusuarios para integrarse en el equipo de la emisora, o desarrollar programas propios, posibilita una mayor implicación de los usuarios. Se trata de unos modos de acceso al medio y a sus contenidos que hacen realidad la idea de una radio hecha "por" y "para" la comunidad universitaria. 


\title{
La radio universitaria y su papel en la dieta mediática de los estudiantes de Colima, México
}

\author{
Marina Vázquez Guerrero (Universidad Colima, México) \\ http://orcid.org/0000-0001-9875-4211 \\ http://scholar.google.com.mx/citations?user=O4f8uB8AAAAJ\&hl=es
}

Arturo García Lezama (Universidad Colima, México)

René López Chagoya (Universidad Colima, México)

Jorge Andrés Velasco (Universidad Colima, México)

Resumen: Los jóvenes están poco presentes en el consumo de medios y ha sido precisamente la radio quien ha tenido una pérdida mayor ante Internet y los dispositivos móviles. Si bien la mayoría de radios universitarias han venido haciendo cambios importantes, no todas tienen un seguimiento de sus radioescuchas. En México, este tipo de radio tiene conoce poco a sus audiencias pues son pocas quienes realizan estudios. Universo 94.9 es una de las radios que destacan en el panorama mexicano por su dinamismo y vanguardia. Dado que estudios previos habían demostrado que un bajo porcentaje de la población escucha esta radio y que la mayoría de jóvenes no consume los medios universitarios se planteó un estudio específico. A través de una investigación con 187 estudiantes de entre 15 y 19 años, los resultados nos muestran un panorama que podría ser reflejo de otros casos en el país: La radio es la tercera opción de consumo y un 67\% la escucha de vez en cuando. Un 66\% no conocen la radio universitaria a pesar de sus más de 13 años al aire y piden que se utilicen recursos tecnológicos y publicitarios para acercarse a ellos, una tarea esperanzadora para aquellas radios que se adhieran a la innovación. 
Palabras clave: radio universitaria; estudiantes, consumo radiofónico, jóvenes.

\section{Introducción}

A partir de que se dio la diversificación de oferta mediática a 1 través de Internet -hace unos 10 años-, los medios convencionales se han enfrentado a múltiples retos para poder sobrevivir. La radio ha sido una de las más afectadas, al encontrarse con menos escuchas fieles y audiencias más exigentes.

Tal y como lo menciona Fernández (2014) "Las nuevas audiencias se reconocen hoy con un status diferente al que teníamos de ella. Activa, demandante y cada vez más infieles nos fuerzan desde la radio a la necesidad de construir programas que demandan creatividad y esfuerzo" (:02). Si bien a lo largo de la historia los jóvenes no han sido el público mayoritario de la radio tradicional, solían tener programas y segmentos específicos y por lo tanto su relevancia dentro del sector. Hoy en día, intentar llegar al joven implica una especialización de la cadena y la inversión en tecnología y plataformas al día para tener su atención con más frecuencia.

Si transportamos este situación a la radio no comercial, el panorama se hace más complicado pues desde siempre, en México, por lo menos, los contenidos culturales o institucionales no son mayoritariamente atractivos para el público en general, por lo que involucrar e interesar a ese sector de la población tan dinámico y exigente como lo puede ser el juvenil, es toda una proeza.

El presente estudio busca hacer una reflexión sobre el reto que implica programar y buscar la atención del joven estudiante de nivel bachillerato en la radio universitaria, en una región específica del pacífico mexicano -Colima-, y la dieta mediática a la que se enfrenta día a día. Se parte de una realidad donde existen 1,750 emisoras (IFT, 2016) y donde tan sólo en la ciudad de México hay 64 emisoras, con personalidades distintas; cada una tiene sus propias esencias y formas de hablar con el auditorio. Específicamente en el estado de Colima existen 21 estaciones de radio, que ofrecen en su mayoría fórmulas 
musicales y filiales de cadenas nacionales. De ellas, tres son de tipo no comercial, con una cobertura limitada. Una pertenece a la Universidad de Colima y es el caso que se aborda a continuación.

\subsection{Los nuevos escenarios de consumo de los jóvenes}

Como lo han venido identificando y anunciando diferentes estudios, en el ámbito mundial, se escucha menos la radio en la audiencia general. A partir de la presencia de Internet se observa que cada vez menos gente consume los medios masivos de manera convencional y ha sido precisamente la radio quien ha tenido una pérdida mayor en este sector, debido al mayor acceso a Internet y la sofisticación de los dispositivos móviles. Los jóvenes prefieren ver televisión e Internet y la radio juega un papel secundario (Reig y Vílchez, 2013). Particularmente en México el tiempo de conexión a Internet al día es superior a las 6 horas, mientras que a la radio por antena de 2.02 horas (IAB México, 2015).

Aún así vemos que crece el consumo de la radio por Internet y los mayores consumidores de radio online - en España- son adolescentes de 14 a 19 años y adultos de 31 a 40 años (López Vidales y GómezRubio, 2015:04). En México hacia el 2014, un 18\% de personas afirmaba que oía más la radio por Internet (IAB México, 2015). Esto nos habla de la relevancia que tiene renovarse y buscar en los espacios donde están las nuevas audiencias.

También implica tomar conciencia de las características de consumo de las generaciones más jóvenes, de quienes se observa que sí escuchan la radio, en dispositivos móviles y fijos, pero por menos tiempo y esta es parte de una forma de vida generacional.

Los jóvenes actuales (...) tienen cierta tendencia a cambiar de actividad a menudo e, incluso, a llevar a cabo varias tareas de forma simultánea. Se podría afirmar que, como colectivo, son multifuncionales y una de las consecuencias de esta característica es la disminución de la atención sobre las tareas que se realizan (Martí, Ribes, Monclús, Gutiérrez y Martínez, 2010:77). 
Las previsiones de cara al futuro en este rubro, no parecen claras en la esfera de los medios no comerciales.

\subsection{Acciones de la radio universitaria en México}

En México, la radio universitaria es un medio no comercial, que emite contenidos sociales, culturales y educativos que buscan contribuir significativamente en el consumo cultural y en la formación de los escuchas. Representa el 4\% de lo que se escucha en antena y la mayoría formaba parte de la red SINPRIES ${ }^{14}$, que después de 22 años de ser coordinada por la ANUIES $^{15}$, desaparece para renovarse y crear la Red de Radios Universitarias de México (RRUM), en plena construcción y reafiliación actualmente.

Si bien la mayoría de las 75 universidades que hacen radio (Vázquez y Chamizo, 2014) han venido haciendo cambios importantes para estar al día en la era digital, no todas tienen un seguimiento puntual del comportamiento de sus radioescuchas, ni de la comunidad para la que se dirigen. Suelen carecer del conocimiento de sus audiencias pues son pocos quienes realizan estudios para la toma de decisiones. Los motivos van desde falta de presupuesto hasta quienes aseguran que no les interesa medir el rating porque su objetivo no es atender públicos masivos, ni se vive de las grandes audiencias. Podríamos decir que es un tema tabú en el sector, cuando actualmente es un punto fundamental para el futuro de todo medio, autogestionado o no porque como lo ha afirmado Beatriz Solís estudiosa de la radio pública "La razón de ser de un medio de comunicación son sus audiencias, sin audiencias un medio de comunicación no comunica" (Gallo, 2014, párr. 31).

\subsection{La radio universitaria y los estudiantes}

De acuerdo a los hallazgos que se han dado a partir de investigaciones específicas sobre la radio escolar (Quintana, 2001; Torregrosa, 2006) y la formación en el medio radiofónico universitario de España y México (Vázquez Guerrero, 2012; 2015), hacer radio permite a un

\footnotetext{
${ }^{14}$ Sistema Nacional de Productoras y Radiodifusoras de las Instituciones de Educación Superior.

${ }^{15}$ Asociación Nacional Universidades e Instituciones de Educación Superior
} 
joven o estudiante grandes posibilidades formativas. No solo les ayuda a expresarse; a realizar actividades de voluntariado a partir de sus conocimientos sino que les permite desarrollar competencias desde las básicas, hasta las relacionadas a su perfil profesional. Por otra parte, al ser radioescucha de este tipo de medios, con objetivos sociales y culturales tienen acceso a temas diferentes a la oferta comercial; un mayor acercamiento a la cultura y la ciencia; logran tener un mayor conocimiento e información sobre la comunidad universitaria y en su conjunto, se aprende, desde la educación informal.

\subsection{Universo 94.9 una radio dinámica y en busca de nuevas audiencias}

Universo 94.9 es una de las radios universitarias que destacan en el panorama mexicano por su dinamismo. Con 3 mil watts de potencia y 13 años al aire, este medio que depende de la coordinación de Comunicación social de la Universidad de Colima cuenta con amplias y modernas instalaciones; 18 empleados y 15 becarios, más la presencia de 200 colaboradores al año. Transmite 24 horas al día y cuenta con señal en streaming, videostreaming y audio a la carta. Interactúa con su audiencia a través de Facebook, Twitter, blog y canal de YouTube.

A diferencia de otras radios, cuenta con áreas como la de Capacitación, donde se ofrecen cursos todo el año. La radio es una productora activa de campañas nacionales y eventos especiales y organiza desde hace varios años el Festival Internacional Colima de Jazz. El World Radio Challenge, realizado en el año 2014, es uno de sus logros más recientes, que tuvo como objetivo que se mantuviera por 70 horas la transmisión continua en la que se podía tratar un tema de libre elección. La radio ganó mayor visibilidad al marcar un nuevo récord por 73 horas de transmisión y lograr activar de manera masiva las redes sociales, con la ayuda de universitarios voluntarios "Una comunidad de 1.235 que se virilizó con un impacto a 19 millones de personas" (Vázquez Guerrero, 2014).

Contrario a los objetivos de otras emisoras de corte cultural o no comercial, esta radio universitaria identifica como su audiencia ideal a 
la comunidad universitaria, ese complejo conglomerado de personas que realizan roles de profesores, trabajadores, estudiantes y funcionarios. Posteriormente buscan impactar en la sociedad colimense y al final en rradioescuchas de otros lugares a través del alcance de Internet. Tienen claro lo que quieren, a dónde van y el esfuerzo es constante por lograrlo. De allí la apertura para hacer este tipo de valoraciones académicas.

\section{Planteamiento del problema}

Si bien la radio universitaria de Colima es una de las más completas en infraestructura, personal y tecnología, persiste el interés por identificar el consumo que se tiene del medio ante la constante percepción de que la radio se escucha poco en general y el impacto en la comunidad es bajo. Los jóvenes hacen radio, hay una alta presencia pero no se refleja en la audiencia estudiantil.

En una encuesta aplicada a 384 personas que viven en los cinco municipios que cubre la radio universitaria, el 18\% de la población manifiesta escuchar Universo 94.9 (Aldape, Ahumada, Araiza, Chávez, Galindo y Palacios 2011 en Acosta et al. 2014). Por otra parte, en 2012 otro estudio (Ceballos, Portillo, y Arellano, 2012) que abordaba el consumo juvenil refiere que es muy bajo el acercamiento que los jóvenes tienen hacia los medios internos de la universidad pues la mayoría de las respuestas fueron "Nunca la escucho" y "no la escucho".

Finalmente en otra encuesta aplicada en 2014 a la comunidad universitaria se obtuvo que el $73 \%$ de los alumnos de nivel superior no escucha Universo, mientras que el 58\% de los trabajadores si la consumen (Acosta, Espinoza y Palacios et al. 2014).

Dado que estos estudios previos habían demostrado que un 18\% del público potencial escucha esta radio; que la mayoría de jóvenes no consume los medios universitarios y que solo $27 \%$ de los estudiantes que cursan una licenciatura sintonizan su emisora, se planteó un estudio específico para los futuros prosumidores de esta radio universitaria que procura la presencia juvenil. 


\section{Metodología}

A través del abordaje de diferentes técnicas aplicadas en su mismo momento se buscó un alcance de tipo descriptivo, identificado por Hernández, Fernández y Baptista (2010) como aquellos que buscan "especificar las propiedades, las características y los perfiles de personas, grupos, comunidades, procesos, objetos o cualquier otro fenómeno que se someta a un análisis"(:80). En este caso, con el propósito de identificar el consumo radiofónico de los estudiantes de nivel medio superior de la Universidad de Colima y conocer de manera específica sus intereses respecto a la radio universitaria, Universo 94.9, así como identificar la manera en que se puede acercar más la radio a ellos.

Las técnicas aplicadas fueron tres: primero una encuesta de opinión a través de un breve cuestionario estructurado que fue autoadministrado en la primera etapa de acercamiento. Posterior a una dinámica grupal donde pudieron conocer las características de la radio universitaria de Colima se aplicó la segunda técnica: la entrevista colectiva que tuvo como base tres diferentes cuestionarios semiestructurados pues se dividió el grupo entre los que no conocían la radio, los que la conocían y a los que les interesaría colaborar en ella. Desde el primer momento de la intervención, la técnica de Observación grupal se puso en marcha identificando actitudes y atención analizadas.

\section{Muestra}

Actualmente en la Universidad de Colima estudian mas de 27 mil jóvenes de los cuales 13,814 pertenecen al nivel medio superior (Universidad de Colima, 2015). Es decir, casi la mitad de la población universitaria cursa este nivel escolar en 34 centros. La determinación espacial de la muestra fue condicionada por la cobertura física que tiene la radio ${ }^{16}$ y el acceso a los bachilleratos, por lo tanto para esta investigación se trabajó en los bachilleratos ubicados en los municipios de Colima y Villa de Álvarez, usando un muestreo por

\footnotetext{
${ }^{16}$ De los 10 municipios del estado, en cinco tiene cobertura la radio: Colima, Villa de Álvarez, Coquimatlán, Cuauhtémoc y Comala.
} 
conglomerados a través del acceso a un salón por plantel como se muestra en la tabla 1.

Tabla 1: Muestreo

\begin{tabular}{|c|c|}
\hline Bachillerato & Ubicación \\
\hline Bachillerato Técnico $N^{\circ} 1$ & Campus Colima. Turno matutino \\
\hline Bachillerato Técnico N 2 & Campus Colima. Turno vespertino \\
\hline Bachillerato Técnico $N^{\circ} 30$ & Colonia La Albarrada. Turno matutino \\
\hline Bachillerato Técnico $N^{\circ} 15$ & Colonia La Albarrada. Turno vespertino \\
\hline $\begin{array}{c}\text { Bachillerato Técnico } \\
\mathbf{N}^{\circ} \mathbf{1 6}\end{array}$ & $\begin{array}{c}\text { Campus Villa de Álvarez. Turno } \\
\text { vespertino }\end{array}$ \\
\hline
\end{tabular}

Fuente: Elaboración propia

Las técnicas fueron aplicadas a la totalidad de 187 estudiantes de cinco bachilleratos universitarios de nivel medio superior, cuyas edades fluctúan entre los 15 y 19 años.

\section{Resultados y análisis}

A través del cuestionario autoadministrado a los sujetos de estudio, sin que se tuviera ninguna información previa del medio estudiado. Se conoció en primer lugar, que la totalidad de los jóvenes consumen más Internet y televisión, sin embargo la radio supera al periódico y a la revista por más del $40 \%$ como se observa en el gráfico 1 . Esto nos muestran un panorama que podría ser reflejo de otros casos en el país: La radio es la tercera opción de consumo.

\section{Gráfico 1}

\section{Consumo de medios por frecuencia}

wayor frecuencia a freccuente uRegular frecuencia a poco frecuente uMinima frecuencia

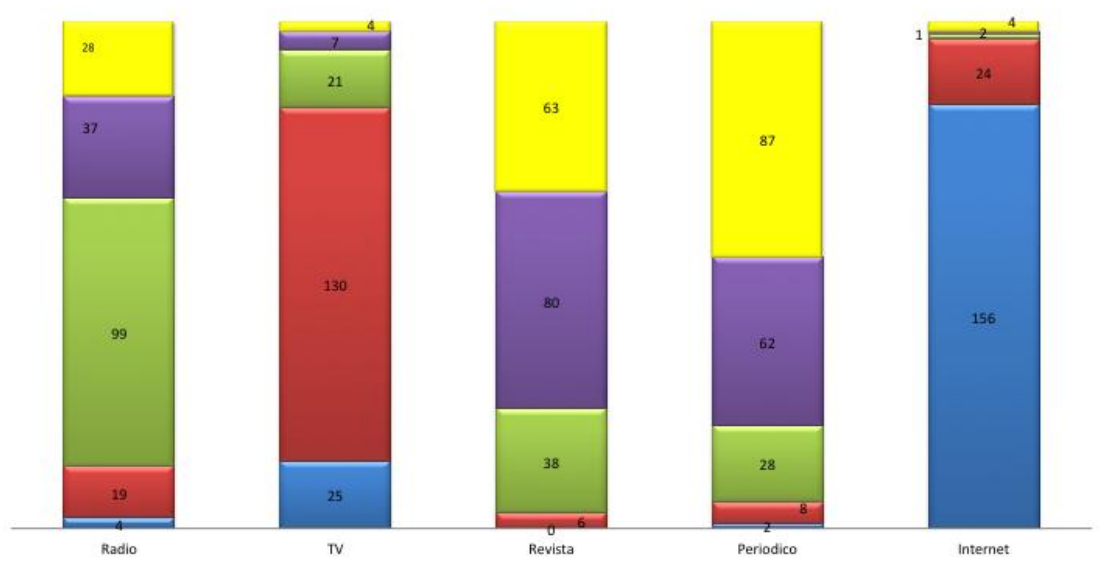

Fuente: Elaboración propia 
Ese tercer lugar en interés por el medio refleja que los jóvenes de 15 a 19 años de edad no tienen el hábito cotidiano por escuchar la radio, dado que un $67 \%$ respondió "de vez en cuando". Gráfico 2

\section{Gráfico 2}

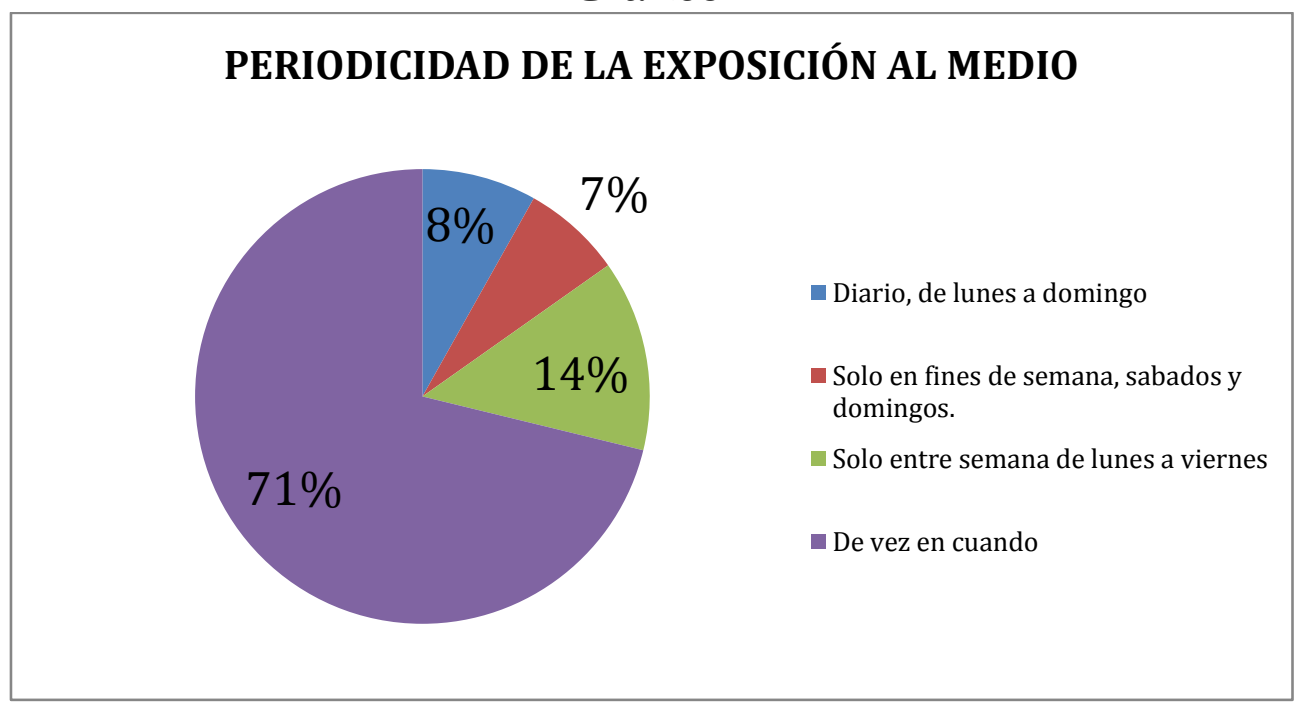

Fuente: Elaboración propia

De un total de nueve emisoras mencionadas en el cuestionario - la oferta radial del momento-, mostrada en el gráfico 3, destaca como la más popular "La mejor", una radio especializada en música grupera, mientras que un 66\% marcó la opción de Universo como una estación que no conocen, a pesar de sus más de 13 años al aire.

\section{Gráfico 3}

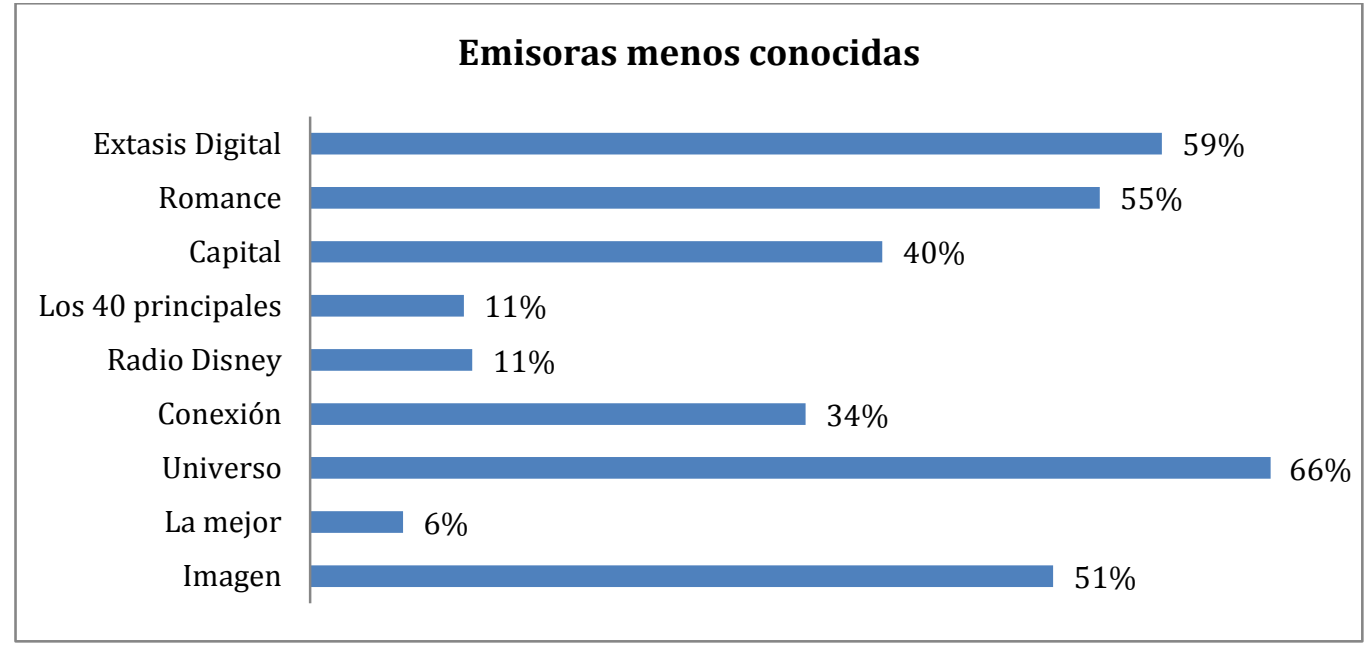

Fuente: Elaboración propia

En cuanto al gusto por el contenido de lo que emiten estas radios, encontramos que la estación "Los 40 principales", que emite música 
pop internacional, es la más gustada en cuanto a programación con 75 respuestas, mientras que solo a 14 de los estudiantes les gusta algo de la programación de Universo. Respecto a la estación favorita de la mayoría, los puntos son para otra emisora de cadena internacional: Radio Disney, que tiene poco tiempo al aire. (Gráfico 4). En este reactivo solo hubo una respuesta positiva para Universo.

\section{Gráfico 4}

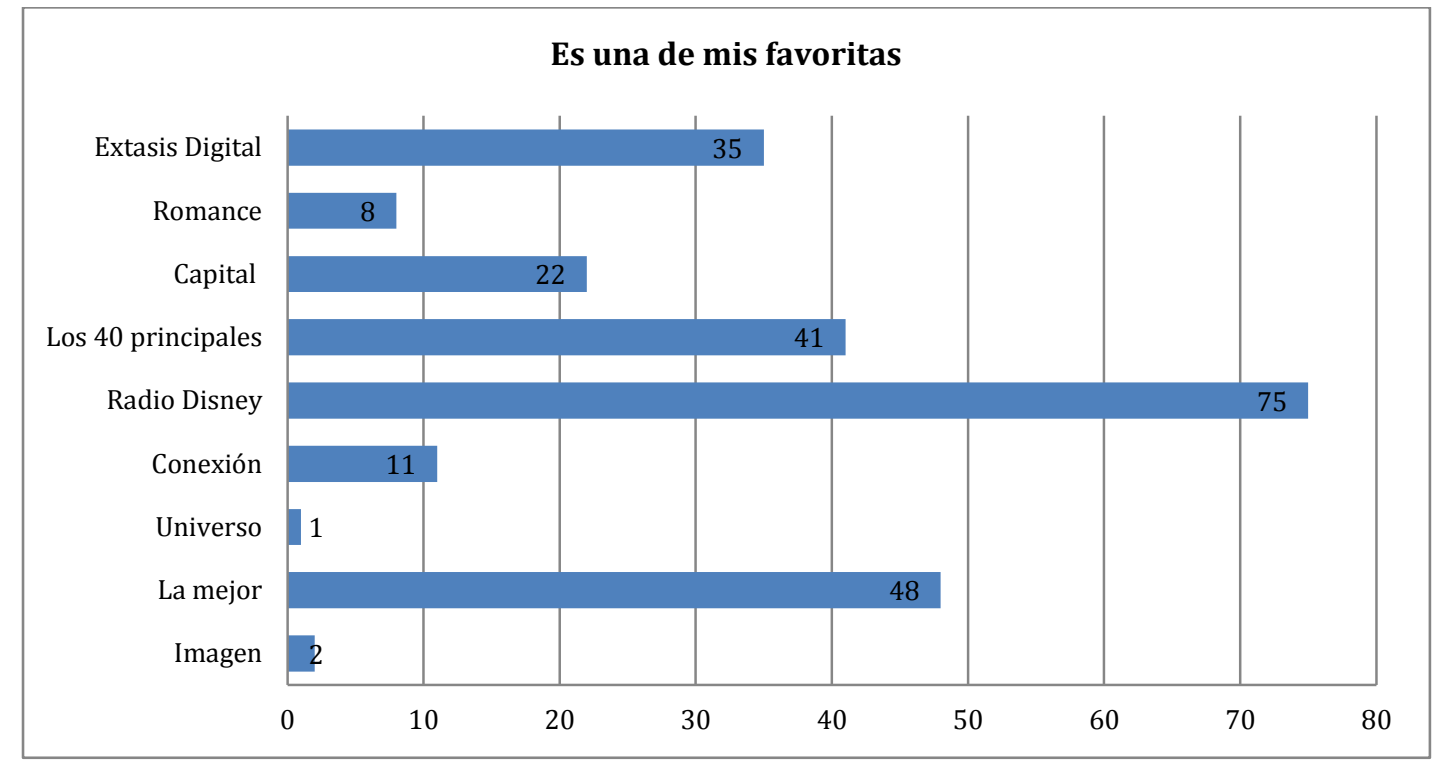

Fuente: Elaboración propia

\subsection{Otros resultados}

Una vez que se dio a conocer un video y audios sobre las características de Universo y su programación, se dividió el grupo entre los estudiantes que sí conocían la radio; los que no la conocían y los que estaban interesados en participar. El grupo más numeroso fue el que no la conocía, sin embargo el grupo de interesados fue superior al que la conocía.

Sobre los resultados de la técnica de entrevista grupal encontramos coincidencias entre los tres grupos: sobre lo que les gustaría escuchar en la radio piden música más movida como la banda; mezcla de géneros o música en celular y de contenido, piden programas de deportes, tecnología, medicina, cultura, chistes y comedia.

Los jóvenes piden mayor interacción con la radio a través de dinámicas o concursos donde "el ganador asista a la estación por el premio" (Grupo 1); o que el medio se haga presente en sus espacios 
escolares como lo afirman los estudiantes del grupo 2 a quienes les gustaría "que fueran a la escuela a transmitir el programa". También aportaron ideas sobre las estrategias que podrían implementarse en la radio para que ellos se interesen en escucharla. Las propuestas van desde recibir publicidad por Internet y las principales redes sociales y aplicaciones gratuitas para teléfono, pues son los sitios donde cotidianamente se informan.

Para los que sí conocían Universo, una radio ideal es aquella que no es aburrida; que emita programas acordes a su edad; música más alternativa, que fomente los talentos escolares y hable de eventos y cultura; para los que no la conocían afirman que una radio sin comerciales es la ideal; que hable de deportes y ponga música pop y electrónica -en Colima, la segunda opción prácticamente no existe- y que se regale algo. $\mathrm{Y}$ para los futuros colaboradores piensan en una radio ideal como aquella donde se informe de la actualidad de su entorno escolar; "que sea realista y divertida" (Grupo 3).

\section{Discusión y recomendaciones}

De acuerdo a los resultados del estudio podemos identificar que hay características generacionales en los estudiantes de la Universidad de Colima, en el sentido de que tienen una dieta variada en el consumo de medios, pero no les dedican demasiado tiempo y eso se debe tomar en cuenta para el tipo de programas y formatos que emite una radio. Los jóvenes viven cercanos a los teléfonos inteligentes y la Internet y allí es donde quieren ser encontrados, aun por medios minoritarios como los universitarios, haciendo uso además, de recursos publicitarios. Se evidencia un desconocimiento general de la tipología de radios existentes, para ellos es una oferta más en el dial, no una medio social, cultural o de entretenimiento. Las fronteras no se consideran en lo general. A pesar de que el panorama no es sencillo para la radio universitaria en el estudio se observa un interés por conocerla y eso ya es una esperanza. Es posible mejorar los porcentajes de audiencia estudiantil si la radio busca estrategias de acercamiento físico y les da opciones en la web 2.0, pues después de la dinámica de información sobre las características del medio, hubo un interés importante por conocerla. Si bien Universo ha ido aumentando su audiencia poco a poco, precisamente a través de 
estudios específicos sobre sus audiencias, sin embargo requiere de acciones segmentadas para contribuir a que sea mayor el número de escuchas de su propia comunidad. Se tiene entonces un área de oportunidad de donde puede obtener muchos resultados satisfactorios. Las redes sociales y los jóvenes están muy unidos, los jóvenes no tienen necesariamente que prender la radio para convertirse en radioescuchas de Universo, pueden lograrlo siendo usuarios de los soportes digitales con los que la estación cuenta y poder estar más conectados con éste exigente sector de la sociedad. La experiencia y práctica puede ser replicable en otras radios universitarias con el mismo interés de tener mayores audiencias y cumplir con su función social de mejor manera. 


\title{
La radio universitaria en Andalucía: experiencias y nuevos retos
}

\author{
Regina Pinto-Zúñiga (Universidad de Málaga) \\ Ohttp://orcid.org/0000-0001-6487-6616 \\ Ghttp://scholar.google.es/citations?user=b3Dm8h8AAAAJ\&hl=es
}

Resumen: La radio universitaria andaluza surge tras movimientos que datan de finales de los noventa. Ha tenido mucha importancia para la creación de este tipo de estaciones la legislación autónoma vigente en la que estas emisoras apoyan su existencia, contemplándose como radios culturales sin ánimo de lucro. Nuestro objeto de estudio está formado por las tres emisoras universitarias que coexisten en Andalucía en el 2016, sosteniendo cada una un modelo funcional diferente. Ante la inminente entrada en vigor de la Ley Audiovisual de Andalucía, que ya en su anteproyecto contempla la prestación de servicio público por parte de las universidades, en esta investigación, también realizaremos un esbozo de las experiencias de radio que coexisten actualmente en la comunidad autónoma, que podrían constituir el punto de partida de futuras radios universitarias.

Palabras clave: Andalucía; ley audiovisual; radio; universidad.

\section{Introducción}

EGÚN la Junta de Andalucía existen once universidades públicas

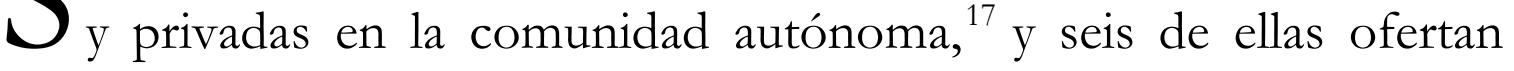

${ }^{17}$ Universidades Andaluzas. (s.f.). Recuperado el 1 de febrero de 2016, de http://www.juntadeandalucia.es/economiainnovacionyciencia/sguit/ 
títulos de Ciencias de la Comunicación. ${ }^{18}$ Se trata de un dato llamativo, ya que, ninguna de las tres emisoras de radio universitarias que funcionan en Andalucía se ubica en una universidad que oferte dichos estudios. De esta forma, UniRadio Huelva pertenece a la Universidad de Huelva, UniRadio Jaén a la Universidad de Jaén y Radiouniversidad.es o UAL Radio a la Universidad de Almería, encontrándonos ante la paradoja de que un medio de una complejidad técnica relativamente sencilla como es la radio, no esté presente en universidades que cada año envían al mercado laboral un número ingente de Graduados en carreras de Ciencias de la Comunicación. Como apunta Rincón (1997), una radio universitaria puede aprovechar su potencial comunicativo en tres dimensiones: una, para formar al personal de la emisora con el objetivo de que programe con sentido, respeto por el oyente y que construya una identidad para la misma; para ser un taller de experimentación y formación de estudiantes de titulaciones de comunicación; y por último como medio de comunicación formador que satisfaga a su audiencia. Por todo ello es significativo hacer hincapié en la importancia de que una universidad ofrezca la posibilidad a sus estudiantes de formar parte de un medio de comunicación, un lugar en el que los alumnos de titulaciones afines al mismo puedan encontrar un lugar en el que empezar y en el que se desarrolle, como apuntan Aguaded y Contreras (2011: 7), la función de servicio público que se le atribuye a los medios universitarios.

Por otra parte, la situación de crisis que atraviesa España no supone un horizonte adecuado para la creación de nuevas emisoras de radio universitaria. En la actualidad existen estaciones de radio que se encuentran en una auténtica situación de supervivencia, pero también se puede comprobar cómo emergen y permanecen activos proyectos que podrían constituirse como los albores de futuras radios universitarias.

El trabajo que aquí se expone surge de una de las líneas de investigación desarrolladas en la tesis doctoral titulada "La radio

\footnotetext{
${ }^{18}$ Universidad.es. (s.f.). Recuperado el 1 de febrero de 2016, de http:// universidad.es/titulaciones?q=comunicación\&level=grad\&branch=\&ite $\mathrm{ms}=10 \&$ page $=1$
} 
universitaria como medio de formación de futuros profesionales en España. Fundamentos para la creación de un modelo formativo integral" defendida en la Universidad de Málaga.

\section{Los albores de las futuras emisoras universitarias andaluzas}

Antes de abordar el análisis de las estaciones de radio existentes en Andalucía, esbozaremos el presente de las experiencias radiofónicas que se están llevando a cabo en la comunidad autónoma. Cada provincia andaluza posee al menos una universidad. En este sentido, sería lógico pensar que las radios universitarias andaluzas deberían ubicarse en universidades que ofertaran titulaciones de Ciencias de la Comunicación, pero como hemos señalado anteriormente, la realidad es bien distinta. Lo que podemos constatar es que, aunque no están constituidas como emisoras de radio, sí que existen experiencias radiofónicas así como talleres de radio que funcionan con continuidad, que perfectamente podrían erigirse como punto de partida para la creación de una emisora universitaria al uso, tal y como funcionan las veinticuatro estaciones de radio universitarias que emiten regularmente en España en el año 2016, registradas en la Asociación de Radios Universitarias de España. ${ }^{19}$

Por orden de antigüedad, señalamos la existencia del programa Aula Abierta, un magazine radiofónico realizado por estudiantes de la Facultad de Comunicación de Sevilla, bajo la supervisión del director docente Fernando Segundo. Según se describe en su web, ${ }^{20}$ se trata de un espacio dinámico dedicado a la actualidad universitaria que cumple en la temporada 2015/2016 su decimocuarto año de emisión, quinto en Radio Andalucía Información (RAI). Este espacio se emite dos veces en semana, una de ellas en redifusión, y cuenta con la colaboración de alumnos de nueve universidades andaluzas.

Sin duda, otra iniciativa destacable en el contexto sevillano surge durante el curso 2012/2013 con la puesta en marcha de la Compañía Radioteatro de la Facultad de Comunicación, dirigida por la profesora

\footnotetext{
${ }^{19}$ Asociación de Radios Universitarias de España. (s.f.). Recuperado el 20 de enero de 2016, de http:/ / www.asociacionderadiosuniversitarias.es /

${ }^{20}$ Aula Abierta. (s.f.). Recuperado el 20 de enero de 2016, de https://aulaabiertaus.wordpress.com/
} 
Virginia Guarinos. En este caso se trata de una actividad en la que se implica fundamentalmente al profesorado pero cuyo alcance trasciende a toda la comunidad universitaria, que por su singularidad desde el punto de vista creativo, resulta de gran interés. La Universidad de Sevilla alberga los títulos de Grado en Comunicación Audiovisual, Periodismo y Publicidad y Relaciones Públicas.

En la Universidad de Málaga, desde el año 2013 se lleva a cabo Escuela de Radio Campus UMA de la mano del profesor Juan Tomás Luengo, adscrito al Departamento de Periodismo de la Facultad de Ciencias de la Comunicación. Colaboran en su mayoría alumnos de Periodismo, aunque también pueden hacerlo estudiantes de Comunicación Audiovisual y Publicidad y Relaciones Públicas, encontrando en este taller una plataforma práctica en la que aplicar los conocimientos de radio aprendidos en las aulas. En este caso, se trata de en un programa de cincuenta minutos de duración que se emite con periodicidad semanal en la segunda cadena de COPE Málaga, en el dial 105.5 de FM. Cada miércoles, los alumnos ocupan un espacio comprendido entre las 13:30 y las 14:30h., en el que realizan un programa de contenido universitario con diferentes secciones. La duración de esta actividad está comprendida entre los meses de noviembre a julio y cuenta con el respaldo de la Universidad de Málaga, que cede un seminario en sus instalaciones para las reuniones semanales destinadas a la preparación del espacio radiofónico. Esta universidad incluye entre su oferta de estudios los Grados en Comunicación Audiovisual, Periodismo y Publicidad y Relaciones Públicas.

La Universidad de Córdoba, según Martín-Pena (2013:138), tiene muy avanzado su proyecto de radio gracias al asesoramiento de otras emisoras universitarias, aunque apunta que por cambios en los equipos universitarios parece estar estancado. Es de especial interés para esta investigación el hecho de que la Universidad de Córdoba no oferte grados relacionados con la rama de Ciencias de la Comunicación, como son Comunicación Audiovisual ${ }^{21}$ o Periodismo ${ }^{22}$ teniendo sin embargo muy desarrollado su proyecto de emisora de radio.

${ }^{21}$ Universidad.es. (s.f.). Recuperado el 20 de enero de 2016, de Servicio Español para la Internacionalización de la Educación (SEPIE): 
Por otra parte, la Universidad de Granada (UGR), que oferta entre sus estudios el Grado en Comunicación Audiovisual, en el año académico 2013/2014 planteaba en tercer curso un taller de radio enfocado como una asignatura de carácter optativo, ${ }^{23}$ mas no tenemos constancia de que los productos radiofónicos elaborados en dicha actividad se llegaran a poner a disposición de los internautas en la red de manera sistemática. La UGR oferta el Grado en Comunicación Audiovisual pero no oferta el Grado en Periodismo ni en Publicidad y Relaciones Públicas.

En cuanto a la Universidad de Cádiz, ésta no ofrece estudios de Grado en Comunicación Audiovisual ni en Periodismo, aunque sí en Publicidad y Relaciones Públicas, pero no hay constancia de ninguna actividad docente relacionada con la radio universitaria o taller de esta naturaleza.

Las restantes universidades andaluzas ofertan el título de Grado en Comunicación con menciones en Comunicación Audiovisual, Periodismo, y Publicidad y Relaciones Públicas, observándose en la Universidad Pablo de Olavide un taller de iniciación a la radio de 14 horas de duración que se produjo en el mes de diciembre de 2015 . $^{24}$ Como en el caso de la Universidad de Granada, tampoco hay constancia de que los productos radiofónicos elaborados en el mismo llegaran a estar disponibles en la red.

http://www.universidad.es/titulaciones?q=Comunicación +Audiovisual\&level $=$ grad\&branch $=$ Ciencias + Sociales $+\mathrm{y}+$ Jurídicas\&items $=10 \&$ page $=1$

${ }^{22}$ Universidad.es. (s.f.). Recuperado el 20 de enero de 2016, de Servicio Español para la Internacionalización de la Educación (SEPIE):

http:/ / www.universidad.es/titulaciones?q=periodismo\&level=grad\&branch $=\mathrm{C}$ iencias + Sociales $+y+$ Jurídicas\&items $=10 \&$ page $=1$

${ }^{23}$ Facultad de Comunicación y Documentación de la Universidad de Granada. (s.f.). Recuperado el 19 de noviembre de 2015,de http://fcd.ugr.es/static/GestorDocencia/*/GCA/3/D2

${ }^{24}$ Taller radio UPO. (s.f.). Recuperado el 1 de febrero de 2016, de https://www.upo.es/portal/impe/web/contenido/dd8a5c77-935a-11e5-8e1f3fe $5 \mathrm{a} 96 \mathrm{f} 4 \mathrm{a} 88$ 


\section{Emisoras de radio universitaria de Andalucía}

En general, para hablar de las emisoras universitarias en la comunidad autónoma andaluza, debemos indicar que existe una normativa que permite la emisión a través de la FM de forma legal mediante el Decreto 174/2002, de 11 de junio, por el que se regula el régimen de concesión por la Comunidad Autónoma de Andalucía de Emisoras de Radiodifusión Sonora en ondas métricas con modulación de frecuencia y la prestación del servicio por parte de los concesionarios. Es por este motivo por el que las estaciones universitarias pueden tener un dial asignado por el que emitir legalmente, siempre que sean radios culturales o sin ánimo de lucro. Aún se está gestando la Ley Audiovisual de Andalucía, de la que ya existe un anteproyecto ${ }^{25}$ que explica que:

"el servicio público de comunicación audiovisual en Andalucía es un servicio esencial de interés económico general que consiste en la prestación de servicios de comunicación audiovisual de ámbito autonómico bajo el régimen de gestión directa por parte de la Administración de la Junta de Andalucía y de ámbito local por parte de los Entes Locales de Andalucía, Universidades Públicas andaluzas y Centros docentes públicos no universitarios."

Por lo que ya se contemplan expresamente en esta ley los medios audiovisuales universitarios, algo que no se observa en la actual Ley 7/2010 de 31 de marzo, General de la Comunicación Audiovisual. Ya en el anteproyecto de la Ley Audiovisual Andaluza se vislumbra en el artículo 59 que mediante la solicitud del Órgano de Gobierno de la universidad que lo requiera, se puede solicitar la prestación del servicio público de comunicación audiovisual para la emisión en abierto de canales temáticos educativos y de divulgación cultural, siendo el mismo trámite para los centros docentes públicos no universitarios. Queda ya prevista en este artículo también la prestación de servicio público radiofónico, y como uno de los puntos principales del mismo, la

\footnotetext{
${ }^{25}$ Anteproyecto de Ley Audiovisual de Andalucía. (s.f.). Recuperado el 2016 de enero de 20, de http://www.juntadeandalucia.es/expycampus tvort/drupaljda/2.\%2020150922_ANTEPROYECTO\%20DE\%20LEY\%20A UDIOVISUAL\%20DE\%20ANDALUC\%C3\%8DA_1erB_V5.pdf
} 
prohibición de emitir mensajes publicitarios a través de dichos medios audiovisuales.

Una vez esbozado el panorama legislativo concerniente a las estaciones de radio universitaria en la comunidad autónoma, realizamos un análisis del modelo funcional de cada una de las tres estaciones universitarias andaluzas.

\subsection{UniRadio Huelva}

UniRadio Huelva fue creada en el año 2007, y además de ser la pionera en Andalucía, supone la emisora de referencia en este ámbito puesto que las otras dos radios universitarias andaluzas que coexisten con ella, han bebido de sus estatutos así como de su constitución durante su periodo de gestación. Martín-Pena (2013: 382-383) apunta que fue a finales de los años noventa cuando empiezan los primeros movimientos en la Facultad de Ciencias de la Educación de la Universidad de Huelva para poner en marcha un laboratorio de medios y una emisora experimental. Sin embargo, no fue hasta la aprobación del mencionado Decreto 174/2002, de 11 de junio, cuando se produjo el impulso necesario para la construcción y puesta en marcha definitiva de UniRadio Huelva.

UniRadio Huelva ha recibido y continúa recibiendo numerosos premios y reconocimientos a nivel europeo y español tanto por su labor como medio de comunicación social como por su compromiso con la educación y los valores democráticos, siendo uno de los programas más populares de la estación El zapato roto realizado por internos y educadores de la prisión de Huelva (Contreras, 2012: 159).

La gestión de la emisora se realiza a través de la Asociación Cultural Radio Universitaria de Huelva, amparada por el Decreto 174/2002 de 11 de junio, como apuntábamos anteriormente, por el cual es legal que una emisora universitaria en Andalucía tenga su propio dial de FM si se trata de una emisora cultural sin ánimo de lucro.

En enero de 2014 la situación de UniRadio Huelva cambió con respecto a años anteriores. Se ha produjo un cambio en el Equipo de Gobierno en la Universidad de Huelva (UHU) que se ha tradujo una reestructuración del personal propio de la universidad, por el que no se 
ha produjo la renovación de numerosos contratos dependientes de la misma, incluidos el de la directora de UniRadio Huelva, así como el del director de programación. ${ }^{26}$ Este cambio en la plantilla de la estación ha sido motivado por la fuerte crisis económica. Contreras es quien ahora asume las labores de dirección de la emisora además de tener el cargo de Presidenta de la Asociación, gestionándola desde el año 2010. Apunta que desde la creación de la estación, se concibió como parte de la universidad y como medio independiente, motivo por el cual se le da forma de asociación sin ánimo de lucro, precisamente, para en caso de que hubiera un cambio de gobierno y de política en la universidad, la radio pudiera seguir funcionando como proyecto educativo, cultural y social. La Universidad de Huelva a comienzos del 2015 ya no aportaba recursos para la manutención de la emisora, pero tiene a bien mantener una radio universitaria mientras que no le suponga un coste económico. Para el sustento de la misma se intentan conseguir subvenciones y convenios tanto con la universidad, como con otras entidades autonómicas y provinciales. ${ }^{27}$

\subsection{UniRadio Jaén}

Por orden de constitución, UniRadio Jaén fue la segunda emisora de radio universitaria que se puso en marcha en Andalucía. En el año 2009 nace esta estación también de marcada orientación cultural, que se autodenomina como emisora de "carácter apolítico, sin consignas ideológicas tendenciosas y, en puridad, altruista" ${ }^{28}$ que plantea una programación alternativa, en busca de la innovación en formatos y contenidos. Otra de las características principales de esta estación es la defensa de los derechos de las personas y de los animales. En palabras de su director: "somos una emisora que defiende a capa y espada el tema de los derechos humanos y de los animales, por ello la tauromaquia es una de las cuestiones que tratamos de evitar". ${ }^{29}$

${ }^{26}$ Contreras, P. (14 de Enero de 2015). Entrevista Directora de UniRadio Huelva. (R. Pinto, Entrevistadora)

${ }^{27}$ Ídem.

${ }^{28}$ UniRadio Jaén. (s.f.). Recuperado el 24 de Abril de 2015, de http://uniradio.ujaen.es/conocenos/uniradio-jaen

${ }^{29}$ Olivares, J. Á. (20 de Febrero de 2015). Entrevista Director UniRadio Jaén.

(R. Pinto, Entrevistadora) 
También se encuentra bajo el paraguas legal que le brinda la Asociación Cultural Radio Universitaria de Jaén.

UniRadio Jaén comienza su andadura en abril de 2010, en un principio, solo mediante emisión on line, y fue en octubre del mismo año cuando se une al carro de las ondas hertzianas mediante el dial 95.6 de la FM. Apunta Martín-Pena (2013: 145), que esta emisora surge de una iniciativa en la cual estudiantes, docentes y equipo de gobierno de la universidad participan y colaboran en la puesta en marcha, así como en la realización de todos los programas, siendo el alumnado el sector más participativo.

UniRadio Jaén, al igual que su antecesora de Huelva, ha recibido diversos premios y reconocimientos procedentes del Instituto de la Juventud, de la Junta de Andalucía y del Ayuntamiento de Jaén, entre otros.

Un elemento destacable de esta emisora resulta su página web, que permite incluso ver el estudio a través de la web cam mientras se está emitiendo en directo, además de una completa fonoteca. En la dirección de la emisora se encuentra Julio Ángel Olivares, Profesor Titular del Departamento de Filología Inglesa de la Universidad de Jaén. Otro aspecto destacable es que la emisora tiene a dos personas contratadas por la asociación que trabajan para la radio, ocupando las figuras de subdirector o coordinador, y de técnico.

Para su director, Julio Ángel Olivares, las redes sociales son uno de los puntos fuertes de la emisora universitaria, formando parte UniRadio Jaén y sus colaboradores de los agentes más influyentes de la provincia de Jaén en el entorno digital. ${ }^{30}$

\subsection{Radiouniversidad.es o UAL Radio}

Es la tercera emisora de radio universitaria que ha visto la luz en Andalucía y hasta el momento la última. Comienza su funcionamiento en el año 2010, bajo una encomienda de gestión a la Fundación Mediterránea Universidad Empresa, que a su vez tiene una oficina de comunicación, que es la que se encarga de gestionar la radio

${ }^{30}$ Ídem. 
universitaria, por lo que, orgánicamente, pertenece al Gabinete de Comunicación adscrito al Rectorado de la Universidad de Almería, que es la propietaria de las instalaciones de la emisora.

Para Martín-Pena (2013: 436), esta estación surge para posibilitar que los participantes sean a su vez emisores y receptores, permitiendo de forma más eficaz la interacción social dentro de la comunidad universitaria, apostando desde su nacimiento por los podcast, el uso de blogs y las redes sociales.

La emisión por ondas hertzianas en UAL Radio es un fenómeno reciente, puesto que se puede sintonizar en el 98.4 de FM desde mayo de 2014. Radiouniversidad.es se describe en su web ${ }^{31}$ como un canal de comunicación abierto y flexible, entre y para el alumnado y el profesorado, y en el que también participa el PAS, a través de las tecnologías de la información y la comunicación. Entre sus objetivos se contempla la utilización del podcast para dar respuesta a las necesidades de información de los estudiantes sobre aspectos básicos de sus titulaciones, actividades universitarias, oferta académica y otros servicios de su interés y para posibilitar la participación activa del alumnado en este medio como una forma de mejorar sus competencias comunicativas, ofreciendo un servicio más dentro de la universidad.

En la actualidad muchos de esos podcast han tomado forma de programas, conservando la riqueza temática de los mismos como: ciencia, igualdad de género, orientación, toros, deportes y noticias, entre otros. Radiouniversidad.es se articula alrededor de la vida de la universitaria almeriense, cuya parrilla intercala música y mezcla distintos géneros, ofreciendo información y entretenimiento.

La responsabilidad de la emisora recae sobre Esther Benavides, que a su vez trabaja para la Fundación Mediterránea Universidad Empresa, encargándose de la comunicación de la universidad junto con otro compañero. Entre sus tareas se encuentran la gestión y producción de

${ }^{31}$ UAL Radio. (s.f.). Recuperado el 24 de Abril de 2015, de http://www2.ual.es/radioual/bienvenido-a-radio-universidad-ual/ 
la emisora, la redacción de diversos espacios y la labor de instruir a los estudiantes que se incorporan. ${ }^{32}$

Radiouniversidad.es fue la primera emisora de radio universitaria en ofrecer sus contenidos a través de una app (Benavides, 2012: 250), aunque en la actualidad ya no cuenta con dicha herramienta de comunicación, debido al coste económico que suponía su mantenimiento y actualización.

\section{Análisis de las radios universitarias andaluzas}

Para esta investigación realizamos un análisis comparativo del sistema de gestión y funcionamiento de las radios universitarias que se ha completado con las entrevistas realizadas a los responsables de cada una de las tres estaciones de radio mencionadas. En todos los casos se trata de emisoras que pertenecen a universidades de titularidad pública, constituyéndose consecutivamente por este orden en primer lugar, UniRadio Huelva en 2007, Uniradio Jaén en 2009 y Radiouniversidad.es también conocida como UAL Radio en 2010.

En cuanto a la dependencia o gestión, las dos primeras pertenecen a una asociación cultural cuyo nombre contiene el que bautiza a la emisora en cada caso, algo que no ocurre en la radio de la Universidad de Almería, puesto que se trata de una encomienda de gestión a la Fundación Mediterránea Universidad-Empresa. Las instalaciones de las tres estaciones se encuentran en el seno de la universidad que les da nombre, por lo que cuentan con el apoyo de la institución superior para funcionar, aunque las dos estaciones pioneras en Andalucía estén constituidas bajo asociaciones independientes. En cuanto a la financiación, en el caso de Huelva, la subsistencia se obtiene mediante proyectos, convenios y subvenciones que les brindan diferentes entidades, siendo la propia universidad que las alberga la responsable de su financiación en los casos de Jaén y Almería.

Entre los compromisos primordiales de las estaciones analizadas en Andalucía se encuentra especialmente la responsabilidad social, siendo UniRadio Huelva un ejemplo paradigmático en este sentido, seguido

\footnotetext{
${ }^{32}$ Benavides, E. (23 de Enero de 2015). Entrevista Responsable Radiouniversidad.es. (R. Pinto, Entrevistadora)
} 
por las otras dos estaciones. Hemos comprobado que la función predominante en la radio universitaria en los casos de Huelva y Jaén coincide, se trata de la función social, mientras que en el caso de Radiouniversidad.es la función principal es la informativa.

El organigrama de las radios universitarias andaluzas también varía en función de la ubicación geográfica en la que nos encontremos. En UniRadio Huelva, aunque se encuentran en un periodo de transición, la intención es continuar manteniendo el formato estructural anterior consistente en los siguientes puestos: un director, un responsable de programación y un técnico con una persona de apoyo. En UniRadio Jaén el organigrama está formado por un director, un subdirector que también es técnico y un técnico, contratados los dos últimos por la asociación cultural. En el caso de Radiouniversidad.es, la estación forma parte del Gabinete de Comunicación de la Universidad de Almería, y su núcleo está formado por su responsable, quien realiza tareas de dirección, producción y redacción, con la ayuda de voluntarios.

Entre las personas que trabajan en la emisora y reciben remuneración por ello, en la radio onubense, cuando la universidad puede hacerse cargo de las nóminas, son el director, el responsable de programación y el técnico. En Jaén, como ya hemos comentado anteriormente, están contratados por la asociación el subdirector y el técnico, ya que el director forma parte del Personal Docente Investigador de la universidad. En Almería la única persona que recibe remuneración por su trabajo es la responsable de la estación, de cuya nómina se responsabiliza la Fundación Mediterránea Universidad-Empresa.

En cuanto a los voluntarios, contabilizados como personas que colaboran en la estación sin recibir remuneración por ello, encontramos que pertenecen a diferentes colectivos: Personal Docente e Investigador (PDI) de la universidad en los casos de Huelva y Jaén; Personal de Administración y Servicios (PAS) en las tres estaciones analizadas; alumnos de diferentes titulaciones en muchos casos realizando el practicum o prácticas curriculares; y en todos los casos, colaboradores externos, es decir, personas que no tienen relación con la universidad pero acuden con asiduidad a la emisora. En cuanto al número de colaboradores en la estación, podríamos situar a UniRadio 
Jaén en primer lugar, UniRadio Huelva en segundo lugar y Radiouniversidad.es en tercer lugar.

Relativo al ámbito de la enseñanza, en todos los casos los responsables de las emisoras manifiestan que los alumnos que participan en la radio universitaria obtienen una formación más completa, mediante el trabajo de competencias transversales que les ayudan a desenvolverse en la vida real. El seguimiento de los mismos se realiza a través de la tutorización individualizada, en la medida de lo posible, por los responsables de la radio universitaria. No alcanzamos resultados sobre estudiantes de Ciencias de la Comunicación, puesto que, como hemos comentado anteriormente, en estas universidades no se ofertan estudios de esta rama. Aun así, obtenemos que en UniRadio Huelva se ofrecen cada año cursos básicos de radio, y también existen asignaturas relacionadas con medios de comunicación que vinculan algunas de sus prácticas a la estación universitaria. En Jaén, coincidiendo con la semana de celebración del aniversario de la emisora, se realizan distintas formaciones relacionadas con la materia radiofónica. En Almería el Trabajo Fin de Grado en algunas titulaciones se enlaza con la radio, de manera que debe ser presentado en formato radiofónico. En esta estación, es la propia responsable la que se encarga de realizar una formación intensiva a los alumnos que colaboran, de manera que están preparados para trabajar en dos semanas.

Desde el punto de vista técnico-estructural, las tres estaciones andaluzas analizadas emiten a través de su propio dial de FM, y en los casos de Huelva y Jaén también se hace uso del streaming o difusión mediante una plataforma web, en este caso, la página web de cada emisora. El podcast es utilizado en las tres estaciones, siendo iVoox la plataforma elegida para la difusión de estos contenidos por UniRadio Huelva y Radiouniversidad.es, mientras que la radio de la Universidad de Jaén utiliza su propia página web para ello. Sin embargo, no hay que olvidar, tal y como recogen Martín-Pena y Aguaded (2016: 248), que existe una tendencia a que emisoras que transmitían en FM dejen de hacerlo, debido a problemas con la administración regional en lo concerniente a frecuencias, o a la alegalidad en la que quedan estas emisoras ante la actual Ley 7/2010 de la Comunicación Audiovisual, destacando que las radios universitarias andaluzas, pese a que aún no se ha publicado la nueva Ley Audiovisual de Andalucía, carecen de 
este problema. La única de las tres emisoras que posee aplicación para la escucha de la radio universitaria mediante dispositivos móviles es UniRadio Huelva, aunque la estación pionera en España en poseer una app fue Radiouniversidad.es, que tuvo que renunciar a ella por problemas de mantenimiento.

El número de estudios disponibles en una emisora es también un elemento importante a la hora de plantear una parrilla de programación. En este sentido, Huelva y Jaén cuentan con dos estudios propios de sendas radios universitarias, utilizados habitualmente, uno para directo y otro para grabaciones, teniendo la posibilidad de realizar autocontrol en los dos estudios mencionados en el primer caso, y solo en uno de los estudios, en el caso de Jaén. En Radiouniversidad.es existe un solo estudio desde el que se realizan todas las tareas necesarias. El software utilizado en las estaciones para gestionar la continuidad es el mismo en Huelva y Jaén, Jazler RadioStar, con licencia, y utilizándose además en el caso jienense Virtual Dj Free. En Almería hacen uso de ZaraRadio. Para realizar labores de grabación y edición encontramos preferencias distintas: en Huelva el programa elegido para estas tareas es Sound Forge, en Jaen Adobe Audition y en Almería Audacity, software libre.

En cuanto a la programación que se emite en las estaciones, UniRadio Huelva hace uso de un modelo generalista en el que cabe todo tipo de contenidos con un marcado carácter social. En el caso de Jaén, debido a los ámbitos con los que se relacionan sus temáticas, de perfil académico y social, se consideran una emisora de radio especializada. Para Radiouniversidad.es el modelo utilizado es mixto, debido a que solo se tratan temas universitarios en algunos programas de la parrilla y no en todos. Todas realizan una disposición de sus programas en mosaico, de manera que se emiten diferentes programas uno tras otro. La divulgación científica es un aspecto que se contempla en las tres estaciones analizadas, a través de diferentes espacios. Se trata de un aspecto muy importante que debe contemplarse en las estaciones, ya que, como apuntan Contreras y Parejo (2013: 36), con la alfabetización científica de la universidad se consigue una población más sensible, formada, y por ende se da cumplimiento a la responsabilidad social corporativa. En nuestro análisis también hemos observado el número de programas que se llevan a cabo en cada estación siendo UniRadio 
Jaén la que más ofrece, en torno a 40, UniRadio Huelva en segundo lugar, y en tercer lugar Radiouniversidad.es. Por todo ello, podríamos decir que el número de programas que contiene la parrilla está directamente relacionado con el número de colaboradores de cada emisora.

Es inevitable pensar en quién escucha la emisora, cuál es el público al que se dirigen los mensajes. La audiencia es un concepto relativo según la estación universitaria en la que nos encontremos. Martín-Pena (2013: 270) deja constancia en su investigación de lo difícil que resulta obtener una medición real de la audiencia en las emisoras universitarias, de forma que existen instrumentos como Google Analytics, iVoox o las redes sociales que pueden ayudar a calcular el impacto de la estación en el público, mas no todas disponen de estas herramientas, por lo que se hace complicada la tarea de obtener una medición de audiencias homogénea con un criterio aplicable a todas las radios universitarias. En su tesis doctoral, Casajús (2014: 149-151) indica que en una primera aproximación, la audiencia de la radio universitaria está conformada por sectores de la universidad y de la sociedad en general, en la que los estudiantes constituyen una gran parte de la misma. En relación con su tema de estudio, indica que las redes sociales también aportan interesantes herramientas para acercarnos más específicamente a conocer las características de la audiencia de la radio universitaria y su comportamiento.

Por todo ello, basándonos en la repercusión en las redes sociales de las emisoras de radio universitarias andaluzas, según los datos obtenidos en enero de 2016, UniRadio Huelva se sitúa como la estación más seguida en Facebook y Twitter con 5.488 "me gusta" y 1.983 seguidores. UniRadio Jaén se sitúa en segundo lugar con 4.046 "me gusta" y 921 seguidores. Y en tercer lugar, la menos longeva, Radiouniversidad.es contado con 389 "me gusta” y 182 seguidores.

Concluiremos este análisis pormenorizado de las estaciones de radio andaluzas abordando cuestiones relacionadas con el código deontológico y el libro de estilo que utilizan. En UniRadio Huelva existe un reglamento o normativa aprobada por el Consejo de Gobierno de la Universidad de Huelva en 2012 así como un decálogo de buenas prácticas que contiene cuestiones relacionadas con el 
funcionamiento y la filosofía de la emisora que deben ser respetadas por todas las personas que participen en ella. UniRadio Jaén establece unos principios que nacen de las enseñanzas de la radio predecesora, y además hace entrega a los colaboradores, al inicio de su actividad en la radio, de un pack que contiene documentos con las normas de funcionamiento, así como los estatutos de la emisora, que cumplen con los objetivos estratégicos que propone la Universidad de Jaén. En Radiouniversidad.es la normativa está basada en los documentos aportados por UniRadio Huelva, puesto que la estación pionera asumió la tarea de ayudar en la creación de las emisoras que surgieron posteriormente.

\section{Conclusiones}

A través de nuestro estudio queda patente que ninguna de las universidades que ofertan titulaciones de Ciencias de la Comunicación en Andalucía posee radio universitaria. Sin embargo, destacamos que tanto la Universidad de Málaga como la Universidad de Sevilla, que cuentan con las tres titulaciones de la rama: Comunicación Audiovisual, Periodismo, y Publicidad y Relaciones Públicas, de un modo u otro, están relacionadas con un proyecto radiofónico, aunque éste no se gestione directamente desde las propias universidades o a través de los fondos de las mismas. Por todo ello, podemos afirmar que docentes y alumnos son conscientes de la utilidad de un medio de relativa complejidad técnica como es la radio, y de lo que aporta a los que participan en ella, tanto en lo concerniente a la formación académica, como a la adquisición de competencias transversales. La Universidad de Sevilla así como la Universidad de Málaga ya poseen experiencias muy cercanas a lo que sería una radio universitaria, por lo que, es posible que solo sea necesario un pequeño impulso para que sendas universidades pusieran a disposición de sus alumnos un medio de comunicación universitario. El uso de este tipo de emisoras para formar a futuros profesionales de Ciencias de la Comunicación sería más que adecuado, además del prestigio que proporciona a un centro de educación superior la posesión de una radio universitaria, la responsabilidad social que lleva implícita, así como la constitución del lugar idóneo para promover la divulgación científica desde el origen, es decir, desde de la universidad. 
Por todo ello, a través de esta investigación hemos desgranado gran parte de los elementos que conforman cada una de las estaciones de radio analizadas, que con la inminente llegada de la nueva Ley Audiovisual de Andalucía quedarán amparadas como radios universitarias. Para los centros que aún no poseen radio universitaria, y que pudieran estar interesados en ponerla en marcha, planteamos la posibilidad de crear un proyecto radiofónico que comience en formato podcast, como plataforma adaptada al oyente (Espino y Marín-Pena, 2012: 23), y que con el paso del tiempo se una al carro de la emisión de contenidos sin interrupción en streaming sin necesidad de hacerlo en FM. Sería posible gracias a los nuevos avances tecnológicos, que además permiten crear desde cero una emisora de radio universitaria sin tener que realizar una gran inversión en equipamiento. Aunque en Andalucía el Decreto 174/2002 de 11 de junio, permite que las emisoras culturales puedan emitir mediante FM, como hemos señalado, no se trata de un elemento imprescindible para crear una emisora de radio universitaria, ya que en España existen estaciones de este tipo que funcionan haciendo uso exclusivo del podcast, con una periodicidad semanal como mínimo, es decir, siguiendo tan solo la premisa de la continuidad de emisión. Puede que nos encontremos ante una nueva forma de oír la radio, un nuevo modelo de escucha que dependa de la existencia de una app y de la interacción en redes sociales debido a la gran demanda de teléfonos inteligentes que existe en España.

Como conclusión, destacamos que la situación económica repercute en el personal que coordina y/o dirige las radios universitarias, ya que se trata de quien verdaderamente se ocupa de sacarlas adelante, por lo que sería recomendable procurar una estabilidad en este equipo de trabajo, lo que se traduciría en un avance hacia la consolidación de estas emisoras. Por otra parte, en aras de dotarlas de solidez, también sería necesario que cada una de las estaciones contara con una base fundamentada en normativas o estatutos de los que los usuarios de las mismas fueran conscientes y a los que acudir ante cualquier duda o consulta. Finalmente, en este análisis hemos detectado la necesidad de la existencia de un reconocimiento oficial para las radios universitarias, debido a la labor comunicativa y social que desempeñan, como medios que se reinventan cada día con la responsabilidad de crear consciencia social, de informar a la 
comunidad, así como de formar a futuros profesionales de la comunicación. 


\title{
Más de diez años de experiencia formativa en OndaCampus Radio
}

\author{
Daniel Martín-Pena (Universidad Extremadura) \\ https://orcid.org/0000-0003-2676-5821 \\ https:// scholar.google.es/citations?hl=es\&user=c3neDSYAAAAJ \\ Macarena Parejo Cuéllar (Universidad Extremadura) \\ Agustín Vivas Moreno (Universidad Extremadura) \\ https://orcid.org/0000-0001-7571-126X
}

Resumen: OndaCampus Radio (OC Radio), la emisora de la Universidad de Extremadura, nace en el año 2004 con dos objetivos. Por una parte, surge para fortalecer el ámbito práctico de los estudios de comunicación audiovisual, de forma que el alumnado tuviera la oportunidad de acceder a prácticas formativas más apegadas a la realidad del mercado laboral. Por otro parte, su puesta en marcha tiene que ver con la intención de la institución de acercar la vida académica a la sociedad. Con estos propósitos como punto de partida, y tras una década de andadura, OC se ha consolidado como una plataforma de comunicación formativa y de libre acceso. En sus doce años de funcionamiento, la radio universitaria ha permitido a los estudiantes complementar a la perfección sus estudios teóricos con una gran dosis de práctica real. A lo largo de esta comunicación vamos a abordar la trayectoria de OC desde distintos puntos de vista, centrándonos en su evolución y en los contenidos que han marcado su trayectoria.

Palabras clave: radio; universidad; Extremadura; historia; estudiantes; formación. 


\section{El fenómeno de la radio universitaria en España}

T A historia del medio universitario radiofónico supone un 1 fenómeno diferente, con sus propias particularidades tanto técnicas como históricas que determinan su presencia social más allá de las aulas universitarias. Como subraya Fidalgo (2009:124-137), uno de los matices que la hacen única es que más allá de informar, este canal surge con el cometido de "dar a conocer a la sociedad lo que acontece en estas instituciones educativas desde el ámbito científico, institucional y social, junto con la labor de preparar a los futuros profesionales de la comunicación".

Sin embargo, aunque hoy es frecuente hablar de radio universitaria, a España llegó con relativo retraso. Las primeras experiencias se sitúan en el contexto americano. En Latinoamérica, será Argentina la que dará los primeros pasos, con la creación de Radio Universidad Nacional de La Plata en 1924 y la emisora de la Universidad del Litoral, Radio LT10, en 1931. Aunque su origen se encuentra años antes, en el movimiento estudiantil universitario conocido como la Reforma de Córdoba de 1918, un movimiento social que reclamaba un cambio en las instituciones académicas en pos de una mayor extensión universitaria.

A partir de 1917 en Estados Unidos, desde los propios laboratorios universitarios, comienza a experimentarse con las primeras transmisiones radiales. El objetivo no era otro que mejorar las comunicaciones en el seno de la marina estadounidense. Universidades como la de Wisconsin, Pittsburg o Detroit se suman al fenómeno de la radio experimental que acabaría siendo el detonante de las Colleges Radios.

Por el contrario, el desarrollo de la radiodifusión en Europa se dilata más en el tiempo. Así, la radio universitaria en este contexto no posee más de medio siglo de historia. En este escenario, son países como Francia o Reino Unido los protagonistas de esos primeros pasos.

Si nos adentramos en el caso de España (Fidalgo 2009), se aprecia cómo no se consolida hasta finales de la década de los ochenta, a 
pesar de experiencias previas como Radio UNED, 10 años antes (Martín-Pena y Contreras, 2014: 101).

Marta y Martín-Pena (2014) consideran que son tres las fases de desarrollo de estas emisoras en España: una primera etapa marcada por experiencias puntuales, una segunda fase de eclosión del movimiento, coincidiendo con el nuevo siglo y de la mano del desarrollo de las TIC, del acercamiento a la sociedad y del auge de las experiencias surgidas al amparo de los estudios vinculados al área de las ciencias de la información, y una última fase, la actual, de cierto estancamiento determinado por una crisis que también afecta a las instituciones académicas.

Con la irrupción de las TIC y, sobre todo a partir del año 2000, lo cierto es que el número de estaciones, tanto de emisión en FM como vía Internet no han dejado de aumentar. Según datos de Martín-Pena (2013:496), hoy el panorama comunicativo está compuesto por cerca de una treintena de radios universitarias, lo que supone un $30 \%$ de las universidades españolas las que poseen este altavoz propio de difusión de su labor académica e investigadora.

En general, se tratan de medios de comunicación atípicos con una clara vocación de servicio público y de aproximación al contexto social (Aguaded y Contreras, 2011). Se puede decir que crear una radio en el marco universitario suele tener como objetivo, en la mayoría de los casos, "abrir un canal de participación, donde se expresen inquietudes o se visualice el día a día de la institución" (Martín-Pena y Espino, 2014: 26-43).

Es cierto que la función principal de la universidad se basa en formar profesionales pero también es su misión transferir los conocimientos generados en los laboratorios a la sociedad. Y, en esa labor de transferencia, la radio posee un incalculable valor educativo (Segura, 2014) a la hora de mostrar a la sociedad los hallazgos científicos llevados a cabo en esas instituciones, tildadas de estancas y tradicionales, pero que ahora pretenden abrirse, al exterior, a través de sus propias herramientas de difusión. En este sentido, como afirman Parejo y Martín-Pena (2014), la radio universitaria trabaja aportando a 
la cadena de la $\mathrm{I}+\mathrm{D}+\mathrm{i}$, una "d", que completa la estrategia de transferencia del conocimiento a la ciudadanía.

Además, la radio universitaria se ha ido convirtiendo en un instrumento con una clara misión pedagógica (González Conde, 2003: 11) en cuanto que, en sus parrillas radiofónicas, lo que priman no son tanto las audiencias como las temáticas, dando con ello respuesta a los cometidos que la institución docente tiene para con la sociedad. Y no solo eso. También a través de la radio universitaria se ofrece una herramienta de comunicación a colectivos que desean tratar temas que no tendrían cabida en el medio convencional. De esta forma se da voz, como afirma Contreras (2012) a colectivos silenciados.

Es una radio especializada y temática, con un enorme potencial a la hora de crear productos informativos únicos, basados en el rigor y la cercanía que le brinda ser parte integrante de la entidad educativa e investigadora de la que hablan y de la que son altavoces, la universidad. Sobre todo en un contexto como el actual, donde las plataformas tradicionales de emisión se mezclan con los nuevos canales de difusión que permiten las TIC. No debemos perder de vista que gracias, en parte, a la red de redes, muchos usuarios pueden acceder a estos otros contenidos alternativos a través de sus teléfonos móviles, sus tabletas, o cualquier otro dispositivo para empaparse de una información que no le ofrecen otros muchos medios de comunicación y esto es importante para conseguir trasladar mensajes e informaciones de índole institucional a la ciudadanía.

\section{La radio de la Universidad de Extremadura, OndaCampus}

El origen de OC se encuentra en el proyecto de "Producción Audiovisuales" que da origen a un convenio de colaboración firmado entre el gobierno regional y la institución académica. A partir de la rúbrica, se acuerda la realización de un programa mensual de televisión y otro quincenal de radio sobre la actualidad de la UEx a cargo de un equipo formado por estudiantes de los estudios de Comunicación Audiovisual tutelados por profesores del centro educativo y por el Vicerrectorado de Coordinación y Relaciones Institucionales de la Universidad. Según reflejaba aquel primer 
acuerdo, las producciones audiovisuales serían facilitadas a las cadenas regionales y locales de televisión y radio, con objeto de obtener un mayor impacto en los distintos puntos geográficos de Extremadura y funcionar como puente hacia la sociedad. El proyecto era todo un avance para la Facultad de Ciencias de la Información y la Comunicación ya que suponía para el alumnado la realización de prácticas reales en todos los sectores de la producción audiovisual: realización, producción, edición, postproducción, documentación, etc., siempre con unos criterios de calidad profesional. Si perfilásemos un símil con los estudios de medicina, la radio-tv universitaria constituiría para el alumnado de comunicación lo que supone para los estudiantes de medicina el hospital clínico.

Los objetivos prioritarios del proyecto eran tres:

- Ofrecer una imagen positiva y veraz sobre las tareas científicas, académicas, culturales y de otro tipo que en ella se realizan.

- Dinamizar el sector audiovisual en Extremadura.

- Facilitar actividades prácticas de producción a un nivel profesional para los alumnos de Comunicación audiovisual de la Universidad de Extremadura, constituyendo un complemento ideal para su formación y su futuro acceso al mercado laboral.

Cabe destacar, en este sentido, que en el año 2004 se está produciendo el debate de la puesta en marcha de la radio-tv regional de Extremadura (Canal Extremadura), un entorno que precisa de actividades que dinamicen el sector audiovisual en la región y contextos favorables en los que pueda formarse adecuadamente la futura cantera de profesionales del ente audiovisual autonómico.

\subsection{Primera etapa (2004/2006): Taller audiovisual OndaCampus Radio y Campus TV}

Durante los dos primeros años OndaCampus no es una radio al uso. Más bien, el proyecto funcionaba como un taller de prácticas voluntarias para el alumnado de los estudios de Comunicación Audiovisual de la UEx. Eran dos talleres independientes pero con sinergias, uno dedicado al medio radiofónico y otro a la televisión. En 
la radio, los estudiantes contaban con la tutela de un grupo de profesores y un becario. Tras muchas pruebas y cambios de formato, en diciembre de 2004 se grabó el programa informativo piloto. Este es emitido por una veintena de emisoras locales y municipales de Extremadura. En la primera temporada (2004/2005) se graban 12 espacios de 30 minutos, más 5 programas especiales. El empuje y la ilusión generada con el proyecto en el seno de la propia comunidad universitaria, hace que la segunda temporada (2005-2006) se inicie con un aumento considerable de la programación, que crece sustancialmente, con la producción de dos nuevos espacios propuestos desde servicios de la propia Universidad pero realizados por el alumnado. Se trata del programa "Con la UEx a Europa" un proyecto concebido desde la Oficina de Convergencia Europea de la UEx que abordaba la adaptación de la Universidad de Extremadura al Espacio Europeo de Educación Superior (EEES) y el espacio realizado en colaboración con la Universidad de los Mayores de la UEx "La Voz de la Experiencia", programa de contenido variado realizado por miembros de la Universidad de Mayores de Extremadura.

La posibilidad de emitir en entornos reales, el trabajo desarrollado en el aula y en esta nueva plataforma de prácticas, supone una oportunidad para la institución a la vez que una importante lanzadera para los estudiantes. Y es que, de alguna manera, la radio-televisión universitaria se convirtió desde su etapa primigenia, también, en un escaparte desde el que demostrar las destrezas comunicativas y como carta de presentación para acceder al mercado laboral por parte de los futuros profesionales de la comunicación. Máxime si tenemos en cuenta, como hemos avanzado, que en el momento en el que la Universidad de Extremadura ponía a punto su radio universitaria, comenzaba el arranque de la Televisión y la Radio Autonómica, y por ello, se planteaba la posibilidad de que este medio se convirtiera en plataforma regional para emitir los contenidos universitarios.

\subsection{Segunda etapa (2006/2010): Puesta en marcha y consolidación de la emisión online}

Esta etapa es producto de la buena acogida del proyecto. En la tercera temporada $(2006 / 2007)$ se pone en marcha la iniciativa 
"OndaCampus Radio, tu radio universitaria por Internet". Con su definitiva puesta a punto, $\mathrm{OC}$ se convierte en la radio institucional de la UEx, y abre su participación a toda la comunidad universitaria e incluso cualquier institución o entidad externa. El inicio es un hito en la universidad. Solo es preciso recordar que aquel año se recibieron medio centenar de solicitudes de realización de programas.

Después de casi tres años de funcionamiento independiente, a comienzos de 2007, OndaCampus Radio y Campus TV pasa a depender administrativamente de la Fundación Universidad Sociedad de la UEx. Esta nueva vinculación redibuja las intenciones del nuevo medio audiovisual universitario de acercamiento a la sociedad, a través del fortalecimiento del servicio público y la democratización de la comunicación.

Así, la parrilla de la nueva emisora se consolidaba con espacios nuevos y con programas que ya constituían un referente en la rejilla programática, como "RadioActivos" (programa realizado con el apoyo del Instituto de la Juventud de Extremadura) o "Mujeres en Otra Onda" (espacio apoyado desde el Instituto de la Mujer de Extremadura). Además, se estrena nueva web con dominio propio (www.ondacampus.es). En paralelo, OC Radio sigue fortaleciendo su estrategia con las emisoras municipales a las que facilita toda su programación, convirtiéndose en productora de contenidos universitarios y lanzadera de futuros profesionales de la información.

La quinta y sexta temporada (2008-2010) están marcadas por un pequeño decrecimiento en la participación de los alumnos, en gran parte debido al Plan Bolonia y la obligatoriedad de las clases, que dejan proyectos voluntarios como el de OndaCampus en un segundo plano para los estudiantes.

\subsection{Tercera etapa (2010/2015): Consolidación de la plataforma formativa audiovisual OndaCampus}

Este periodo se extiende desde la séptima temporada (2010/2011) hasta la actualidad. Esta etapa constituye un relanzamiento del proyecto. Comienza con la puesta en funcionamiento de una plataforma web mucho más interactiva y con un lenguaje más 
cercano a los nativos digitales. Se apuesta firmemente por la promoción inicial con objeto de captar a mayor número de alumnado, de tal manera que cada temporada tiene un eslogan propio que constituye el "leitmotiv" sobre el que se desarrolla el resto de actuaciones.

Tabla 1: Eslóganes de las últimas cinco temporadas de OndaCampus

\section{Temporada/Año \\ Eslogan}

\begin{tabular}{|c|c|}
\hline $\begin{array}{c}7^{\mathrm{a}} \text { temporada } \\
(2010 / 2011)\end{array}$ & $\begin{array}{c}\text { "Siete años, siete razones: Formación, Información, } \\
\text { Libertad, Imaginación, Diversión, Ilusión y Sueños" }\end{array}$ \\
\hline $\begin{array}{c}8^{\mathrm{a}} \text { temporada } \\
(2011 / 2012)\end{array}$ & "Toma el control" \\
\hline $\begin{array}{c}9^{\mathrm{a}} \text { temporada } \\
(2012 / 2013)\end{array}$ & "Sólo faltas tú" \\
\hline $\begin{array}{c}10^{a} \text { temporada } \\
(2013 / 2014)\end{array}$ & "Súbete al 10" \\
\hline $\begin{array}{c}11^{a} \text { temporada } \\
(2014 / 2015)\end{array}$ & "La pieza que te falta" \\
\hline
\end{tabular}

Fuente: elaboración propia (Datos extraídos de www.ondacampus.es)

La octava temporada se inicia con la participación activa de los miembros de OC en la puesta en marcha de la Asociación de Radios Universitarias de España que surge a raíz de un encuentro de radios universitarias de España celebrado en Badajoz en junio de 2010 (Martín-Pena y Aguaded, 2013), y además se pone en marcha la campaña OC9 (Operación Comprometida 9 meses), donde se aborda un objetivo del milenio de forma mensual, realizando micro-espacios, cuñas, promocionales y campañas de diseño, que refuerzan el perfil social de la emisora. Además, se inicia una estrategia de presencia de OndaCampus en los perfiles de redes sociales de Facebook, Tuenti y Twitter.

La novena temporada destaca nuevamente por la puesta en marcha de un proyecto radiofónico universitario de divulgación científica, "Semillas de Ciencia", liderado por OndaCampus y que cuenta con la 
financiación de la Fundación Española para la Ciencia y la Tecnología (FECYT). En él participan 20 emisoras pertenecientes a la ARU. En paralelo, se continúa reforzando los canales interactivos, y se comienza a trabajar en el perfil de OndaCampus en la plataforma iV oox, con el objetivo de extender sus contenidos en la red social de referencia en temas de audio.

La décima temporada vuelve a suponer un repunte en la producción de programas auspiciado por la promoción realizada y por la visita de personalidades mediáticas a la inauguración y cierre de la temporada (Toni Garrido y Jordi Évole) en el marco de una lista de eventos culturales, sociales y educativos bajo el nombre "Los 10 de OC", así como por el plan de formación añadido ofrecido a los estudiantes bajo el proyecto "Una formación de 10". Además, a lo largo de esta temporada se estrenan las aplicaciones para Smartphones de OC bajo los sistemas IOS y Android, lo que facilita la conexión con las nuevas generaciones de jóvenes, que tienen otra forma diferente de escuchar y conectar con la radio.

La última temporada de OC (2014/2015) marca un nuevo punto de inflexión, ya que la emisora de radio y la plataforma de televisión se integran en la estrategia comunicativa institucional de la Universidad de Extremadura a través del Gabinete de Información y Comunicación, lo que supone una apuesta más allá de la formación del alumnado, que continua siendo prioritaria, pero ahora el esfuerzo por reforzar la estrategia comunicativa de la universidad se convierte en una tarea fundamental.

\section{Los datos de OndaCampus después de una década de funcionamiento}

A través de este capítulo pretendemos poner de manifiesto el desarrollo generado por OC como plataforma de prácticas para el alumnado de los estudios de comunicación de la UEx hasta derivar en un medio de comunicación propio de la institución académica que transfiere su conocimiento a la sociedad. Para ello, resulta conveniente analizar el perfil de los colaboradores de OC ya que básicamente acoge a dos tipos de colectivos: 
- Internos: alumnos de otras disciplinas académicas, personal docente e investigador, personal de administración y servicios.

- Externos: egresados universitarios, ciudadanos independientes, organizaciones del tercer sector, ONGs y colectivos sociales.

Una de las maneras de entender el impacto que ha tenido la radio-tv es analizando las cifras del participación, precisamente, del alumnado de comunicación audiovisual y el número de programas por temporada. En el inicio, OC era concebido como un taller audiovisual desde donde ofrecer prácticas voluntarias, pero reales a los futuros profesionales de la comunicación. El alumnado de la disciplina de comunicación, que se ha volcado en participar activamente en este medio de comunicación, hace de este proyecto un lugar donde aprender a ser lo que Hurtado (2007) denomina "profesionales multitarea" y periodificadores de lo que circula en la red de redes (Martínez, 2005). Como puede apreciarse cada temporada participa en OC Radio un número considerable de estudiantes (gráfico 1):

Gráfico 1: Número de alumnos participantes en OC

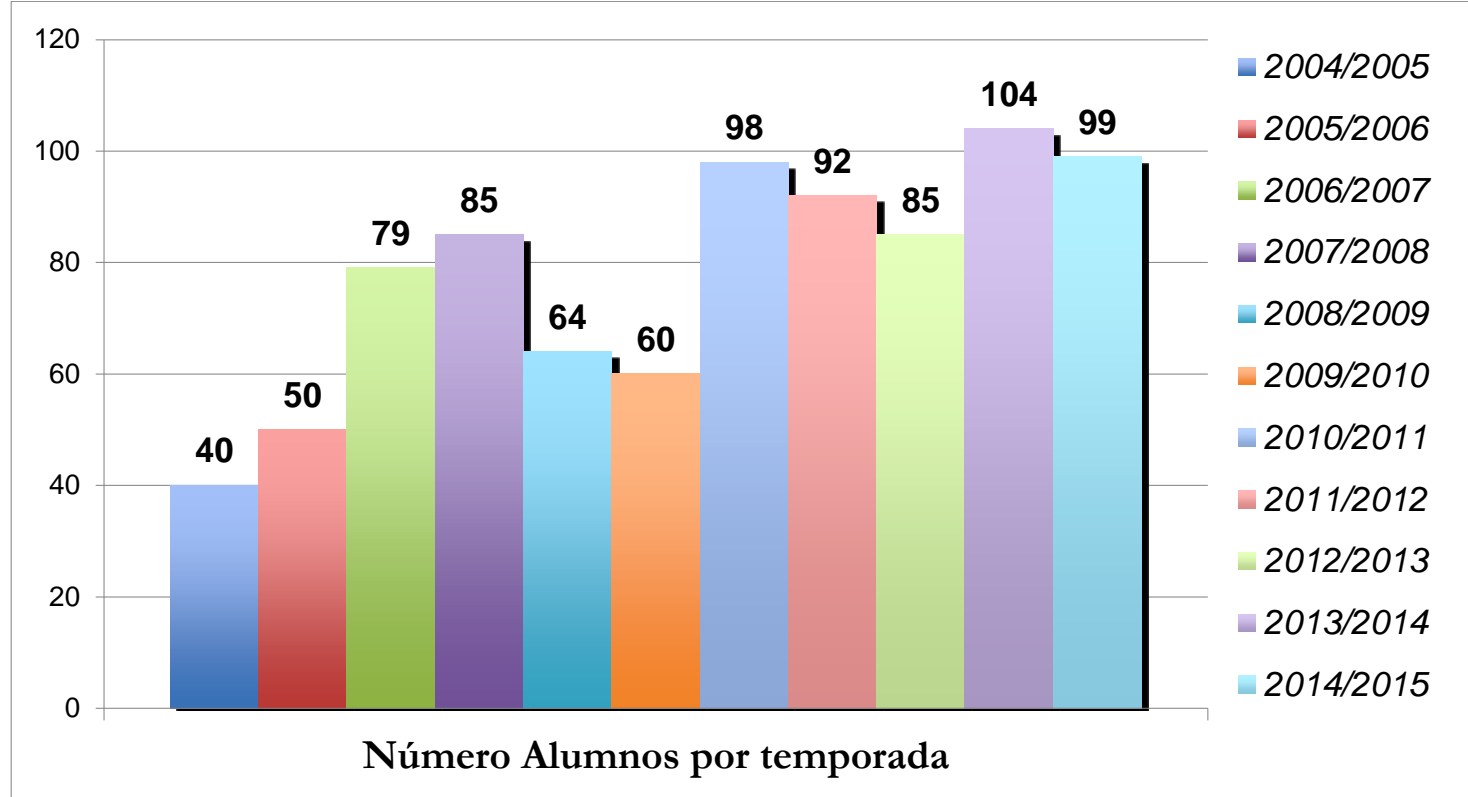

Fuente: elaboración propia a través datos extraídos memorias anuales OC

Como podemos observar en el Gráfico 1 son un total de 856 los alumnos del Grado de Comunicación Audiovisual y del Grado de Información y Documentación los que han participado en las 11 temporadas de OndaCampus, lo que constituye una media de 78 
alumnos por temporada. Si extrapolamos el gráfico a las etapas que hemos desgranado en el apartado 2 de este artículo podemos determinar que OC pasa por los siguientes periodos:

- Etapa 1 (2004/2006): El proyecto es un taller audiovisual con unas plazas determinadas. Se realizaron 4 grupos de prácticas de 10 personas que se encargaban de los programas informativos $y$ especiales. Ya en la segunda temporada fueron 5 grupos los encargados de desarrollar la programación.

- Etapa 2 (2006/2010): Las dos primeras temporadas (2006/2008) se caracterizan por el aumento de la participación del alumnado (motivado por el streaming las 24 horas del día). Por el contrario, el periodo comprendido entre 2008/2010 se vive una reducción en las cifras de alumnos participantes, casi un $25 \%$ menos que en las dos temporadas anteriores. El motivo de este descenso se debe buscar en un primer impacto del nuevo sistema de enseñanza universitaria, el conocido como Plan Bolonia que resta protagonismo a la extensión universitaria.

- Etapa 3 (2010/2015): Desde la dirección de OC se ponen en marcha estrategias específicas de promoción para captar a los alumnos y un acercamiento al profesorado del área de comunicación audiovisual para vincular parte de las prácticas docentes a la radio universitaria como sucede con asignaturas como "Comunicación Periodística" de segundo curso. Estas acciones suponen un claro repunte en el número de estudiantes, cercano al $65 \%$ alcanzando su máximo apogeo en las dos últimas temporadas. La décima temporada se superó por primera vez la centena de alumnos y la undécima se rozó esa misma cifra.

El gráfico 2 recoge el número de programas realizados tanto por alumnado de Comunicación Audiovisual como por parte de los otros colectivos participantes en OndaCampus. En este sentido, puedo observarse como al inicio, en las dos primeras temporadas, el número de espacios radiofónicos era muy reducido, debido a que era la fase inicial del proyecto en la que OndaCampus funcionaba como taller práctico. A partir de la tercera temporada, la media de programas se sitúa en 27 . En cuanto a la tipología de los mismos, es muy variada 
aunque predominan los programas tipo magazine y los musicales/culturales.

Gráfico 2: Número de programas en OC

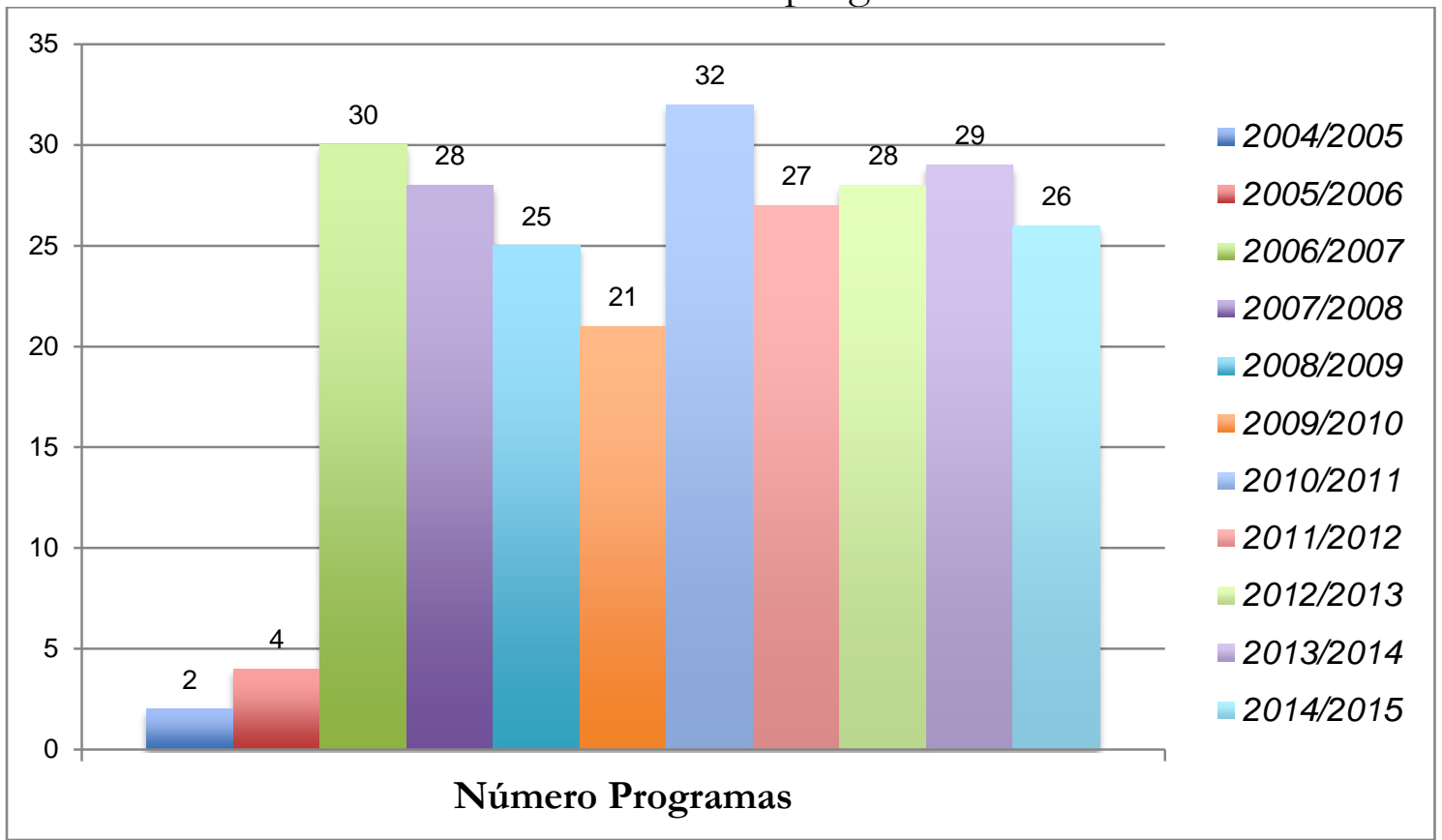

Fuente: elaboración propia a través datos extraídos memorias anuales OC

\section{Conclusiones}

Después de más de 10 años de funcionamiento, OC se ha convertido en una plataforma formativa referente en el panorama regional. Este proyecto reporta un claro beneficio para los alumnos que de manera voluntaria deciden participar aportando sus ideas, proyectos y programas radiofónicos. Es un hecho constatable que los estudiantes que a lo largo de sus años de estudios deciden involucrarse en OndaCampus están en mejores condiciones prácticas para afrontar su acceso al mercado laboral que los alumnos que han decidido no hacerlo, y así lo manifiestan los empleados de los diferentes medios que acogen a alumnos en prácticas en el marco de la asignatura del "Practicum" que cursan en el cuarto año de estudios. Además, como recogen Parejo y Martín-Pena (2011) son varios los casos de éxito de antiguos colaboradores que se encuentran, a día de hoy, ocupando cargos de responsabilidad en medios de comunicación regionales.

En la actualidad se dan las circunstancias idóneas para permitir que esta plataforma formativa continúe siendo un punto de referencia. Una nueva etapa comienza en la radio-tv de la Universidad de 
Extremadura caracterizada por su capacidad de integración. Con dos grandes retos, por un lado el papel del destacado del personal de OC en el marco de la Asociación de Radios Universitarias de España con el objetivo de aglutinar en proyectos cooperativos a todas las radios universitarias españolas, como ha sucedido con el programa de divulgación científica "Semillas de Ciencia" (www.semillasdeciencia.es) o proyectos europeos como "EuroPhonica" (www.europhonica.eu) en colaboración con emisoras estudiantiles de otros países del contexto europeo (Francia, Italia, Portugal y Alemania). Y la integración de OndaCampus en la estrategia comunicativa de la Universidad de Extremadura a través del Gabinete de Información y Comunicación, que permitirá a la emisora relanzar su papel interno en el seno de la comunidad universitaria y afianzar su perfil externo tejiendo puentes firmes con la ciudadanía. Y en todo este entramado el papel de los estudiantes de la especialidad de comunicación audiovisual irá claramente en aumento. 



\section{El relevo generacional en la plantilla de una radio universitaria, como elemento dinamizador de su parrilla de programación y su estructura organizativa. El caso de iradioUCAM}

Ma Carmen Robles Andreu (Universidad Católica de Murcia) ORCID: http://orcid.org/0000-0001-6963-3234

Google Académico:

https://scholar.google.es/citations?user=Nsh3QoAAAAJ\&hl=es\&oi=ao

Isabel $\mathbf{M}^{\mathbf{a}}$ García González (Universidad Católica de Murcia) ORCID: http://orcid.org/0000-0003-0069-8448

Google Académico: https://scholar.google.es/citations?user $=\mathrm{cB} 4 \mathrm{~A}-$ 6sAAAAJ\&hl=es

Beatriz Correyero Ruiz (Universidad Católica de Murcia) https://scholar.google.es / citations?user $=$ cB4A-6sAAAAJ\&hl=es\&oi=ao

Resumen: La plantilla de una radio universitaria está compuesta, en su gran mayoría, por alumnos cuya pertenencia a la universidad se limita a un tiempo determinado, en ocasiones, el estrictamente necesario para culminar sus estudios. Esta circunstancia hace que sus integrantes varíen cada temporada y, con ellos, los programas que componen la parrilla de programación.

Con esta idea de renovación constante, tanto de equipos como de programación, y a través del caso concreto de la radio universitaria de la Universidad Católica de Murcia, iradioUCAM, en este trabajo se describe el modelo de gestión alcanzado para su correcto funcionamiento tras seis años de actividad. 
Partiendo de la renovación de la plantilla podemos explicar cómo se ha consensuado y consolidado una estructura organizativa que, similar a la de un medio radiofónico actual, sirve como plataforma de experimentación profesional para todos aquellos alumnos que pertenezcan a ella.

Los trabajos de integración de miembros y creación de productos que se realiza cada comienzo de temporada, así como el seguimiento de todos los procesos que se dan a lo largo de ésta, quedan reflejados en una serie de etapas de trabajo que pueden servir como referente para el trabajo de otros medios de estas características.

Palabras clave: radio universitaria; programación; estructura; plantilla; parrilla; gestión de equipos; fases.

\section{Introducción}

T A formación y la experimentación en el ámbito de la LComunicación son dos de los ejes que consideramos fundamentales para la creación de una puesta en marcha de una radio universitaria. Teniendo en cuenta estos pilares, en 2010 se crea iradioUCAM, en el seno de la Facultad de Comunicación de la Universidad Católica de Murcia como iniciativa del grupo de investigación Digitalac pero eso sí, gracias al interés y al empuje de un nutrido grupo de alumnos que, apasionados del medio radiofónico, demandan mayor volumen de prácticas en radio. Una actividad formativa extra académica que desde su gestación estuvo respaldada por la institución, entendiendo ésta como un valor añadido a la formación curricular de los alumnos.

Así, el 23 de abril de 2010 iradioUCAM publicaba su primer programa de radio, "Arte en la palabra". Éste era uno de los cuatro proyectos que, durante dos meses y medio -hasta la finalización del curso académico-, sirvieron para experimentar con las fórmulas, procesos y rutinas de trabajo necesarias para desarrollar una radio universitaria.

Desde su origen, la radio universitaria de la UCAM ha emitido su programación en Internet a través de podcast. La gran mayoría de los 
productos son magazines, de no más de treinta minutos de duración que han configurado una parrilla tipo mosaico con contenidos muy variados. Tan variados han sido sus contenidos como sus componentes ya que, a pesar de iniciarse vinculada a los estudios de Comunicación, el acceso a ella ha estado abierto a toda la comunidad universitaria, es decir, estudiantes, PDI (Personal Docente e Investigador) y PAS (Personal de Administración y Servicios). Aunque el grueso de la plantilla se ha conformado por alumnos de la Facultad de Comunicación, son muchos los estudiantes y profesores de otros títulos que han participado en ella y para los que se ha tenido que diseñar una formación más específica debido al desconocimiento, en ocasiones absoluto, del medio radiofónico.

No sólo la variedad de sus integrantes es un factor enriquecedor del trabajo que en ella se realiza sino que también su continua renovación aporta un valor añadido de gran calado. La marcha de alumnos que finalizan sus estudios, la de aquellos que salen al extranjero a continuar sus grados, sumado a la llegada de nuevos miembros a la plantilla supone una continua reestructuración, no sólo de ella sino de lo que nos resulta más interesante, el reciclaje parcial o total de la parrilla cada temporada.

\section{El relevo generacional de los miembros de una radio universitaria. El caso de iradioUCAM}

Para comprender el sistema de trabajo de iradioUCAM es necesario puntualizar que el relevo generacional de los miembros de cada uno de sus programas se debe a ese carácter cíclico de los estudios universitarios, lo cual como comentábamos es un reflejo en la renovación continua de su plantilla así como en la de su parrilla de programación.

Año tras año, los alumnos que integran la radio entran y salen del equipo condicionados por sus circunstancias personales $y$ profesionales mientras que otros muchos deciden acceder a ella por primera vez. Estos movimientos provocan una reestructuración periódica que suele coincidir con el cierre del curso académico presente y el inicio del siguiente. 
Existen muchos motivos para que se produzca esa fluctuación, dichos motivos los podríamos resumir atendiendo a tres tipos de alumnos: los que abandonan el proyecto, los que se vuelven a integrar en él y los que llegan por primera vez.

En el caso de los alumnos que deciden dejar la radio, las principales razones son: la finalización de sus estudios y por lo tanto, el fin de su vida universitaria; la consecución de una beca para desarrollar sus estudios temporalmente en el extranjero; o, la necesidad de centrar su atención únicamente en los estudios -ya sea por decisión propia o tomada por parte de la coordinación de iradioUCAM, atendiendo a esa labor de seguimiento académico que mencionábamos anteriormente-.

En este último punto, debemos puntualizar que la importancia que se da a la formación dentro de la radio no tendría sentido si no se hiciera un seguimiento en paralelo a la formación académica del estudiante por lo que, desde el principio, la continuidad del alumno en el proyecto viene condicionada por los resultados académicos que obtiene en sus estudios reglados. Esto supone una revisión del expediente académico de cada alumno una vez concluido el periodo de exámenes correspondiente al primer semestre (convocatoria de febrero). Si los resultados no han sido satisfactorios, el estudiante pierde el derecho a continuar dentro del proyecto radiofónico al que pertenezca hasta que no se produzca una evolución en positivo de las calificaciones.

Además hacemos referencia a aquellos antiguos miembros de la radio que han mostrado interés por volver a formar parte de ella. Este tipo de casos tienen que ver con los perfiles expuestos en el apartado anterior. Es decir, alumnos que vuelven de estudiar en el extranjero y piden su reintegración de la misma manera que lo hacen los que perdieron el derecho a formar parte de la radio por no llegar a los mínimos académicos exigidos.

Dentro de este tipo de alumnos, cabe destacar el caso de aquellos que, vinculados o no con la institución, solicitan volver a acceder a la radio debido, principalmente, a tres motivos: no dejar de practicar o perfeccionar sus conocimientos y capacidades radiofónicas, no querer 
desprenderse de su sentimiento de pertenencia al proyecto $\mathrm{y}$, por último, que el programa del que formaran parte no haya encontrado un relevo natural que permita su continuidad en la parrilla. De esta forma, son muchos los productos que se mantienen o se recuperan cuando uno o varios integrantes de él deciden retomarlo.

Atendiendo a esta importante apreciación, es necesario explicar que, al igual que la composición de la plantilla varía cada año, la parrilla de programación también lo hace. A pesar de que tres de los cuatro programas con los que comenzara sus emisiones iradioUCAM sigan existiendo a día de hoy, hay que decir que durante sus siete temporadas han sido muchos los productos que han nacido y que han desaparecido cuando todos o parte importante de sus integrantes han dejado de pertenecer a la radio. Esto significa que, en gran medida, el sentido de los proyectos se lo imprime el grupo de personas que lo hacen, es decir, que la identidad de esas personas queda marcada, de manera indisoluble, en la esencia del programa.

La llegada de nuevos miembros a la plantilla siempre supone una revitalización para su estructura. Los nuevos integrantes quieren formar parte de iradio porque quieren aprender a hacer radio. Cuando llegan pueden querer integrarse en alguno de los programas existentes bien porque sientan afinidad con la temática o, como en el caso de los más activos y decididos, por querer emprender un nuevo proyecto ideado de forma individual u orquestado por algún grupo.

Con todo este conglomerado de ideas, cada mes de septiembre, la coordinación de iradioUCAM rediseña su estructura para alcanzar una parrilla de programación coherente con su plantilla. Conectar a personas con temáticas, roles, tareas, capacidades, habilidades, competencias e ilusión es la clave para conseguir el fin último de nuestra radio universitaria: que los alumnos que la hacen posible lo hagan a través de un proceso de aprendizaje dirigido y continuado en el que adquieran el mayor número de competencias profesionales vinculadas con el medio radio a través de la coordinación de dos profesoras del área de Comunicación Audiovisual. 


\section{La estructura organizativa de iradioUCAM. Innovación docente hacia la profesionalización}

La estructura organizativa de la radio se ha ido fraguando a lo largo de sus seis años de vida hasta conformar la que hoy la define como una plataforma de experimentación profesional. Esta denominación encuentra su origen en el objetivo sobre el que iradioUCAM sustenta su trabajo: la adquisición de competencias profesionales vinculadas con el medio radiofónico. Para ello, se han ido integrado en los procesos productivos tantos roles como rutinas profesionales sean necesarios para desarrollar el trabajo que va desde la ideación de un producto hasta su difusión pública, pasando por su producción, grabación, edición, etc.

Fruto de la experimentación y evaluación del trabajo realizado cada temporada, de las necesidades surgidas y de los procesos no resueltos, la estructura organizativa se ha consolidado con la configuración de cinco grandes equipos que son:

- Equipo de producción: Bajo la supervisión de un equipo de dos o tres productores generales de iradioUCAM, cada programa cuenta con un miembro que represente esta figura tan imprescindible. Las labores de producción consisten principalmente en la consecución de todos aquellos elementos necesarios para la elaboración del programa: audios, declaraciones, entrevistas, acreditaciones, así como otras tareas relacionadas con otros equipos de trabajo como el de Comunicación elaborando informaciones relacionadas con el programa semanal así como generando contenido para redes sociales.

- Equipo técnico: Compuesto por todos los técnicos de iradio que trabajan bajo la supervisión de un coordinador encargado de revisar los trabajos, los controles técnicos y que actúa como persona de referencia a la que recurrir en el momento en que surjan dudas sobre cualquier cuestión de este ámbito.

- Equipo de comunicación y diseño: Este nutrido equipo es el encargado de trabajar en la identidad visual de iradioUCAM así como en el mantenimiento de la página web (publicación de 
programas, noticias, ideación de campañas promocionales), mantenimiento de redes sociales, etc.

- Equipo de redacción: En este equipo se incluyen el cuerpo de redactores, locutores y presentadores.

- Equipo de salidas y eventos especiales: La asiduidad con la que iradio afronta eventos externos ha llevado a la creación de un equipo dedicado exclusivamente a la organización y producción de estas salidas que precisan y suponen un esfuerzo extra para todo el equipo de la radio. En él se integran miembros del resto de equipos así como de la plantilla general. Hay que destacar que a este tipo de eventos acuden aquellos programas a los que se les quiere premiar por su trabajo, esfuerzo y evolución, sirviendo no sólo de ejemplo para el resto de la plantilla sino, lo más importante, como elemento de motivación para seguir mejorando.

El desempeño de estas funciones, supervisado y evaluado desde la coordinación de la radio, está diseñado para que los estudiantes adquieran un amplio número de competencias que podemos clasificar dependiendo de su grado de especificidad en competencias generales (trabajo en equipo, habilidades en las relaciones interpersonales, capacidad crítica, creatividad, etc.) y competencias específicas (capacidad de organización, planificación y dirección; capacidad y habilidad para buscar, seleccionar y jerarquizar cualquier tipo de fuente o documento; capacidad y habilidad para expresarse con fluidez y eficacia comunicativa; capacidad y habilidad para utilizar las tecnologías y técnicas informativas y comunicativas, etc.).

En relación con lo anterior, no hay que olvidar, como afirma López Vidales (Martín-Pena, 2014:23) que para los estudiantes una radio universitaria implica, entre otras cuestiones, cumplir con labores docentes. En este sentido hay que decir que son muchas las emisoras universitarias que han puesto en marcha algún proyecto de innovación docente adscrito a las facultades de comunicación, como son las siguientes: Universidad de Huelva (UniRadio), Europea Radio (Universidad Europea de Madrid), InfoRadio (Universidad Complutense de Madrid), Radio Unizar (Universidad de Zaragoza) e iradioUCAM (Universidad Católica San Antonio). Si bien la 
naturaleza de cada proyecto es diferente, el común denominador de todos ellos ha sido la adaptación de los estudios de comunicación al EEES. En el caso de iradio, es una radio que nació auspiciada por la Facultad de Comunicación de la UCAM y en este sentido, durante los cursos 2012-2013 y 2013-2014 se puso un marcha un proyecto de innovación docente -que describen detalladamente Correyero, García y Robles (2013)- que explica el interés que hay detrás de esta emisora por convertirla en una herramienta que contribuya a mejorar la preparación profesional de nuestros alumnos.

\section{La parrilla de programación de iradioUCAM. Identidad e integración}

El proceso de integración que hace posible que cada año iradio ponga en marcha una nueva temporada radiofónica se puede explicar a través de cuatro etapas de trabajo o fases establecidas atendiendo a cuatro variables: la acotación temporal que se considere necesaria para ella; los objetivos que se pretenden alcanzar en cada una las etapas, ya sea a nivel general de iradio, de forma grupal por programa, o de manera individual con cada uno de sus miembros; los procesos a poner en marcha para alcanzar los objetivos planteados; y, la evaluación de la evolución y el estado del proyecto y con ello el resultado, es decir el reflejo que de todo ello se obtiene en la parrilla de programación de la radio universitaria.

De esta forma, vamos a explicar, a través de cuatro fases, el trabajo que se realiza desde que se inicia la temporada, con la integración de los nuevos miembros en la plantilla de iradioUCAM, hasta que ésta finaliza, cuando se hace una evaluación de los programas, de sus integrantes así como de todos los procesos globales e individuales que han tenido lugar.

A continuación se exponen las fases mencionadas explicitando detalladamente las siguientes cuestiones: acotación temporal de la fase, objetivos a alcanzar en ella, procesos puestos en marcha y el resultado que se obtiene de la evolución de ese proceso en la parrilla de programación. 


\section{Fase 1. Puesta en marcha de una nueva temporada coincidiendo con inicio curso académico: Training iradio $\boldsymbol{U C A M}$}

- Acotación temporal:

Esta fase se desarrolla durante el mes de septiembre de cada curso académico y contempla tres procesos de trabajo: el de inscripción en el Training iradio, el desarrollo del propio curso Training iradio y el cierre de los proyectos de programas que de él se deriven.

- Objetivos que se pretende alcanzar:

Los procesos que en ella se desarrollan están encaminados a sentar una base sólida sobre la que cimentar una nueva temporada radiofónica por lo que los objetivos con los que se plantean dichos procesos son fundamentales para garantizar la continuidad de la radio como plataforma de aprendizaje. Estos objetivos se podrían resumir en uno: diseñar una nueva temporada radiofónica, pero de manera más concreta diremos que son: incorporar nuevos miembros en la platilla de iradio; reconstruir su estructura organizativa interna; renovar y crear nuevos equipos de trabajo que den continuidad a los programas existentes; y, plantear, analizar y consensuar nuevas propuestas de programas, pudiendo proceder éstas de la propia coordinación de la radio así como de los miembros de la platilla o de los de nueva incorporación.

- Procesos:

Aprovechando el periodo previo al comienzo del curso académico, iradioUCAM celebra cada mes de septiembre un seminario de iniciación e integración en la radio llamado Training iradioUCAM. A él pueden acceder todas aquellas personas que estén interesadas en formar parte de la plantilla de la radio y hayan completado el formulario de inscripción publicado en la web de ésta. Este aspecto es importante mencionarlo puesto que a través de él, las coordinadoras pueden conocer información detallada sobre las preferencias, intereses, objetivos e inquietudes de cada uno de esos potenciales miembros de iradio. 
Una vez filtrada toda la información obtenida a través de los formularios se estructura este curso intensivo en el que todas las solicitudes tienen cabida y de las que el 95\% terminan integradas en el proyecto. El curso está organizado de manera que los alumnos de nuevo ingreso puedan asimilar, en forma y contenido, la identidad de la radio. Para ello se involucra en todos los procesos a aquellos miembros de temporadas pasadas que continúan dentro del proyecto. Como veremos más adelante, estos actúan como elementos clave de integración e instrucción en todas las fases de la temporada hasta alcanzar el nivel de igualdad y horizontalidad en el trabajo. Si hablamos de la esencia en sí del Training iradio diremos que éste está diseñado para: recepcionar a los interesados en formar parte de la plantilla de la radio universitaria; informarles sobre el proyecto iradio en toda su dimensión -inicios, historia, evolución, estructura, pautas de funcionamiento, formación específica-; formarles de manera general y específica dependiendo del perfil en el que estén interesados -locución, técnica, producción-; introducirles en equipos de trabajo por programas; orientarles en la elaboración, exposición y defensa de proyectos radiofónicos; $\mathrm{y}$, evaluarles y diseñarles un programa de trabajo orientado según sus capacidades y posibilidades.

Así, a su finalización, cada uno de los miembros de iradio debe estar integrado en un equipo que trabajará un proyecto radiofónico. Este proyecto será expuesto y evaluado, tanto por la coordinación como por el resto de integrantes de la plantilla y culminará con su presentación y puesta a disposición de sus compañeros una vez perfilado y listo para empezar a poner en práctica.

- Resultado en parrilla:

Fruto de la exposición y evaluación de cada uno de los proyectos se consensua el número y características de los programas que conformarán la nueva temporada radiofónica. Estos deberán presentarse en formato proyecto en el que desarrollarán, de forma muy definida: el nombre del proyecto, la esencia e identidad del contenido así como sus secciones, participantes y planificación temática para parte de la temporada. Es en este momento en el que la parrilla de iradio empieza a cobrar forma convirtiéndose en un 
mosaico de temas, personas e ideas heterogéneas destinadas a un oyente de las mismas características. Ahora bien, aún no están sonando sino que son sólo proyectos que aún tienen que cobrar forma y sentido una vez que pasen el filtro de la siguiente fase. Once programas arrancaron la temporada 2015/16 pero, como veremos más adelante, no son los únicos que están sonando porque a ellos se han sumado otros. Esto deja ver el carácter abierto de una parrilla que no se cierra a evolucionar y crecer.

Tabla 1: Resumen Fase 1

\begin{tabular}{|l|l|}
\hline Fase 1 & $\begin{array}{l}\text { Puesta en marcha de una nueva temporada coincidiendo con el } \\
\text { inicio del curso académico: Training iradioUCAM }\end{array}$ \\
\hline $\begin{array}{l}\text { Acotación } \\
\text { temporal }\end{array}$ & $\begin{array}{l}\text { Inicio del curso académico, desde septiembre hasta comienzos del mes } \\
\text { de Octubre. }\end{array}$ \\
\hline Objetivos & $-\quad \begin{array}{l}\text { Reconstruir su estructura organizativa interna. } \\
\text { Renovar y construir equipos de trabajo que den continuidad a los } \\
\text { programas existentes. } \\
\text { Plantear, analizar y consensuar nuevas propuestas de programas, } \\
\text { pudiendo proceder éstas de la propia coordinación de la radio así } \\
\text { como de los miembros de la platilla o de los de nueva incorporación. }\end{array}$ \\
\hline Procesos & $\begin{array}{l}\text { Training iradio: inscripción, el desarrollo del propio curso y el cierre } \\
\text { de los proyectos de programas que de él se deriven. }\end{array}$ \\
\hline Resultado \\
en parrilla
\end{tabular} \begin{tabular}{l}
$\begin{array}{l}\text { Presentación de los proyectos que conformaran la parrilla. } \\
\text { Durante la temporada 15/16 se presentan 11 programas. }\end{array}$ \\
\hline
\end{tabular}

Fuente: elaboración propia

Fase 2. Trabajo por proyectos de programas

- Acotación temporal:

Esta fase comprende el periodo que transcurre desde que se cierra definitivamente el proyecto de programa de radio hasta que se emite el tercero de ellos. Este espacio temporal no debe superar la quincena del mes de diciembre ya que, teniendo en cuenta que las emisiones de iradio comienzan a mediados del mes de octubre, consideramos que dos meses y medio es un tiempo razonable para ponerlo en marcha. 
- Objetivos que se pretende alcanzar:

Durante todo este periodo, el trabajo está orientado a diseñar la estructura del programa de radio, delimitar las tareas de cada miembro del grupo, identificar el rol profesional que cada uno va a desempeñar, trabajar la identidad sonora y visual del producto, trabajar las secciones y contenidos del programa así como las formas expresivas y su puesta en escena y, por supuesto, realizar una evaluación continua de los resultados.

- Procesos:

Una vez finalizado el Training, los equipos comienzan a trabajar de forma independiente al resto de la plantilla. Ahora la atención se centra en testar la estructura del programa planteada en el proyecto para darle forma, nutriéndola de contenido, dotándola de identidad sonora y experimentando en su puesta en escena. Este trabajo se lleva a cabo a través de un proceso de interacción directa entre la coordinación de la radio y cada equipo que, semanalmente, prepara un producto cerrado listo para grabar al que vamos a llamar programa piloto. Mientras que durante la preparación del programa el coordinador mantiene cierta distancia ante el trabajo de los alumnos, el día de la grabación, éste supervisa cada uno de los detalles estructura del programa, contenidos, guión, audios, técnica, locución, puesta en escena-. Esto significa una supervisión exhaustiva de todo el trabajo realizado en aras de realizar una crítica lo más constructiva posible. Durante el periodo de grabación de pilotos, el grupo trabaja en la perfección de su producto y, durante este tiempo, se pueden grabar tantos programas como sea necesario. El inconveniente de este proceso es que el grupo puede caer en la desmotivación al ver que su trabajo no termina de fraguarse y es ahí donde hay que hacer un importante trabajo que contrarreste esas sensaciones negativas. Las críticas que se realizan después de cada grabación deben ser objetivas pero asertivas y deben proceder, en gran medida, de los propios miembros del grupo aunque a ellas se sumen las de la coordinación. La composición de los equipos nos recuerda que dentro de cada programa puede existir un miembro conocedor de los procesos y rutinas con las que se trabaja en la radio. Este factor supone una posible aceleración de los procesos de la misma manera que lo es el nivel de conexión que se establezca entre ellos, pero a 
veces no son las personas sino los contenidos los que dificultan la evolución. Sean unas u otras razones, existe la certeza de que, a lo largo de toda esta etapa, es necesaria una supervisión continua pero con grandes dosis de flexibilidad y confianza.

- Resultado en parrilla:

El periodo de tiempo dedicado a la grabación de programas pilotos sirve como proceso de testeo de contenidos y estructuras pero también como probeta en la que experimentar con las relaciones entre los miembros de los equipos. Esa identidad de grupo que se va conformando encuentra su reflejo en el producto trabajado. Esto significa que lo que en proyecto podía ser una estructura o contenido ideal, se diluya o encuentre otras líneas de expresión. De esta forma, la parrilla que se planteaba en la fase inicial de Training puede cambiar por la desaparición de alguno de los programas o por la reorientación de otros. Eso sí, es al cierre de esta fase cuando queda finalmente conformada la parrilla con la que arrancará la temporada.

Tabla 2: Resumen Fase 2

\begin{tabular}{|c|c|}
\hline Fase 2 & Trabajo por proyectos de programas \\
\hline $\begin{array}{l}\text { Acotación } \\
\text { temporal }\end{array}$ & $\begin{array}{l}\text { Desde que se cierra el proyecto de programa de radio hasta que se emite } \\
\text { el tercero de ellos (aproximadamente dos meses y medio, no debe } \\
\text { superarse la primera quincena de diciembre). }\end{array}$ \\
\hline Objetivos & $\begin{array}{l}\text { - } \quad \text { Diseñar la estructura del programa de radio. } \\
\text { - } \quad \text { Delimitar las tareas de cada miembro del grupo. } \\
\text { - } \quad \text { Identificar el rol profesional que cada uno va a desempeñar. } \\
\text { - } \quad \text { Trabajar la identidad sonora y visual del producto. } \\
\text { - } \quad \text { Trabajar secciones y contenidos del programa así como la forma } \\
\quad \text { y la puesta en escena. } \\
\text { - } \quad \text { Realizar una evaluación continua de los resultados. }\end{array}$ \\
\hline Procesos & $\begin{array}{l}\text { Trabajo independiente de cada grupo. } \\
\text { Supervisión periódica de la Coordinación. } \\
\text { Grabación de pilotos. } \\
\text { Crítica constructiva con grandes dosis de flexibilidad y confianza. }\end{array}$ \\
\hline
\end{tabular}




\begin{tabular}{|l|l|}
\hline Resultado & $\begin{array}{l}\text { Quedan terminados los programas que conformaran la parrilla de esa } \\
\text { en parrilla }\end{array}$ \\
& $\begin{array}{l}\text { temporada. A lo largo de la fase existe la posibilidad que algunos } \\
\text { programas desaparezcan o se reconviertan en otros. }\end{array}$ \\
\hline
\end{tabular}

Fuente: elaboración propia

\section{Fase 3. Evolución del producto radiofónico}

- Acotación temporal:

Esta es la fase que alcanza mayor prolongación en el tiempo ya que se suele extender desde finales de noviembre, por ser la fecha máxima de lanzamiento de un programa en la parrilla, hasta junio, fecha en la que, coincidiendo con el cese de la actividad académica, iradioUCAM da por finalizada su temporada.

- Objetivos que se pretende alcanzar:

El objetivo más importante durante esta etapa es que el grupo logre la independencia con respecto a la Coordinación, es decir, que todo su trabajo se afronte desde la perspectiva del aprendizaje colaborativo.

- Procesos:

Una vez que el grupo ha emitido, al menos, tres programas de radio, comienza el verdadero periodo de trabajo autónomo por parte del equipo en relación con la coordinación de iradio. A partir de ese momento, la gran variación que se produce con respecto a la etapa anterior es que el coordinador ya no está presente de manera directa en ninguno de los procesos, abandonando el único en el que todavía mantenía su participación, en el de la grabación del programa. El grupo trabaja de forma independiente y se enfrenta solo a las grabaciones. De esa forma, la orientación durante los momentos previos a la grabación así como durante ésta desaparecen, de la misma manera que lo hace la crítica que se realizaba inmediatamente después. El coordinador hará su crítica una vez que el producto ya se haya emitido lo que supone una importante apuesta por la confianza en las posibilidades del programa, del equipo en conjunto y de las personas que lo componen desde una perspectiva más individual. 
- Resultado en parrilla:

Durante este periodo lo más importante que puede ocurrir en la parrilla es que alguno de los programas desaparezca o que se dé cabida a alguno nuevo. En el caso de la caída de la parrilla, no suele ser habitual pero sí es algo que se contempla cuando se detectan fallos estructurales o funcionales en el equipo que repercuten en el producto final. Lo que sí es habitual es que, una vez superado el primer cuatrimestre del curso, se incluya algún proyecto que quedara pendiente de completar en la segunda fase así como la integración de otros que hayan surgido con posterioridad, casos de spin-off o productos de nueva creación. Otro de los elementos que suele alterar la parrilla es la vuelta de aquellos alumnos que han estado fuera durante un periodo de tiempo disfrutando de una beca académica internacional tipo Erasmus ya que tienen la oportunidad de recuperar su espacio, con lo que sumaría un programa más a la parrilla.

Tabla 3: Resumen Fase 3

\begin{tabular}{|l|l|}
\hline Fase 3 & Evolución del producto radiofónico \\
\hline temporal & $\begin{array}{l}\text { Desde finales de noviembre, por ser la fecha máxima de lanzamiento de } \\
\text { un programa en la parrilla, hasta junio }\end{array}$ \\
\hline Objetivos & $\begin{array}{l}\text { - Lograr la independencia por parte del grupo con respecto al } \\
\text { coordinador, es decir, que todo su trabajo se afronte desde la perspectiva } \\
\text { del aprendizaje colaborativo. }\end{array}$ \\
\hline Procesos & $\begin{array}{l}\text { Trabajo autónomo por parte del equipo en relación con la coordinación de } \\
\text { iradio. El coordinador ya no está presente de en ninguno de los procesos } \\
\text { (abandona el único en que se mantenía, el de grabación del programa). } \\
\text { El coordinador hará su crítica una vez que el producto ya se haya emitido }\end{array}$ \\
\hline Resultado & $\begin{array}{l}\text { Salida o entrada de algún programa } \\
\text { en parrilla habitual que desaparezca un programa, salvo excepciones } \\
\text { Entrada de uno nuevo en el paso de primer a segundo cuatrimestre } \\
\text { Recomposición de equipos por la llegada de algún antiguo miembro } \\
\text { (Erasmus) }\end{array}$ \\
\hline
\end{tabular}

Fuente: elaboración propia 


\section{Fase 4. Evaluación de la temporada a través del análisis de los programas y sus miembros desde una doble perspectiva, global e individual}

- Acotación temporal:

Esta fase tiene lugar en el mes de julio, una vez que ha finalizado la temporada de iradio y ya se han recopilado todos los datos necesarios para llevar a cabo un profundo análisis de los resultados conseguidos.

- Objetivos que se pretende alcanzar:

El objetivo principal de esta etapa es evaluar todo el trabajo desarrollado a lo largo de la temporada, analizando los programas de la parrilla así como a cada miembro de la plantilla, para dejar sentadas las bases sobre las que sustentar la Fase 1 de la siguiente temporada.

- Procesos:

Es el momento de revisar la trayectoria de cada uno de los programas atendiendo a diferentes criterios como son el número de podcast emitidos, las temáticas desarrolladas, el nivel de elaboración de contenidos así como la aceptación de los productos -atendiendo al número de reproducciones así como a su grado de difusión en redes sociales-. Sólo revisando cada una de estas variables se puede emitir una valoración que sirva para decidir sobre la continuidad o no del programa en una próxima temporada. De la misma manera que se analizan los programas también se hace lo mismo con sus integrantes. Estos son sometidos a un minucioso análisis en el que lo más importante es medir el grado de evolución y aprendizaje que ha alcanzado cada uno de ellos en el rol asignado y, por lo tanto, a través de las funciones que ha tenido que desempeñar en él.

A partir de aquí se toman decisiones sobre programas, equipos y personas. Con respecto a los programas se pueden plantear diferentes posibilidades como la eliminación, la reestructuración o el mantenimiento. En cuanto a las personas, las decisiones se deben trasladar directamente a los protagonistas, valorar conjuntamente las situaciones y decidir de forma consensuada sobre su futuro. 
- Resultado en parrilla:

Aunque esta fase ya no tenga una plasmación real en la temporada en curso sí que es fundamental realizar un correcto análisis para la puesta en marcha de la siguiente. De aquí se extraen las conclusiones que orientarán las propuestas que se formulen en la Fase 1 del nuevo proceso que se pondrá en marcha en la siguiente temporada.

Tabla 4: Resumen Fase 4

\begin{tabular}{|c|c|}
\hline Fase 4 & $\begin{array}{l}\text { Evaluación de la temporada a través del análisis de los programas y } \\
\text { sus miembros desde una doble perspectiva, global e individual }\end{array}$ \\
\hline $\begin{array}{l}\text { Acotación } \\
\text { temporal }\end{array}$ & $\begin{array}{l}\text { Julio (finalizada temporada, se recopilan datos necesarios para realizar } \\
\text { profundo análisis sobre resultados conseguidos). }\end{array}$ \\
\hline Objetivos & $\begin{array}{l}\text { - Evaluar todo el trabajo desarrollado a lo largo de la temporada } \\
\text { - Analizar los programas de la parrilla así como a cada miembro de } \\
\text { la plantilla, } \\
\text { - Dejar sentadas las bases sobre las que sustentar la Fase } 1 \text { de la } \\
\text { siguiente temporada. }\end{array}$ \\
\hline Procesos & $\begin{array}{l}\text { Revisar la trayectoria de cada uno de los programas. } \\
\text { Medir el grado de evolución y aprendizaje que ha alcanzado cada alumno } \\
\text { en el rol asignado. } \\
\text { Eliminación, reestructuración o mantenimiento de programas } \\
\text { Permanencia o no de los miembros de iradio }\end{array}$ \\
\hline $\begin{array}{l}\text { Resultado } \\
\text { en parrilla }\end{array}$ & $\begin{array}{l}\text { Evaluación del proyecto y viabilidad para la próxima temporada. } \\
\text { Planteamiento de productos potenciales para la próxima temporada. }\end{array}$ \\
\hline
\end{tabular}

Fuente: elaboración propia

\section{Conclusiones}

El modelo de trabajo que ha ido perfeccionando iradioUCAM durante sus seis años de funcionamiento ha dado como resultado la consolidación de su estructura organizativa así como de una parrilla 
de programas coherente, cada temporada, con los recursos humanos con los que se encuentra. Desde la coordinación de la radio, trabajamos convencidos de que el relevo generacional que anualmente se produce en la plantilla de iradio supone un elemento dinamizador de su parrilla de programación así como de su estructura organizativa. El trabajo que genera es ingente, ya se han expuesto las dificultades a las que se enfrenta cada año la coordinación para reconfigurar su estructura organizativa, la composición de los equipos de cada programa y, por consiguiente, una parrilla que renace cada temporada.

Esto es lo que lleva aparejado el espíritu universitario, la renovación continua y un relevo generacional que no cesa, y no debe hacerlo si pensamos en el objetivo por el que están aquí, salir al mundo profesional y enfrentarse a él con las mayores garantías de éxito.

Después de seis años de trabajo y siete temporadas emitiendo contenidos nos encontramos en disposición de asegurar que iradio ha alcanzado una estructura sólida que permite a los alumnos trabajar en la adquisición continua de competencias profesionales en el ámbito de la comunicación radiofónica, trabajo que le ha acercado al entorno de la radio profesional. A través de la fórmula del trabajo en grupo que hemos ido desgranando en cada una de las cuatro fases expuestas, y que también se han ido perfeccionando con el paso de las diferentes temporadas, podemos hablar de la consolidación de un proceso de formación propio extrapolable a otras radios universitarias cuya estructura organizativa sea parecida a la de iradioUCAM pero que sobre todo tengan un carácter docente y de experimentación profesional como el nuestro. La savia nueva "rejuvenece" el espíritu de la radio universitaria pero no hay que olvidar que ésta no es sólo la que aportan los nuevos miembros. Creemos oportuno reflexionar sobre ese rejuvenecimiento continuo y cómo éste debe llevar aparejado una gran dosis de ilusión y motivación por parte de los gestores de la radio universitaria, tan o más importante que la de los propios alumnos por la complejidad que supone reciclar periódicamente el medio. 


\section{Radio universitaria, estudiantes y calidad: el podcast como instrumento de enseñanza en Radio UMH}

\section{Carmen Ponce López (Universidad Miguel Hernández Elche)}

Resumen: Las radios universitarias se están convirtiendo en el lugar idóneo para que los estudiantes de las instituciones de enseñanza superior puedan formarse en materia de comunicación, al tiempo que comparten sus intereses e inquietudes con el resto de la sociedad a través de un producto radiofónico. La aparición de nuevas tecnologías ha conseguido atraer de nuevo a los jóvenes a la radio, después de un período de tiempo en el que han preferido otros medios de comunicación para informarse o entretenerse. Este acercamiento ha provocado un aumento de su interés por la radio en todos los sentidos y que, además, quieran convertirse en parte activa, en productores de contenidos y espacios radiofónicos. La emisora de la Universidad Miguel Hernández de Elche, Radio UMH, ofrece a sus alumnos la posibilidad de formarse y de colaborar en su programación. Desde la propia institución académica se les presta apoyo docente y asesoramiento profesional para, además, conseguir un producto de calidad. En este sentido, el podcast como medio de difusión está resultando ser un instrumento muy útil para la enseñanza y para iniciarse en el medio radiofónico.

Palabras clave: radio universitaria; Radio UMH; calidad; podcast; estudiantes. 


\section{Introducción}

— L panorama de las radios universitarias ha experimentado un importante cambio en España desde las primeras producciones de Radio UNED en 1974. Tras la puesta en marcha de la emisora de la Universidad de La Laguna en 1987, surgieron algunas otras estaciones. Pero la mayoría de la treintena existente en la actualidad se ha creado a partir del año 2000. Tal es la importancia que han adquirido para las universidades y el auge que han experimentado en los últimos años que, en 2011, se agruparon para constituir formalmente la Asociación de Radios Universitarias de España (ARU), integrada por más de 20 emisoras hoy en día; el objetivo es la colaboración y el intercambio de información y experiencias entre ellas, así como con otras asociaciones similares de Europa y, sobre todo, de América, donde existe una tradición de este tipo de emisoras en la enseñanza superior mucho más larga que en España.

Este nuevo movimiento ha suscitado gran interés por estudiar las radios universitarias. $\mathrm{Y}$ es que, tras la eclosión vivida en la primera década del presente siglo, parece necesario analizar y reflexionar sobre algunos aspectos para poder seguir avanzando. Rodero y Sánchez (2007) aseguran que, a lo largo de su historia, "la radio ha sido el medio de comunicación que ha generado más popularidad y reconocimiento del público". Por ello, estas autoras denuncian que sea el medio sobre el que menos se investiga y reivindican una transformación de este medio abanderada por las universidades desde dos perspectivas: la investigación y la pedagogía. Rodero y Sánchez explican que para llevar a cabo la primera es necesario que docentes e investigadores apuesten por ello y que cuenten con apoyo económico. En cuanto a la segunda perspectiva, la pedagógica, dichas autoras consideran que "la Universidad podría liderar los programas de acercamiento de la radio a la sociedad con actuaciones concretas en la escuela, en sus propias aulas y en los diferentes ámbitos de la esfera pública".

A este respecto Marta y Segura (2011: 346-347) están convencidas de que las radios universitarias son el medio adecuado para acercar la Universidad a la sociedad, trasladándoles a los ciudadanos lo que allí se hace, lo que acontece, los conocimientos y avances científicos que 
se generan pero, además, cómo perciben e interpretan la realidad sus propios estudiantes, principalmente los de titulaciones relacionadas con la Comunicación, ya que estas estaciones radiofónicas pueden ser lugar de formación y experimentación en la materia. De esta manera, cumplirían una doble función pedagógica: la dirigida a los ciudadanos en general y a los propios estudiantes universitarios.

Esta aportación se centra en el papel formador de este tipo de emisoras, prestando especial atención al aprendizaje de los estudiantes de las universidades que se acercan al medio radiofónico por primera vez.

\section{Radio y Universidad: desarrollo de las radios universitarias}

El origen de la radio universitaria a nivel mundial lo encontramos en Estados Unidos. Concretamente fueron las universidades de Detroit, Wisconsin y Pittsburg las primeras que comenzaron a emitir en pruebas en 1917. Pero fue la radio universitaria de los Últimos Santos de Salt Lake City la primera en obtener una licencia oficial en 1921.

Vázquez (2012: 60) asegura que en Estados Unidos fue importante el papel de las universidades en el desarrollo del medio y del sistema americano de radiodifusión comercial: "Los miembros de las facultades de física, de ingeniería eléctrica, y otros campos técnicos poseyeron el conocimiento científico fundamental y la innovación práctica de la ingeniería necesarios para la propagación de la radio".

En América Latina, la primera estación radiofónica de una institución de enseñanza superior se creó en la Universidad de La Plata en 1924 en Argentina (Marta y Martín, 2014: 10-11).

El desarrollo en Europa fue posterior. Fidalgo (2009) apunta que tuvieron que pasar varias décadas para que las universidades del viejo continente apostaran por la puesta en marcha de estaciones radiofónicas. Los primeros países en implantarlas fueron Inglaterra y Francia en los años sesenta del pasado siglo. En Alemania, Portugal y España no se iniciaría el fenómeno hasta finales de los ochenta. Y en Italia, incluso, se desarrollaría a lo largo de los noventa (Martín, 2013: $52)$. 
En el caso español e italiano, se da la circunstancia de que las radios universitarias, hoy por hoy, todavía no están contempladas en sus respectivas legislaciones y por ello no pueden optar a licencias de emisión, cosa que no ocurre en otros países europeos (Aguaded y Martín, 2013: 67).

Esta puede haber sido una de las causas de que el desarrollo del fenómeno de la radiodifusión en las instituciones de enseñanza superior en Europa haya sido más tardío y más lento que en América. Pero, en general, Aguaded y Martín apuntan al monopolio sobre los medios de comunicación en buena parte de los estados europeos hasta finales del siglo XX y a los regímenes dictatoriales de muchos de esos países como principal barrera para lograr cierta liberalización del mercado audiovisual.

El fenómeno de la radiodifusión universitaria en España consta de tres fases bien diferenciadas (Marta y Martín, 2014: 2-3). A partir de 1974 nos encontramos las primeras experiencias y, por tanto, el nacimiento del fenómeno de la mano de la UNED y de Radio San Fernando (actualmente, Radio Campus) de la Universidad de La Laguna. Se produce un desarrollo lento y hasta la última década del siglo no se crean Radio Complutense, Radio Universidad de Salamanca y 98.3 Radio de la Universidad de Navarra.

Con la llegada del siglo XXI, se produce una expansión del fenómeno con la puesta en marcha de una quincena de emisoras en tan solo una década, gracias a las tecnologías y, sobre todo, a internet. En esta fase, también se produce la consolidación de la radiodifusión universitaria como medio de formación del alumnado de las instituciones académicas y de acercamiento a la sociedad que le rodea.

En la actualidad, la situación está marcada por la crisis económica que padece España y que, por supuesto, afecta también a las universidades. En el año 2011 se crea la Asociación de Radios Universitarias (ARU) con el objetivo de defender intereses comunes, intercambiar experiencias y establecer colaboraciones.

Como hemos visto, la implantación de la radio universitaria en España es tardía; tiene que pasar más de medio siglo desde su 
nacimiento en América hasta que llegue a nuestro país. Una vez que se dan las primeras experiencias, el desarrollo es muy lento. No es hasta principios del presente siglo cuando se produce una verdadera eclosión de este tipo de estaciones radiofónicas. Marta y Martín (2014: 12) explican que estuvo condicionada por la creación de Facultades de Comunicación y, por tanto, de titulaciones relacionadas con el medio radiofónico. Pero también por las posibilidades que comenzó a ofrecer internet para producir y emitir contenidos de manera fácil y rápida.

De hecho, Internet ampliará las posibilidades de difusión de información sobre las instituciones académicas y de divulgación del conocimiento científico; dará a las emisoras universitarias una dimensión 'glocal' ${ }^{33}$, ya que su ámbito de influencia no será sólo su entorno más cercano sino que se extenderá a nivel mundial (Marta y Martín, 2014: 13). La primera estación en emitir a través de la red fue la de la Universidad de León en 1997; un año más tarde se sumaría a esta tendencia la de la Universidad de La Laguna y en 2012, la mayoría de las radios universitarias utilizaban internet, bien de manera exclusiva o combinándolo con sus emisiones de FM (Marta y Segura, 2012: 112).

El desarrollo de las tecnologías de la Información ha dado un impulso a estas emisoras y, al mismo tiempo, ha facilitado la colaboración y el intercambio de experiencias entre ellas, haciendo más visible el fenómeno radiofónico universitario (Aguaded y Martín, 2013: 68-69).

El origen del movimiento asociativo en este campo lo encontramos en Iberoamérica; en los años 90 del pasado siglo se crearon redes de emisoras universitarias en Chile, México, Argentina y Colombia. Todas ellas se unieron y en 2009 se creó la Red de Radios Universitarias de Latinoamérica y el Caribe (RRULAC), que aglutina a

\footnotetext{
${ }^{33}$ Este término es un neologismo, desarrollado por el sociólogo Roland Robertson, que proviene de 'global' y 'local' y que hace referencia a la interacción y conjunción de estos dos aspectos en un mismo campo de actuación.
} 
las estaciones de los países mencionados y también de Brasil, Uruguay, Venezuela, Nicaragua y República Dominicana.

Como es lógico, el trabajo en red en Europa es más reciente; funcionan asociaciones en Reino Unido, Francia, Suecia e Italia, donde son más activos en este sentido ya que cuentan con dos plataformas paralelas de representación de medios universitarios. En el caso de España, en 2011 se crea la Asociación de Radios Universitarias de España (ARU), bajo cuyo paraguas se encuentran una veintena de emisoras. Precisamente, la red española y una de las italianas firmaron un convenio de colaboración con la RRULAC en 2012 para el intercambio de experiencias (Martín 2013: 32).

Aguaded y Martín (2013: 69) están convencidos de que "el siguiente paso, y para poder dar respuesta a todas las demandas que llegan desde el contexto iberoamericano, es crecer en red a nivel europeo". En la actualidad, en la Unión Europea existe la Red Europea de Radio (Euranet) en la que colaboran varias emisoras universitarias del continente, entre ellas, algunas españolas.

Casajús (2011: 80) cree que la creación de estas redes de radios universitarias facilita la visibilización del trabajo de estas estaciones, además de que "potencia su valor como fuente de información social, generación de conocimiento y divulgación científica, académica y cultural, a la vez que reivindica la importancia de estas emisoras en el universo de la comunicación".

\section{El caso de Radio UMH}

Radio UMH nace en el año 2007 en la Universidad Miguel Hernández de Elche y se integra en la Asociación de Radios Universitarias de España (ARU). Desde sus inicios emite a través de la FM para toda la provincia de Alicante y a través de internet, utilizando tanto el streaming como el podcasting.

En las últimas temporadas, su parrilla la integran unos 70 programas de temáticas muy diversas y abordan desde la información al entretenimiento, pasando por la divulgación científica. Los espacios están realizados por miembros de la comunidad universitaria, tanto estudiantes como personal docente e investigador y de administración 
y servicios. En total, una media de 300 colaboradores participan desinteresadamente cada temporada para llenar de contenido Radio UMH.

\subsection{Radio UMH: emisora institucional y formativa}

Radio UMH aparece en el panorama de la radiodifusión con varios objetivos. Entre ellos destaca servir de vehículo de información para dar a conocer las actividades de todo tipo desarrolladas en sus cuatro campus a la comunidad universitaria, difundir el conocimiento científico generado en la institución académica y estrechar las relaciones con su entorno. Pero también se plantea "servir de instrumento docente, de prácticas e innovación a los alumnos de las titulaciones de las Licenciaturas de Periodismo e Ingenierías de Telecomunicación, así como de aquellas otras que por sus características precisen de este medio en su actividad docente", según se recoge en el Reglamento de la Radio Universitaria, aprobado por el Consejo de Gobierno de la Universidad Miguel Hernández, en su sesión del 7 de noviembre de 2007.

La emisora de la UMH es gestionada, desde sus inicios, por su Oficina de Comunicación que, a su vez, depende del Vicerrectorado de Relaciones Institucionales. Y aunque siempre se ha velado por el cumplimiento de los objetivos marcados en su origen, en los últimos años se ha apostado por potenciar más todavía la faceta formativa de la radio universitaria. Además de las prácticas realizadas en ella por estudiantes de Periodismo y Telecomunicación, bien a través de diferentes asignaturas de sus respectivos planes de estudio o bien con la realización de programas en Radio UMH, los alumnos de cualquier titulación de la Universidad Miguel Hernández han podido optar a colaborar en su programación con el desarrollo de espacios radiofónicos. Para apoyarlos en esta tarea, desde la Oficina de Comunicación se impulsó un Proyecto de Innovación Docente en el curso 2013-2014 con el objetivo de ofrecerles asesoramiento profesional, apoyo docente y, al mismo tiempo que se contribuye a la formación de los estudiantes en materia radiofónica, conseguir mejorar la calidad de los programas. Esta iniciativa ha tenido continuidad en cursos sucesivos. 


\subsection{La calidad en el proceso de aprendizaje de los estudiantes}

El Proyecto de Innovación Docente desarrollado en la temporada 2013-2014 en Radio UMH corrió a cargo de la autora de este trabajo, periodista y colaboradora de Radio UMH e inmersa en su tesis doctoral sobre la formación de los estudiantes a través de la radio universitaria. Su tarea consistió en realizar un seguimiento de los programas que realizaban los estudiantes y que pasaba por tres fases:

-Supervisión de sus guiones para darles alguna indicación o consejo que les permitiera ponerse ante el micrófono en las mejores condiciones posibles.

-Escucha del espacio radiofónico o acompañamiento durante el mismo.

-Tutoría para comentar el desarrollo del programa, analizar situaciones, problemas o dudas que pudieran haber surgido y realizar propuestas de mejora para futuras ocasiones.

Este proyecto contribuyó a la mejora de la calidad de los programas realizados por estudiantes en Radio UMH, que recibieron asesoramiento en materia de producción, redacción y locución radiofónica, entre otros aspectos, y pudieron llevarlo a la práctica y experimentar una evolución a lo largo de toda la temporada. En general, la iniciativa fue bien valorada por los propios alumnos.

Sin embargo, también puso de manifiesto que había que introducir otros elementos a la hora de conseguir un compromiso más firme por parte de los estudiantes para colaborar en que ese esfuerzo en favor de la calidad iba a ser efectivo. Hasta ese momento, los jóvenes presentaban una propuesta de espacio radiofónico que era estudiada por los responsables de la emisora y, en caso de ser aceptada, se incluía en la programación para ser emitido a través de la FM y simultáneamente en internet por medio de streaming; además se incorporaba después el podcast al blog de Radio UMH, acompañado de una descripción del mismo y una foto de los participantes. Al final de la temporada, los alumnos recibían una compensación académica en forma de créditos de libre configuración, en función de la duración y la periodicidad del programa que habían realizado, pero sin tener en 
cuenta si el estudiante había adquirido unas competencias determinadas o en qué grado se había esforzado por mejorar la calidad del espacio radiofónico en cuestión.

En la temporada 2014-2015 se le da continuidad a esta iniciativa pero se da un paso más con el fin de motivar a los alumnos para que aprovechen el apoyo docente que reciben y mejoren la calidad de los programas en los que colaboran. Para valorar el trabajo y el compromiso de estos estudiantes, la autora de este estudio, profesora de Periodismo Radiofónico, propone la introducción de dos nuevos elementos para la tutorización de esos espacios radiofónicos:

-Unos criterios de valoración de esas prácticas en Radio UMH, estableciendo unos requisitos básicos para obtener los créditos de optativas concedidos por el Observatorio Ocupacional de la universidad (Cuadro 1).

-El podcast como única forma de difusión de los contenidos radiofónicos elaborados por los estudiantes, en su fase inicial y sólo hasta alcanzar unos niveles mínimos de calidad.

Cuadro 1: Criterios valoración prácticas Radio UMH

\begin{tabular}{ll}
\hline CRITERIOS VALORACIÓN PRÁCTICAS RADIO UMH \\
\hline \multirow{3}{*}{ Asistencia } & $\begin{array}{l}\text { A la grabación o emisión del programa radiofónico en el que se } \\
\text { participa. No se obtendrán los créditos con faltas superiores al } \\
\text { 20\% del número total de emisiones del espacio radiofónico. }\end{array}$
\end{tabular}

\begin{tabular}{ll}
\hline & $\begin{array}{l}\text { Se estará presente al menos con } 10 \text { minutos de antelación a la } \\
\text { grabación o emisión del programa radiofónico en el que se }\end{array}$ \\
participa. Y todos los integrantes del programa deberán quedarse al \\
finalizar la grabación o emisión del programa si la persona que les \\
tutoriza así lo considera, para mantener una charla y dar los \\
consejos y propuestas de mejora que estime convenientes.
\end{tabular}

El guion se enviará a la dirección de correo electrónico de Radio $\begin{array}{ll}\text { Guion } & \text { UMH (umhradio@umh.es) y a la profesora Carmen Ponce } \\ \text { (mponce@umh.es) SIEMPRE con } 48 \text { horas de antelación a la } \\ \text { grabación o emisión del programa radiofónico. }\end{array}$

El guion tendrá que estar bien estructurado y contener las especificaciones técnicas necesarias para una óptima realización del programa. 


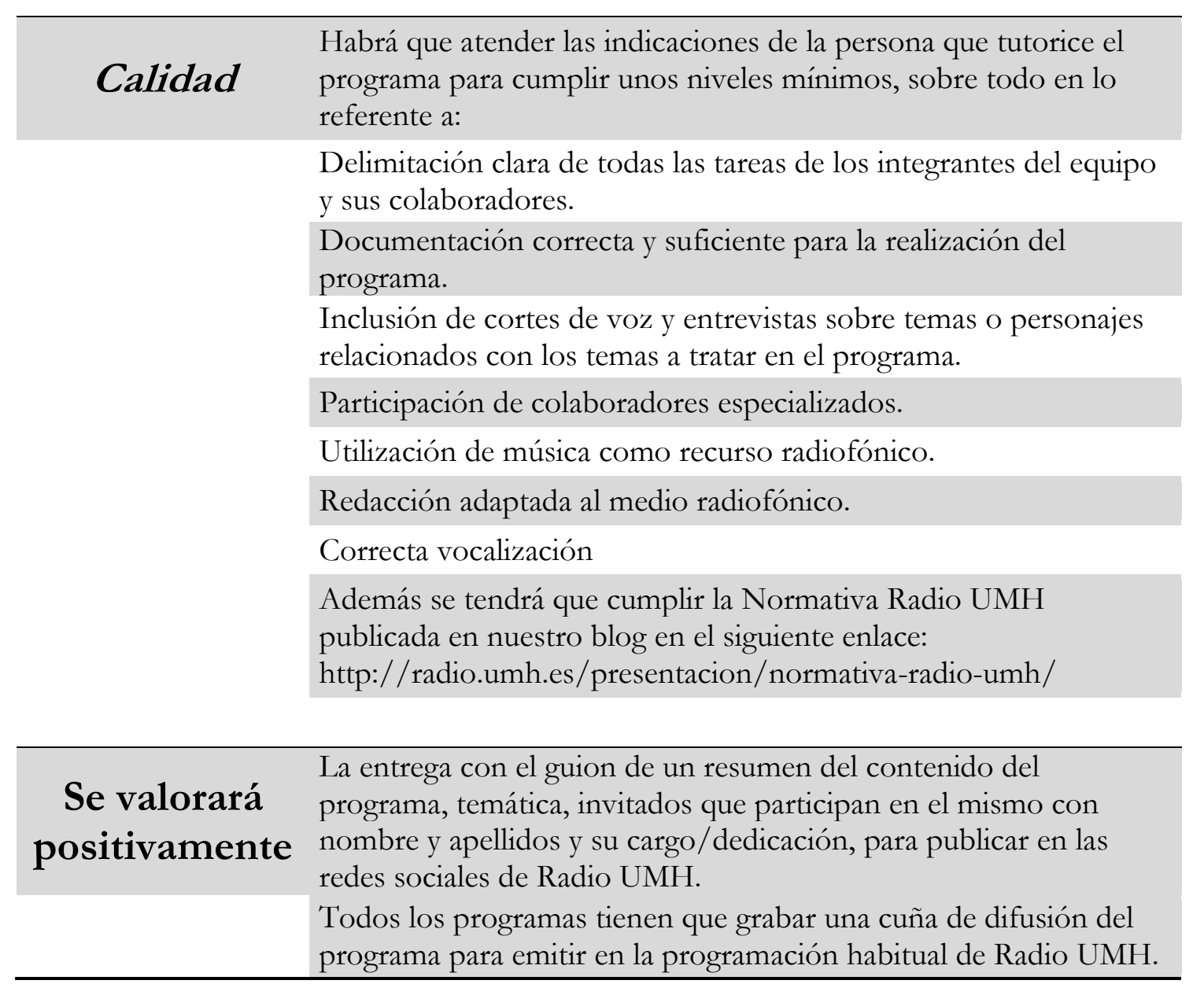

Fuente: elaboración propia

Estos criterios se publicaron en el blog de Radio UMH (radio.umh.es) y se comunicó a los alumnos que debían cumplir dichos requisitos para obtener los créditos correspondientes. De esta manera, ellos sabían desde un primer momento que iban a obtener apoyo docente y asesoramiento profesional pero que adquirían el compromiso de aprovecharlos para mejorar la calidad de sus programas.

Además, los espacios de los alumnos que se iniciaban esa temporada en el medio radiofónico no iban a formar parte de la programación habitual de Radio UMH emitida a través de la FM sino que se iban a grabar en los estudios de la emisora y el podcast se difundiría en su blog. Si los estudiantes cumplían los requisitos básicos, mostraban interés por mejorar y alcanzaban unos niveles mínimos de calidad, sus programas podrían incorporarse a la parrilla de la emisora y ampliar las vías de difusión de sus contenidos a la FM. Si no lo hacían, seguirían trabajando solo en podcast hasta conseguirlo, con el 
compromiso y la motivación como ingredientes fundamentales en ese proceso.

En esa temporada 2014-2015, los estudiantes de la Universidad Miguel Hernández presentaron sus propuestas de programas con temáticas variadas. El número de aquellos que fueron aceptados y cuyos colaboradores no habían tenido contacto con el medio radiofónico fue de trece y sus nombres son: "A capella FM", "A página abierta", "Discos de neptunio", "El primero era mejor", "Gol olímpico", "Héroes anónimos", "Humhor con 'h' intercalada", "Intersecciones", "Juntos por Elche", "La primera hora de Radio UMH" (finalmente cambiaría el nombre por "Pelotazo y a correr"), "Más allá del fútbol", "Mundo peculiar" y "Sintonice con ellas". Se les propuso un programa mensual de 30 minutos, cuyo podcast sería subido al blog de la emisora y con la posibilidad de incorporarse a la programación de Radio UMH para la FM si cumplían las normas y conseguían unos niveles mínimos de calidad.

De los trece iniciales, cuatro de ellos decidieron finalmente que no iban a seguir adelante y de otro sólo llegó a grabarse el primer podcast y no continuó. De esta manera, se quedaron en el camino aquellas propuestas de alumnos que no iban a poder comprometerse con lo establecido y permanecieron aquellos que parecían estar interesados realmente. Finalmente, fueron 8 los proyectos que se acogieron a esta nueva forma de trabajar. De ellos, dos tuvieron una trayectoria irregular, no grabando algunos programas a lo largo del curso y no continuando en el presente por voluntad propia. Del resto, tres consiguieron promocionar esa misma temporada, uno al final de ella y de cara a la siguiente y dos continúan este nuevo curso en podcast con la intención de seguir mejorando. 
Gráfico 1: Evolución alumnos

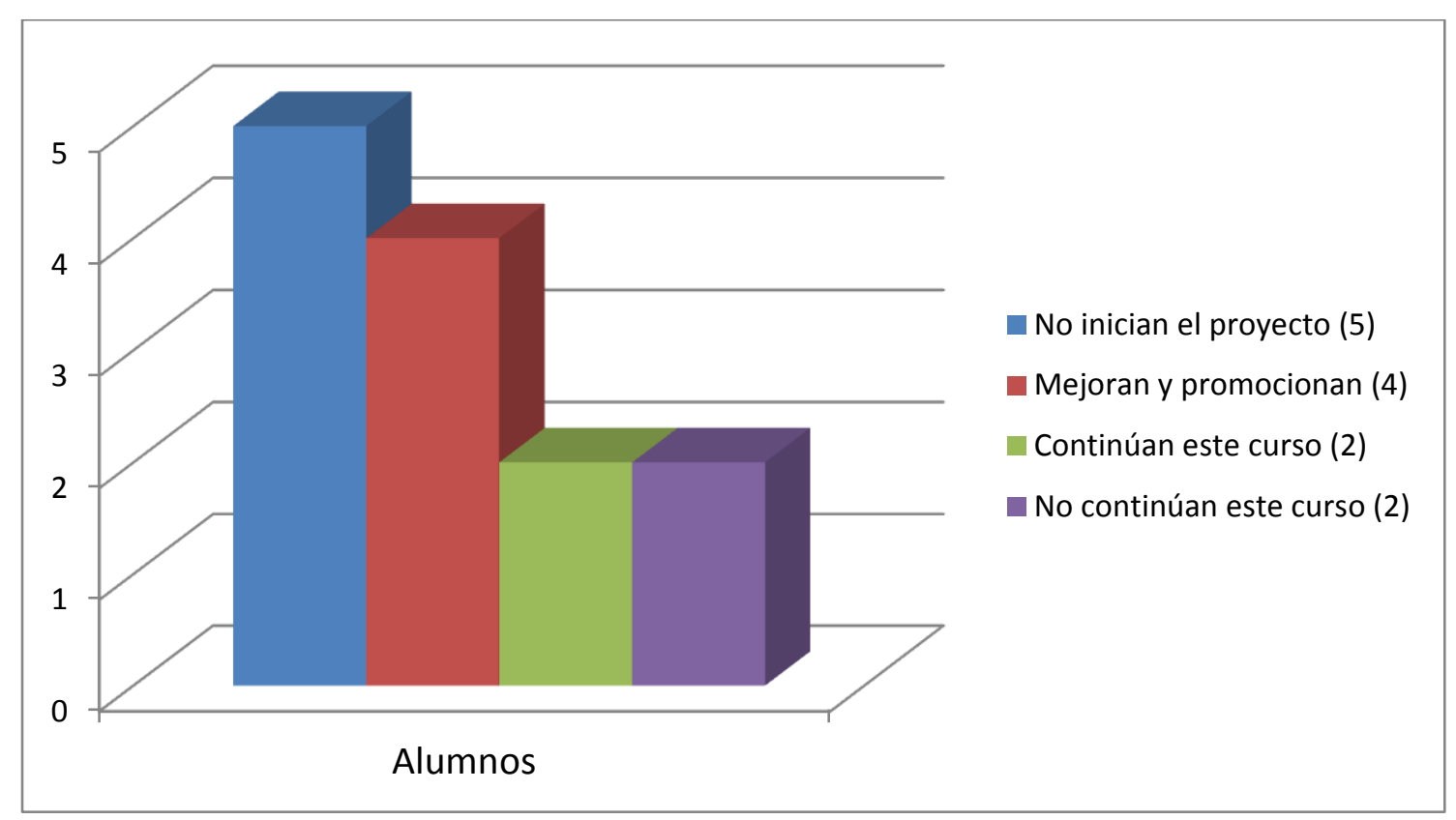

Fuente: elaboración propia

\section{Conclusiones}

El podcast permite trabajar con los alumnos más cómodamente ya que ellos se sienten más tranquilos porque no tienen la presión del directo, sabiendo que la grabación podría llegar a pararse y editarla o postproducirla; así pueden ir aprendiendo poco a poco pero sobre seguro porque están asesorados.

A los responsables de sus programas nos permite garantizar que el producto emitido a través de FM tiene unos mínimos de calidad y ofrecer la radio universitaria a la sociedad que le rodea como un medio más, como una alternativa más en el panorama comunicativo.

De esta manera, también motivamos a los estudiantes para que se esfuercen por mejorar y progresar porque ese trabajo tiene una recompensa; el podcast puede llegar a casi cualquier rincón del planeta a través de internet pero, hoy en día, todavía son muchos los que sintonizan su receptor de radio para escucharla en el coche, en casa...por lo que acceder a la parrilla de FM también les resulta atractivo. 
Los resultados de esta experiencia docente han sido satisfactorios ya que ha permitido que centremos nuestros esfuerzos en aquellos alumnos que realmente están interesados en el medio radiofónico y en elaborar contenidos de calidad y, por tanto, aprovechan la formación que se les ofrece a través de la radio universitaria. Entendemos que este método de trabajo ha sido bien valorado y aceptado también por los estudiantes, incluso por los que no promocionaron el pasado curso, ya que han optado por continuar con nosotros; ello demuestra que siguen teniendo interés por mejorar a lo largo de éste y que no les importa hacerlo a través del podcast.

En este curso 2015-2016 y con esta metodología claramente establecida, se han recibido nuevas propuestas de programas de estudiantes. En total, se han vuelto a aceptar trece y, de momento, todos han decidido formar parte del proyecto y grabar sus primeros programas.

Por tanto, podemos concluir que el podcast facilita la tutorización y el control de la calidad de estos espacios radiofónicos, al tiempo que sirve de estímulo a los estudiantes para mejorar y aspirar al resto de modalidades de emisión.

* Esta contribución forma parte de la investigación que está realizando la autora para su tesis doctoral sobre la formación de los estudiantes de Ciencias de la Información en la radio universitaria. 



\section{Análisis de las radios universitarias en Ecuador}

Juan Manuel Aguiló (Pte. Red Radios Universitarias del Ecuador)

Resumen: En este artículo, más allá de las definiciones radiofónicas, analizaremos la esencia de las radios universitarias a través de las categorías que permite la nueva Ley Orgánica de la Comunicación. Todo esto desde la perspectiva de los medios universitarios, mostrándolos como una parte fundamental de la extensión universitaria y muy acorde a la definición recogida en la Ley Orgánica de Educación Superior de que las universidades son comunidades académicas. Desde el primer encuentro de Radios Universitarias del Ecuador realizado en la Universidad de los Hemisferios el 28 y 29 de Octubre del año 2013, se han tratado de categorizar a las radios universitarias. ¿Son públicas, son privadas o son comunitarias? Pero más allá de los encasillamientos todo pasa por la voluntad política de las universidades de abrirse a conquistar el espacio mediático.

Palabras clave: Radios Universitarias; medios comunitarios; medios públicos; radios comunitarias; Universidad;infograf Comunicación.

\section{Inicios de la radio en Ecuador}

T A radio como tal, hace su entrada en el país de la mano de Don $\perp$ Francisco Andrade Arbaiza, quien con un transmisor construido por él mismo en el año 1926, instala en el barrio Las Peñas de Guayaquil, la emisora radio París, HC2FA. Radio París también se 
escuchaba fuera del Ecuador ya que al difundir en onda corta su señal llegaba a otros países (Yaguana y Delgado, 2014).

De igual manera en Quito, pero en el año 1929, surge una radio experimental, Radiodifusora Nacional HC1DR, la cual era promovida por el estado. Esta emisora, construida por Cesar A. Semanate y Victoriano Salvador junto a otros colaboradores, solo tenía cobertura en la ciudad y su programación, que se emitía solo en las noches, incluía música nacional, algunos eventos deportivos y de vez en cuando una que otra noticia. Radiodifusora Nacional fue cerrada en 1935 por disposición gubernamental y solamente abría su señal cuando se celebraba algún evento especial.

Pero la historia plantea que el primer aparato radial estuvo en Riobamba instalado por Carlos Cordovéz, un Ingeniero Electrónico graduado en Yale, quien con un transmisor de $100 \mathrm{w}$ inicia transmisiones para radioaficionados. Pero no es sino hasta el jueves 13 de junio de 1929 que Radio El Prado de la ciudad de Riobamba inicia oficialmente sus transmisiones radiales. Debido a la ubicación de Riobamba como punto estratégico entre Guayaquil y Quito producto del ferrocarril, esta ciudad vivió una época de esplendor por lo que no es casual que se considere a Radio El Prado de la ciudad de Riobamba como la primera Radiodifusora del Ecuador. También contribuyó a su popularidad el que Radio El Prado fuera la primera empresa de grabación de discos de aluminio y que por sus estudios pasaran grandes artistas nacionales. Además en muchas ocasiones servía de enlace con radios internacionales cuando ocurría un hecho de gran relevancia.

En esta época, la radiodifusión nacional toma gran auge con el surgimiento de varias emisoras, fundamentalmente luego de 1928, año en el que se decreta el Reglamento de Instalaciones Radioeléctricas privadas bajo el gobierno de Isidro Ayora. Entre estas radios están Ecuadoradio en Guayas (1930), HCJB La Voz de los Andes en Pichincha (1931) y La voz del Tomebamba en Azuay (1934), las cuales marcaron el devenir de la Radiodifusión Nacional. 


\section{Las Radios Universitarias}

Desde los comienzos de la radio, las universidades de Estados Unidos, fundamentalmente las facultades de física, ingeniería eléctrica y otros campos técnicos, aportaron el conocimiento científico y la innovación práctica para el desarrollo de la radiofonía. Se comienza a experimentar con radios universitarias desde el año 1917. Universidades de Pittsburgh, Detroit y Wisconsin toman la delantera, aunque es la Universidad de Los Santos de Los Últimos Días en Salt Lake City quien obtiene su licencia de manera oficial en 1921. Estas universidades influyeron de manera notable en el desarrollo del medio y en la formación del sistema americano de radiodifusión comercial y ya en 1936 se habían concedido alrededor de 202 licencias de transmisión a instituciones universitarias, siendo a finales del siglo XX un número superior a las 1.200 emisoras universitarias (Aguaded y Martín-Pena, 2013).

En Latinoamérica, producto de la reforma de Córdoba (República de Argentina), surge un detonante que originó de forma indirecta la aparición del fenómeno de las radios universitarias en ese país y por ende en el resto del continente (Aguaded y Martín-Pena, 2013). En el año de 1918, al surgir esta reforma, la República de Argentina abogaba por un cambio de rumbo en la educación superior y la extensión universitaria, lo que hizo que el 5 de abril del año 1924 surja la primera radio Universitaria de Latinoamérica en la Universidad de la Plata. Esta radio tenía como propósito la divulgación científica como elemento de extensión universitaria, desarrollando una gran difusión cultural para vincular a la universidad con el medio social en el que actúa. Por este motivo esta fecha fue esogida para celebrar el día de la radio universitaria a nivel latinoamericano. Colombia fue el siguiente país en desarrollar la radio universitaria en Latinoamérica con el surgimiento de la emisora cultural en la Universidad de Antioquia en 1933 y posteriormente Chile con la radio de la Universidad Técnica Federico Santa María (Radio UTFSM) que nace el 7 de abril de 1937 gracias a la inquietud científica de sus investigadores. Casi a la par de Chile, las instituciones de educación superior de México se incorporan a la radiodifusión universitaria, siendo la radio de la Universidad Autónoma de México en sus funciones de transmitir información, divulgar conocimiento y 
promover la cultura quien inicia transmisiones el 14 de Junio de 1937 (Aguaded y Martín-Pena, 2013).

Según datos de la RRULAC (Red de Radios Universitarias de Latinoamérica y el Caribe) la cantidad de radios universitarias en nuestro entorno suman, entre países miembros y asociados, un total de 212 emisoras que corresponden a 147 universidades (www.sites.google.com/a/rrulac.org/rrulac, 2014) aunque MartínPena plantea que en América Latina son más de 300 las radios universitarias de habla hispana y si incluimos Brasil, el número asciende a 350, ocupando alrededor de un 10\% del espectro radioeléctrico (Aguaded y Martín-Pena, 2013)

\subsection{Radio universitaria en Ecuador}

La radio universitaria en el Ecuador tuvo que esperar más de 50 años para dar su primer paso. El 17 de marzo del 2011 la Universidad Central del Ecuador sale al aire con sus emisiones de prueba, luego de haber presentado su proyecto de radio universitaria en el año de 1973. $\mathrm{Y}$ a pesar de que la Universidad Central del Ecuador pierde su frecuencia por manejos administrativos en el año 2013, emisoras como las radios de la Universidad Católica Santiago de Guayaquil, de la Universidad Técnica del Norte de Ibarra, de la Universidad San Gregorio en Portoviejo, de la Universidad de Bolívar en Guaranda y La Universidad Politécnica Salesiana, han tomado la posta y representan dignamente a la universidad ecuatoriana en el espectro Radioeléctrico.

La radio universitaria en Ecuador comienza a nacer en la década de los años 50. Las escuelas de comunicación social y/o facultades de periodismo incluían como parte de sus laboratorios de prácticas para los alumnos los centros de producción. Por tanto, la raíz de la radio universitaria en Ecuador, está en los mismos laboratorios de producción sonora de cada una de las universidades. Es allí donde surge el embrión de lo que hoy conocemos como radio universitaria.

En esta primera etapa los laboratorios de prácticas de radio se constituyeron en un lugar propio para que los estudiantes, principalmente de comunicación, se enfrentaran a una estructura 
tecnológica muy similar a la que en su vida profesional iban a encontrar. En ellos podían realizar ensayos y experimentos que complementaban la formación teórica en radio. Además, al laboratorio de radio, se le asignó la tarea de ser el lugar donde se producía la comunicación institucional de la universidad y los mismos estudiantes junto a algunos docentes se encargaban de elaborar los programas que posteriormente eran enviados a los medios radiales. Esta práctica no sólo reforzaba los conocimientos adquiridos en el aula, sino que hacía que los estudiantes se pudieran escuchar al aire.

Algunas universidades se aventuraron a emitir una señal que cubría el campus, parecido a un circuito cerrado, para lo cual fue necesario colocar altavoces en sitios estratégicos como la cafetería, los patios, descansos y otros lugares de confluencia.

Con esta práctica la radio universitaria comienza a construir un sinnúmero de vínculos con la comunidad universitaria, siendo el medio que abre la puerta para que esa comunidad se involucre voluntariamente, creando individuos más reflexivos, responsables, críticos, comunicativos y activos socialmente. Una vez establecida la práctica de difusión en el campus universitario, algunas universidades reclamaron su espacio dentro del espectro radioeléctrico, consiguiendo una frecuencia, lo cual les dio mayor amplitud, pero a su vez les implicó un mayor trabajo.

Inexplicablemente esta nueva posición dificultó el crecimiento vertiginoso que hasta ese momento tuvieron. Pareciera que la responsabilidad adquirida trastocó el empuje y la vigorosidad que años atrás mostraron. Algunas emisoras incluso perdieron su misión y visión, pasando a ser competencia de los medios privados, haciendo una calcomanía de sus programas y de la forma como sus locutores los conducen, y otras se perdieron en el limbo de las radios comerciales.

Muchas universidades obtuvieron su anhelada frecuencia en antena por diferentes vías. Según las estadísticas de la Secretaría de Telecomunicaciones, hasta febrero del 2015 solamente existen 4 radios universitarias en amplitud modulada (AM) y 6 en frecuencia modulada (FM) distribuidas en la sierra y costa ecuatoriana. 
- Emisoras en AM:

- Universidad Católica de Cuenca.

- Instituto Técnico Superior Carlos Cisneros.

- Radio Excélsior.

- Universidad Central del Ecuador.

- Emisoras en FM:

- Universidad Católica de Cuenca.

- Universidad Estatal de Bolívar.

- Universidad Técnica del Norte.

- Universidad Nacional de Loja.

- Universidad Laica Eloy Alfaro.

- Universidad Particular San Gregorio de Portoviejo.

$\mathrm{Al}$ momento de esta investigación, de las 11 radios universitarias en frecuencia abierta en el país, solamente 8 mantenían programación al aire. La Universidad Central del Ecuador en Quito (1280 Khz AM Pichincha) y la Universidad Laica Eloy Alfaro de Manabí (101,7 Mhz FM Manabî) no presentan una programación en sus frecuencias respectivas. Las universidades que no obtuvieron o no solicitaron frecuencia, que fueron la mayoría, encontraron en Internet un espacio libre de restricciones y de condicionamientos burocráticos para la emisión de contenidos.

Lo que hizo la radio universitaria en Internet fue retomar sus objetivos principales. Por un lado, contribuir en la práctica de los futuros profesionales de la carrera de comunicación social y periodismo, y por otro, difundir el pensamiento crítico y los análisis académicos de los temas de interés colectivo.

En el ejercicio de estas actividades se fue descubriendo que la radio, al ser parte de una universidad, es sinónimo de universalidad y de diversidad y no puede llegar a ser otro medio más de comunicación. Esta debe convertirse en un referente, no sólo en su estructura de medio como tal, sino en el modelo a mirar por el resto de medios ya que es un medio único, diferente e interesante, donde se conjugan las funciones de educar, entretener, informar, influir y universalizar (Yaguana y Aguiló, 2014). 


\section{La Red de Radios Universitarias de Ecuador}

El 28 y 29 de octubre del año 2013, en la Universidad de Los Hemisferios, Quito, se realiza el primer encuentro de radios universitarias en el Ecuador, congregando a seis universidades del país. La Universidad Estatal de Cuenca, La Facultad Latinoamericana de Ciencias Sociales, La Universidad Tecnológica Equinoccial, La Universidad Central del Ecuador, La Universidad San Francisco de Quito y como anfitriona, La Universidad de Los Hemisferios. En este encuentro se empezó a debatir sobre la radio universitaria ecuatoriana y se perfiló la futura creación de la Red de Radios Universitarias del Ecuador. También se evidenció la necesidad de que las radios universitarias deben trabajar en red para poder insertarse dentro del gran universo mediático y se acordó mediante carta de intención firmada por las universidades participantes que: "tendrá como propósito ser un espacio académico comunitario, creado para estrechar vínculos entre las instituciones educativas universitarias del país que actúan en el campo de la comunicación radiofónica" y cuyo objetivo central "será contribuir al acercamiento, desarrollo y fortalecimiento de las relaciones académicas y comunicacionales entre las instituciones integrantes de la red" (Red Radios Universitarias del Ecuador, 2013).

Un segundo encuentro de las radios universitarias ecuatorianas se celebra en la Universidad de Cuenca el 9 y 10 de enero del 2014, marcando una fecha histórica ya que con el auspicio de 12 universidades se crea oficialmente la Red de Radios Universitarias del Ecuador en cuya carta constitutiva plantea "la creación de la Red de Radios Universitarias del Ecuador" y se designa una comisión directiva con las funciones específicas de "visibilizar la red ante organismos de control y de estado, Vincular a la RRUE con la Red de Radios Universitarias de Latinoamérica y el Caribe, fortalecer las radios en las instituciones y motivar su creación" entre otras (Red Radios Universitarias del Ecuador, 2013).

La RRUE surge cuando la universidad y las comunicaciones en el Ecuador, pasan por momentos importantes con la aprobación de las leyes orgánicas de Educación Superior (LOES) y de comunicación (LOC). Es por eso que asume un sentido histórico que la ha llevado 
en su corto año de vida a contar con más de 18 universidades en su seno.

\section{Reflexiones sobre el papel de las radios universitarias}

En el artículo "Radio Universitaria desde una perspectiva docente" escrito por Jorge Sariol, se plantea el uso que damos a los medios de comunicación dentro de los procesos de enseñanza y aprendizaje de nuestras universidades: “(...) rara vez, el sistema de enseñanza usa los "medios" como instrumentos para conseguir que los estudiantes, sean los protagonistas de la construcción del conocimiento" (Sariol, 2007).

Vemos como en las universidades han proliferado los medios radiofónicos, el Internet lo ha hecho posible, pero han sido muy pocos los centros de enseñanza que han asumido la construcción del conocimiento a través de los medios audiovisuales con propuestas apegadas a su propia determinación.

Muchas de las Radios presentes en las universidades tienden a hacerse más comerciales dejando de lado el motivo por el cual nacieron "apoyar la cultura, la orientación, la enseñanza y la difusión de la investigación científica y humanística; promover la cultura y la historia universal, sobre todo la música de alto valor estético y folklórico" (Vilar et al., 1988). Lamentablemente este contenido, aleja a las audiencias hacia las cuales va dirigida la radio universitaria ya que, esta misma vorágine tecnológica ha desvirtuado el concepto original de la Radio Universitaria.

El perfil de las radios universitarias siempre ha sido motivo de discusión y análisis entre sus gestores, sobre todo porque a más de ser una radio que funciona con el respaldo de la institución universitaria a la que pertenece, debe insertarse en todo un universo mediático y servir a una comunidad mucho más amplia. $\mathrm{O}$ sea, poseen una clara función de divulgación del conocimiento generado en las instituciones de educación superior (IES) con un fuerte compromiso con la educación y el aprendizaje, y, por otra parte una función de servicio y compromiso social (Aguaded y Contreras Pulido, 2011).

Más allá de las diferencias existentes entre los modos de gestión de las radios universitarias, pasando por sus propias legislaciones, modos de 
trabajo, contenidos, etc. podemos encontrar muchos aspectos que nos permiten ir perfilando una línea común de trabajo.

Si en algo estamos de acuerdo es que es un medio alternativo, una opción diferente ante los medios comerciales y públicos con sus estructuras y programación un tanto viciadas. O como dijera Vázquez (2012), "su función primordial (de las radios universitarias) es contribuir a la educación informal y al desarrollo social. La mayoría es financiada por su propia institución o por asociaciones culturales. Los contenidos son producidos con la participación de la comunidad universitaria, lo que le aporta una riqueza particular por la divulgación del conocimiento científico. La mayoría de estas emisoras buscan favorecer la imagen de su institución".

Para el Dr. Daniel López, Decano de la Facultad de Comunicación de la Universidad de Los Hemisferios, quien hace radio universitaria “...debe repensar los modelos... Y debe ser gestor de la comunicación para el desarrollo donde los promotores de la emisora gestionan las iniciativas ante las restantes facultades...y se convierten en mediadores entre estas y la comunidad. La emisora debe ser un proyecto corporativo de la universidad donde no solamente existan las disposiciones presupuestarias sino que exista la voluntad política para que la emisora crezca en relación con los contenidos internos que se producen".

Según Efraín Luna, Director de la Radio de la Universidad Católica Santiago de Guayaquil, la radio es un pilar fundamental de los procesos de vinculación con la comunidad y la universidad debe estar al servicio de la comunidad a través de la radio. Así mismo, Eric Samson, Coordinador de la carrera de Periodismo Multimedios de la Universidad San Francisco de Quito, plantea que el ideal de radio universitaria debe ser una radio que impacte tanto dentro como fuera de la universidad y debe estar sometida a las mismas reglas que los medios tradicionales.

La Internet es la plataforma ideal para radio COCOA, dice Bernarda Troccoli, Directora de Radio COCOA de la Universidad San Francisco de Quito, debido a la línea editorial que manejan donde convergen diferentes medios. La música es el eje y el espíritu 
independiente es la filosofía. Gabriela Robles, community manager, no se ha guiado por lo comercial por lo que no se sienten tentados por una frecuencia.

El maestro José Ignacio López Vigil, coordinador de Radialistas Apasionadas y Apasionados, plantea que: "las radios universitarias sean públicas o privadas, deben ser comunitarias, porque si hay algo que corresponde a la definición de una comunidad es una comunidad universitaria. Supongamos una universidad pública, tendría que hacer un proyecto comunitario al servicio de la comunidad que la sustenta. Un universidad privada, en el supuesto de la asignación de una frecuencia privada, su proyecto comunicacional debe ser comunitario al servicio de la comunidad que atiende". Por su parte Hernán Reyes asesor del Consejo de Regulación de la Información y la Comunicación (CORDICOM): el futuro de la radio universitaria a corto plazo no está en Internet, se puede complementar con el Internet y es indispensable pelear por una señal abierta.

Las radios universitarias representan a la institución que los acoge poniendo a disposición de profesores, alumnos, investigadores y personal administrativo sus espacios. En contraparte, la universidad tiene en su emisora el medio idóneo para difundir a la sociedad sus actividades, los proyectos de investigación y la actividad científica y académica. Todo esto inserto dentro de los procesos de experimentación que se construyen en estos centros de producción para apoyar en la formación de los estudiantes de las carreras de periodismo y comunicación social.

Otra de las características que se potencia con la radio universitaria es el diálogo colectivo, que se lo aplica al momento de diseñar los programas. Es ahí donde se ponen en juego el criterio y punto de vista de los actores de la comunidad universitaria, desde alumnos hasta autoridades.

Esta práctica se convierte en un nexo de cercanía del medio con la audiencia. Es la diversidad de criterios y pensamientos los que rigen a la radio universitaria y la empatan con la diversidad de públicos a la cual se dirige. Esa cualidad le da una ventaja única sobre el resto de 
medios, convirtiéndola en una verdadera radio ciudadana (Yaguana y Aguiló, 2014).

La diversidad de pensamiento también le agrega otra ventaja que es el conocimiento del entorno. Según Rocha (2008) "la institución educativa tiene una ventaja sobre cualquiera de esas otras ofertas y es que está empotrada en un entorno social específico, vive y es de ese entorno".

Se entiende entonces que las radios universitarias poseen un rol social importante y que "...no constituyen un apéndice académico de la institución educativa ni un complemento para asistir alguna de sus funciones, sino que se trata de una entidad integrada como factor necesario para el desarrollo de las funciones esenciales que se asignan a la universidad..." (Dido, 2008).

\section{Conclusiones}

En muchas universidades se ha planteado la interrogante de la necesidad de una radio universitaria. Esto surge por el mismo hecho de asumir que actualmente existe una exorbitante cantidad de emisoras de radio, tanto de antena como en línea y analizan si es prudente que cada universidad disponga de una emisora. Se puede producir contenidos desde las mismas universidades para alimentar las emisoras ya existentes, tanto las públicas, privadas o comunitarias, aprovechando los espacios que son poco utilizados, como los horarios de la madrugada y fines de semana (Yaguana y Aguiló, 2014)

De todos modos, antes de emprender cualquier acción, es necesario planificar la producción de contenidos en base a la política comunicacional de cada universidad. Pero entendiendo que las radios universitarias tienen un gran futuro, y si bien su incidencia no ha sido sentida, en corto tiempo se revestirá de mucha importancia, ya que implica un modelo nuevo y variado, apto para ejercer algunos de los derechos ciudadanos que las emisoras públicas y privadas dejaron de lado.

El trabajo organizado a través de redes para potenciar su actividad, da como resultado el cumplimiento de muchos de los postulados que la radio de antaño se propuso, como por ejemplo, ser la voz de las 
personas que no tienen espacios en otros medios que basan sus contenidos en intereses comerciales o políticos.

Hay que tener presente que cualquier medio de comunicación que lleve el identificativo de universitario se deriva de la academia. Por tanto, es lógico pensar que su orientación debe estar cimentada en un objetivo totalmente formativo en el más alto nivel; pero, al mismo tiempo hay que considerar que su espacio de difusión ya no se circunscribe únicamente a un aula, una facultad o un campus universitario, sino a toda una colectividad, en la cual encontramos una gama infinita de personas con diferentes niveles de formación, edades, gustos, preferencias e inclinaciones.

En un primer momento se creyó que la radio generalista podría ser la solución. Es decir que las universidades dispongan de emisoras que cautiven los diferentes tipos de públicos en diferentes horarios; mas la experiencia y las tendencias actuales de la radiodifusión nos encaminan a otros tipos de alternativas como puede ser: las redes de radios universitarias o bien las radios universitarias especializadas en un cierto ámbito o temática.

Sea cual sea la alternativa, lo imprescindible es que la radio universitaria no solo se dirija a la comunidad universitaria, sino que sea su objetivo dar respuestas a la sociedad. Entonces, nuestro pacto social se debe centrar en tres bases:

Primero, en el compromiso de difundir el conocimiento científico generado y a realizar una explicación profunda de nuestra actualidad. Esto unido a la calidad de la producción radiofónica con el objetivo de atraer a universitarios y público en general. Si la radio universitaria se dedicase a hacer lo que hacen otros medios, se generaría una desconexión entre investigación universitaria y realidad social.

La segunda base es el trabajo práctico relacionado con la formación de comunicadores. Esto, junto a la enseñanza a través de la radio, constituye un vínculo con la comunidad, reforzando los procesos de extensión universitaria. Hacer docencia en la radio es sembrar oyentes a largo plazo (Aguaded y Contreras Pulido, 2011) 
La tercera base pasa por: la promoción cultural a través de la posibilidad de difusión del talento y espíritu universitario como punto de encuentro entre los problemas de la sociedad y las soluciones dadas por la universidad; también por su función de ser altavoz de la cultura, ofreciendo espacios de promoción a artistas que no encuentran un lugar en la gran industria.

A estas bases se suma que, parte de ser universitario es compartir conocimiento y experiencia y discutirlo con sus pares. Por ello, las radios universitarias deben enlazarse para crear redes que favorecen el intercambio y la discusión académica sobre determinadas situaciones, creando grupos de estudio y trabajo sobre los problemas de las realidades universitarias.

Conocimiento científico generado con calidad, participación docente y difusión cultural son las razones de ser de la radio universitaria y es el camino para buscar nuestro espacio en la jungla mediática de nuestra sociedad.

Mayor libertad en la elección de contenidos y mayor agilidad, caracterizan a las radios universitarias frente a otros medios de comunicación. Si empleamos esta libertad, alineándola con: la calidad, la vocación universitaria y el compromiso con la audiencia, nuestro futuro sería prometedor. Si aprovechamos las características que nos hacen distintos, si nos olvidamos de las visiones a corto plazo y establecemos un compromiso con nuestras instituciones, podremos establecer nuestra figura como algo imprescindible, tal como cualquier otro servicio de la Universidad (Aguaded y Contreras Pulido, 2011).

Fernández Chapou plantea que: "Es determinante que la radio universitaria, debido a que está inserta dentro de una institución de servicio público, generadora de conocimiento y con la responsabilidad de transferencia de este a la sociedad, sea un medio de carácter público, una extensión de dichos principios. Por tanto, debe ser protagonista en la comunicación social y particularmente en una comunicación alejada de objetivos mercantiles y desvinculada de intereses políticos. Sus fines no deben ser otros que ser solidarios y de verdadero servicio público. Para ello se requiere de un compromiso 
férreo, ya que este tipo de emisoras representan instancias que pretenden impulsar las causas fundamentales de la ciencia, la cultura, el análisis crítico y de responsabilidad de una sociedad. Por ello, el rol humanístico jugado por los medios de comunicación universitarios cobra ahora una importancia relevante". 


\section{El diseño gráfico e infografía para las radios universitarias en internet}

Santiago Martínez Arias (Universidad Complutense de Madrid) orcid.org/0000-0002-6839-2130

Resumen: Dentro del diseño web es importante contemplar qué papel juegan los elementos gráficos desarrollados a la hora de la ordenación y generación de contenidos dentro de las radios universitarias. El diseño web es una de las disciplinas aparentemente menos tratadas en los planes de estudios de Comunicación. El ámbito de las radios, particularmente, necesita del concurso de Internet para generar visibilidad y efectividad en la comunicación. La construcción y generación de proyectos radiofónicos desde el punto de vista del medio audiovisual requiere la elaboración de un proyecto gráfico en Internet.

Los proyectos comienzan con la creación de una emisora de radio universitaria tradicional, a continuación la creación de una radio en Internet, para acabar concluyendo el trabajo con la consecución de un proyecto global en el que el diseño de la web tiene un valor fundamental. En las actuales programaciones docentes del terreno de la comunicación, cada una de estas cuestiones está planteada de forma individual o aislada, por ello nuestra propuesta se basa en partir, a la inversa, de lo particular para llegar a lo general con un proyecto global de medio de comunicación con amplia atención al diseño web.

Palabras clave: Radio en internet; diseño web; cibermedios universitarios; infografía; retórica gráfica. 


\section{Introducción}

$\mathrm{U}$ NA radio universitaria en la actualidad es en muchas ocasiones por definición una radio a través de Internet. La forma de abaratar el proyecto de una radio, o de un medio de comunicación en general, es la distribución del mismo a través de la red. Referencia obligada son, por tanto, todos los estudios referidos a la radio en Internet: Ortiz 2014, McMillan 2009, Meseguer 2009, Martínez \& Martínez 2013, entre otros. Por esta razón, la de la traslación a Internet de una emisora de radio, necesitamos de un soporte tecnológico para la adecuación de nuestro proyecto.

Se trata de estudiar aquí una parte importante, si no vital, del trabajo dentro de este tipo de medios de comunicación: el diseño de las plataformas web. La cuestión no es baladí, ya que así como la puesta en marcha en Internet de un proyecto de comunicación escrito es relativamente sencilla, lo que respecta a una radio que pretenda ofrecer programas en directo necesita sin duda de una mayor inversión y de una especialización tecnológica que no está al alcance de cualquiera.

Para comenzar las emisiones en directo de una radio, aunque sea en una franja horaria determinada o con un número limitado de horas de programación, como hacen muchas de las radios universitarias españolas, se precisará de un aparato tecnológico muy específico. Este objeto de estudio sin embargo excede los resultados de esta investigación y no nos vamos a ocupar de ello aquí, de forma que nos centramos en el reflejo gráfico de ese proyecto en Internet. Tan importante como todo ello es la elaboración de un proyecto gráfico para la red que sirva de espacio de atracción para la posible audiencia. El objeto principal de esta estrategia consiste en ofrecer un espacio web que lleve directamente al receptor a nuestra programación radiofónica de una forma sencilla y aplicando la persuasión gráfica e informativa al diseño.

Partiendo de una descripción de la radio en Internet, relacionamos la parte de creación de radios universitarias en la red con su aspecto gráfico en el universo web, para más tarde incidir sobre la parte fundamental que supone la introducción de nuevas formas de 
comunicación en el diseño de dichas páginas de entrada a los medios audiovisuales radio.

\section{Breve apunte histórico radio en Internet}

Los cibermedios, desde su aparición a principio de los años noventa, han ofrecido nuevas posibilidades de desarrollo de la capacidad docente con una inversión en tecnología relativamente asequible. Cada medio o grupo de medios en general ha abordado también ese cambio de forma distinta en función de sus propias características. Es decir, los medios impresos se han reconvertido en plataformas de cibermedios en las que integran texto e imágenes, en movimiento o no, y los audiovisuales han sufrido una evolución necesariamente paralela al desarrollo de Internet.

En este nuevo escenario global de las comunicaciones la radio en España ha conseguido sumarse a esos cambios y no perder el tren de la red. Las emisoras universitarias, particularmente, son las que más han padecido el cambio. En este punto debemos tener en cuenta, además, la incidencia del soporte en el propio medio. La radio como medio ha encontrado una forma de distribución global que supera uno de sus primeros condicionantes, las ondas. Pero en ese nuevo mercado global audiovisual la competencia es mucho mayor, de forma que el punto de partida del medio es completamente distinto, como si se tratara de dos medios distintos. Y con ello también ha variado necesariamente el público objetivo. El perfil-tipo de audiencia de la nueva forma de distribución de la radio como medio ha variado sustancialmente en los últimos diez años.

Comprobamos que en el campo de las radios universitarias su incidencia es desigual. Así como la mayoría tienen frecuencia en la que emitir de forma tradicional, aunque sin extensas distribuciones de señal, algunas de éstas se limitan a trabajar desde una distribución única a través de Internet.

La radio ha ido a la zaga en este terreno frente a otros medios de comunicación, aunque su adaptación ha sido también más rápida, en el proceso de producción y de configuración y adaptación al nuevo soporte. El aparato receptor ya no es un transistor, sino que hemos 
pasado a un dispositivo móvil o un ordenador. Por ejemplo, al contrario que con otros medios, como los ciberperiódicos, el prefijo "cíber" en la radio ha significado una especie de sustitución del medio original por uno distinto. "En algunos casos se habla - con cierta ampulosidad- de ciberradio para describir un paso evolutivo trascendente del medio que lo es en tanto que su desarrollo se ha acompasado sin problemas a la revolución tecnológica en la que estamos inmersos, pero en realidad [...] la radio sigue quedándose en la frontera; sigue siendo un medio unidireccional..." (Martínez y Martínez 2013: 490). En cualquier caso, al igual que todos, se ha roto la limitación del espacio radioeléctrico y la siempre difícil y polémica concesión administrativa para la distribución de la señal.

Las radios universitarias, desde la aparición de la pionera de la Universidad de La Laguna, cumplen estos requisitos ampliamente, siendo además una incubadora de ideas y proyectos que hacen crecer el valor de las ciberradios. Los portales en los que se insertan tienen el valor añadido de la red. Así, incorporan archivos o podcasts, vídeos, blogs de protagonistas y chats, convirtiendo en cibernético el medio dentro de la generación 2.0, y transformándose en un medio con nuevas posibilidades.

Las radios universitarias son herederas directas de estas circunstancias. Y si tenemos en cuenta que hay quien piensa en la radio en Internet como un medio distinto de la radio tradicional o convencional, podemos llegar a creer que las radios universitarias sean un medio distinto. Creemos que como mucho se trata de un género dentro de la radiodifusión. El soporte es distinto, pero todavía queda mucho camino por recorrer para considerar a la radio un cibermedio en toda la extensión de la palabra.

\section{Web de medios audiovisuales (radio) en Internet}

Uno de los elementos diferenciadores citados es el aspecto gráfico de la página web del medio audiovisual. En la radio tradicional el oyente, el receptor, tiene que imaginar situaciones, escenarios, caras y cualquier otro elemento de las retransmisiones basándose únicamente en el sonido. Ese, además, es el elemento diferenciador del trabajo del profesional de la radio. Es decir, ante la falta de imágenes, el 
periodista tiene que narrar y ofrecer referencias para que el oyentereceptor construya con su imaginación todos los elementos narrados. La página web de entrada en los nuevos cibermedios sustituye esa imaginación y pone a disposición del receptor muchos elementos de los que antes carecía, desde la cara de un locutor o presentador, hasta la posibilidad de participar en un programa por un canal distinto.

De forma que en una web de radio tenemos, como hemos visto más arriba, no sólo sonido sino que disponemos de textos, imágenes -fijas o en movimiento, incluidos los gráficos y la infografía-, chats, grabaciones de archivos, enlaces para ampliar la información, etcétera. Tomemos como ejemplo uno de los elementos del diseño gráfico web que se utiliza cada vez más, como lo es la infografía. Al igual que en la prensa impresa clasificamos la infografía como imagen -frente a otros elementos como texto o elementos tipográficos-, en los desarrollos gráficos de Internet ocupa el mismo lugar. El hecho a destacar en este contexto es la ampliación de la información gracias a este nuevo género periodístico de la información gráfica. Como ejemplo viene necesariamente a colación ya que podemos definir el propio diseño web como un diseño infográfico.

Aunque en las radios universitarias analizadas vemos disparidad de criterios a la hora de trasladar a Internet los proyectos. Así, encontramos desde una sencilla página de texto en la que únicamente encontramos acceso a la escucha de la radio, tanto en directo como a través de la grabación de diversos programas (Onda Expansiva de Universidad Politécnica de Madrid), hasta otras en las que se integra toda la información de los diversos medios de comunicación de una universidad y en la que tiene una presencia fundamental el diseño gráfico en general, y la infografía en particular.

\subsection{Infografía y radio}

El terreno informativo que ocupa el diseño gráfico web, y la infografía en particular, es muy amplio, aunque en lo académico todavía quedan grandes espacios por explorar. Hay que tener en cuenta que el diseño de la infografía web condiciona el proceso de la comunicación, de forma que se hace necesario la inclusión en las programaciones docentes de la infografía como materia de estudio 
para mostrar al alumno cómo se produce el proyecto global de la creación de un cibermedio, en este caso audiovisual. Paralelamente a ello se producirá ese proceso de alfabetización del receptor que ya goza de una amplia culturización visual en el entorno informativo que deberemos aprovechar. Esa alfabetización se lleva a cabo mediante la creación y transmisión de los códigos en los que se expresa el periodismo gráfico.

No hay que perder de vista tampoco, en un proyecto de medios en Internet como lo son las radios universitarias, las nuevas formas de transmisión de la información a través de las redes sociales y dispositivos móviles. Con ellos se amplía notablemente las posibilidades de distribución y de relación directa y feedback del oyente en los cibermedios, y como ocurre en numerosas ocasiones seguimos la estela del mercado norteamericano con productos como USA Today, que en España todavía no tiene la intensidad que demanda el mercado. Así las universidades, en el papel de empresas informativas en lo que respecta a los medios en Internet, deberán tener una actitud más agresiva a la hora de incluir y contemplar el fenómeno de esta nueva forma de comunicación.

\subsection{Adaptación a las radios}

Si nos adentramos en la aplicación del diseño a las web de radio convencionales encontraremos un despliegue discreto del nuevo género periodístico como es la infografía. Ciertamente la función del desarrollo web de las grandes cadenas es conseguir audiencia, sea a través de la red o mediante las ondas herzianas tradicionales, y para ello despliegan diseños web atractivos que hagan de la visita a la página un lugar de captación de audiencias. El desarrollo de grandes corporaciones multimedia ha hecho que aquellas páginas de entrada en las radios se vean en ocasiones escondidas u ocultas en el universo de las empresas matrices. RNE, por ejemplo, está en la portada de la página de la corporación Radio Televisión Española, sin embargo el acceso a la radio RNE no es intuitivo. Lo mismo ocurre en las radios universitarias. Aquí asistimos al desarrollo de un esfuerzo distinto y más orientado en ocasiones a facilitar al público la navegación por la página que a ofrecer información. 


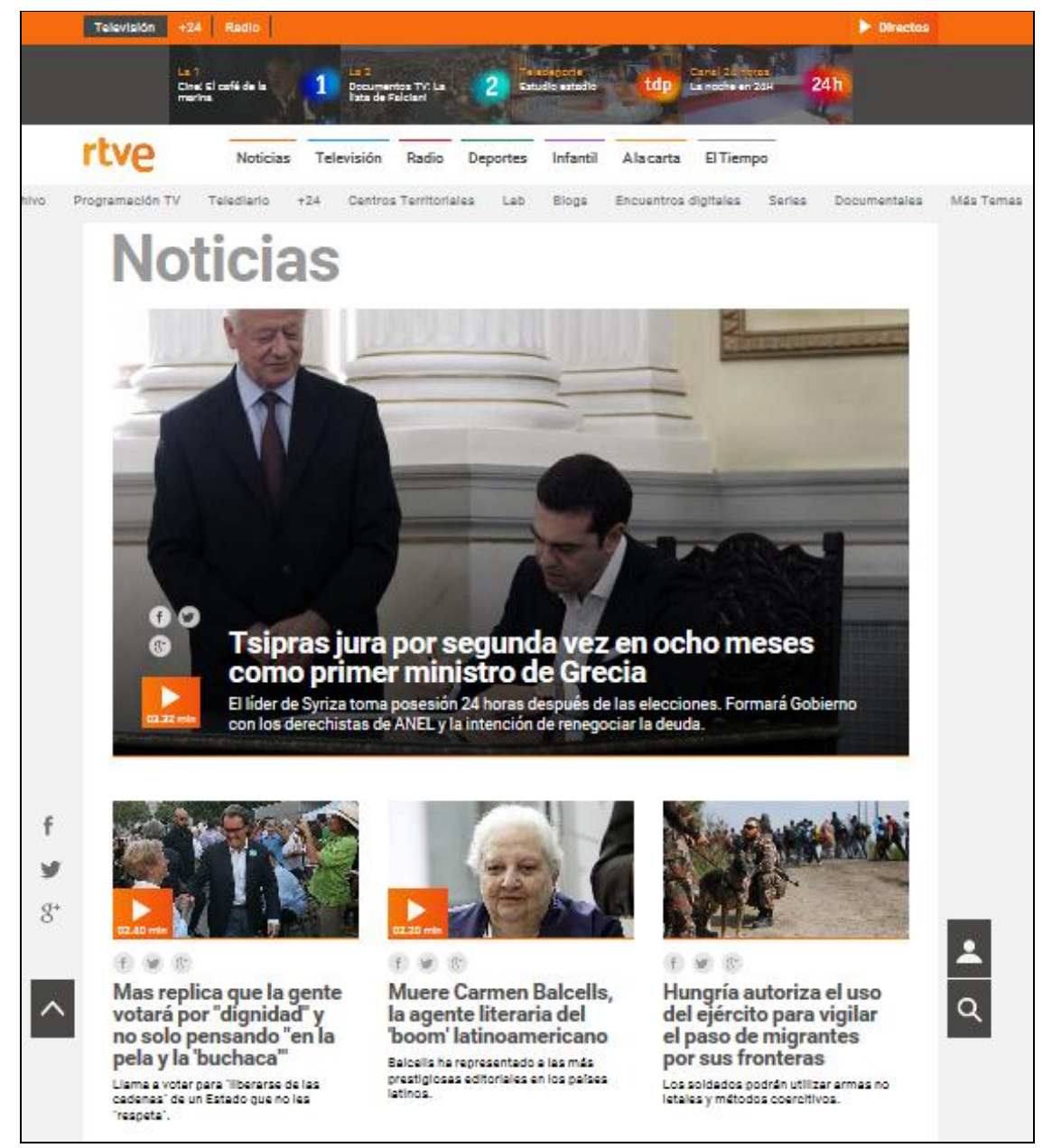

Página de entrada en la web oficial de RTVE. Fuente: www.rtve.es

\section{Diseño web en la enseñanza universitaria}

Todo ello nos hace pensar en el estatus actual en el plano docente del diseño gráfico web en general y de la infografía y la infografía periodística en particular. De la primera podemos decir que es una disciplina que necesita ser acotada para obtener un significado unívoco. De la segunda sabemos que constituye un género periodístico nuevo en sus distintos desarrollos o soportes para su expresión. Aunque también es cierto que la infografía multimedia o para Internet es una disciplina que se confunde en muchas ocasiones con la propia del diseño de páginas web. Pero en realidad no es un marco para una página sino un soporte expresivo para la información. Para hacer llegar la información al público de una manera muy directa y eficaz. Y esa disciplina, y género periodístico, ha de tener su necesario reflejo en la enseñanza universitaria. 


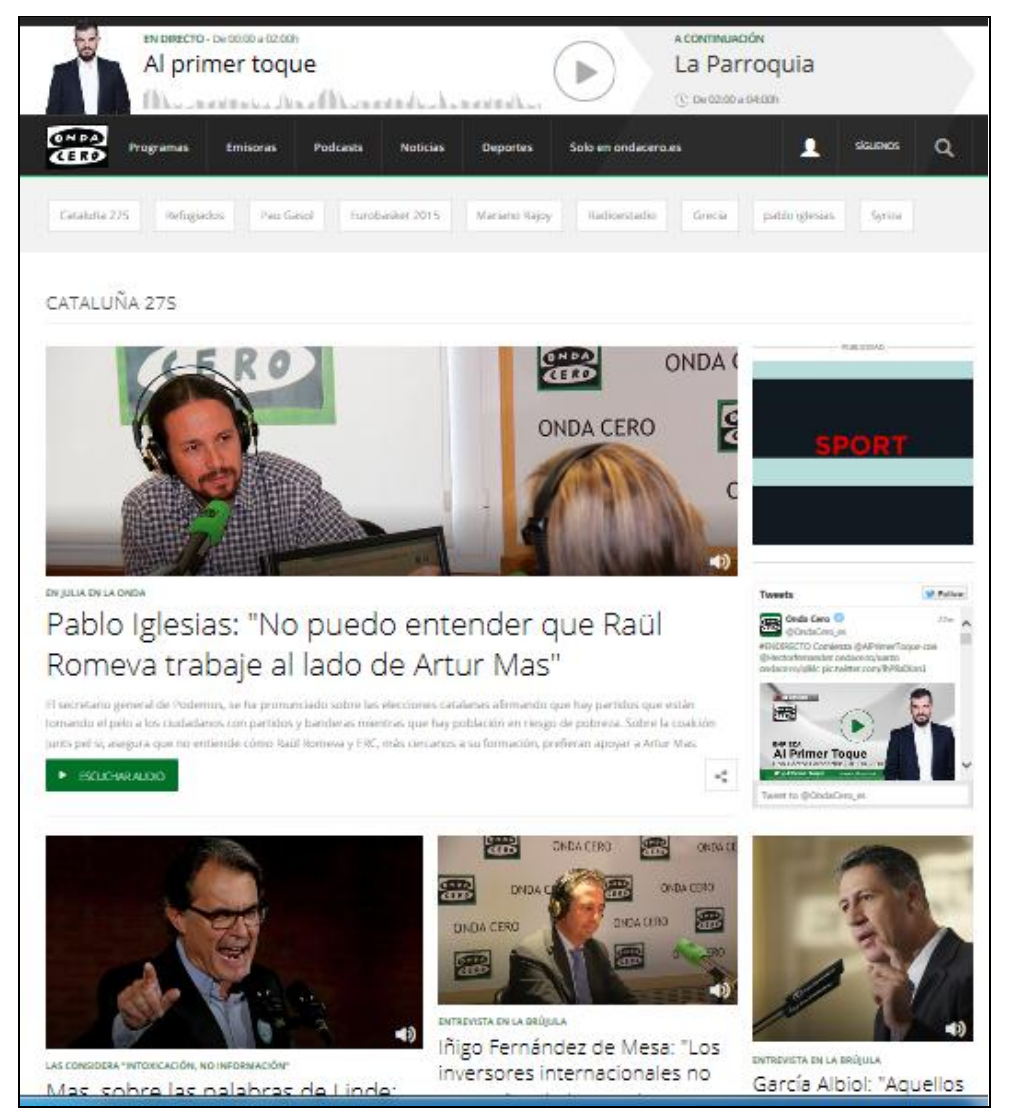

Página de entrada en la web oficial de Onda Cero. Fuente: www.ondacero.es

Encontramos escasos proyectos en los que esté contemplada la infografía y el diseño gráfico web como materia académica. Sí la vemos como disciplina próxima al diseño gráfico de una forma muy general y abierta, en ocasiones. Error común ya que cada día más las nuevas formas de comunicación están derivando hacia la expresión gráfica de las informaciones en lo que Alberto Cairo denomina el "arte funcional" (Cairo 2000).

Tradicionalmente ha sido más una asignatura incluida en el grado de Bellas Artes, o también en Arquitectura, donde se incluía como parte de las asignaturas pertenecientes a la especialización. Encontramos también una desigual incidencia de la asignatura Infografía, o la enseñanza de esta disciplina, en alguno de los más de cuarenta Grados en Comunicación que se ofrecen en las universidades de toda España, tanto públicas como privadas. Al igual que encontramos incidencia desigual en lo que a la implantación de emisoras de radio se refiere. También descubrimos que la forma de tratar la asignatura es diversa, en función de la adaptación también diversa que se ha 
realizado de esta disciplina dentro de los medios de comunicación, básicamente impresos. Todo ello tiene que ver en muchas ocasiones con la confusión generada en torno al término Diseño Gráfico o Infografía como tal.

El hecho es que el diseño gráfico web y la infografía deben definirse, en el sentido que la estamos tratando, como una forma de comunicación. Como comunicación en estado puro que es, en la relación entre el profesional, emisor de la información, y el público receptor.

\subsection{Los medios de comunicación en las universidades}

Cuando se construyen proyectos de medios enmarcados dentro de los proyectos docentes el objetivo que se proponen alcanzar está basado en la necesidad de potenciar las destrezas prácticas del alumno que sirvan a su futuro desempeño profesional. Entramos aquí en el debate del periodismo como oficio o como profesión. Debate estéril a estas alturas del siglo XXI pero que ha hecho correr ríos de tinta en otras épocas. Muchos desencantados alumnos de Comunicación encuentran siempre difícil la tarea de estudiar teoría de la comunicación para el desarrollo de una profesión eminentemente práctica. Sin embargo ya hemos resuelto el debate estableciendo un equilibrio entre las materias teóricas y las prácticas de los planes de estudio.

Las radios universitarias entran de lleno en esa parte práctica de la profesión periodística. Terreno éste en el que debido a la dificultad técnica han tardado más en desarrollarse, a las radios nos referimos, frente a los medios impresos o los diarios y periódicos en Internet. Así lo recogimos en un trabajo anterior en el que se analiza de forma comparativa los medios de comunicación en Internet de diversas universidades de todo el mundo (Martínez 2012: 18). La labor de ordenación partía en ese caso de las clasificaciones realizadas en los rankings internacionales que atienden a criterios de calidad normalizados y a los que se añadían otros parámetros de calidad del propio estudio.

Las nuevas tecnologías han facilitado el proceso de incorporación a proyectos de medios de los estudiantes universitarios, y la radio en 
particular es un buen ejemplo de ello. Suponen, además, una salida al mundo real desde el mundo virtual, y al mundo profesional desde el ejercicio de la enseñanza. Un proyecto serio de cibermedio universitario ofrece una nueva forma de comunicación, no sólo un mero ejercicio de estilo. El trabajo del docente y del técnico especializado deberá poner de manifiesto las posibilidades que en ambas direcciones tienen este tipo de proyectos. Es decir, su funcionamiento como medio tradicional, en aquel caso el periódico y en este la radio, y sus posibilidades como cibermedio (Martínez 2012: 29). El problema es la financiación, ya que en último extremo, y a pesar de ser medios universitarios, no hay que perder de vista la posibilidad de obtener recuperaciones de la inversión realizada, a través de la publicidad o mediante algún tipo de patrocinio. La publicidad ya sabemos que es un mercado cautivo y como motor de la comunicación tiene dificultades difíciles de salvar. El problema en el fondo será el incremento de las audiencias.

\section{Radios universitarias y diseño gráfico web: ejemplos}

Entrando en el fondo de esta cuestión el ejemplo más claro de esta integración entre infografía y radio universitaria lo encontramos en un trabajo realizado por la Universidad Europea de Madrid. Su medio de comunicación, elaborado por profesores y alumnos de los grados de Comunicación, se llama EuropeaMedia y se autodefine como "la clínica de medios de la Universidad Europea de Madrid" en el que convergen los diversos medios dedicados a la práctica del periodismo en sus diversas modalidades por parte de los alumnos. Tiene su entrada y sitio web independiente de la propia universidad (europeameida.es), aunque también podemos acceder a través de la página principal de la Universidad Europea de Madrid. EuropeaMedia es un portal de medios y en él está incluida la emisora de radio, a la que se dedica un gran espacio. Según hemos señalado anteriormente, la necesidad de crear un espacio de comunicación global también hace que se incorpore el género de la infografía en la página, que en este caso está integrado desde el inicio de la navegación en la misma en un apartado denominado como tal "Infografías". 
Imagen 1: Página de entrada en la web de medios de la Universidad Europea

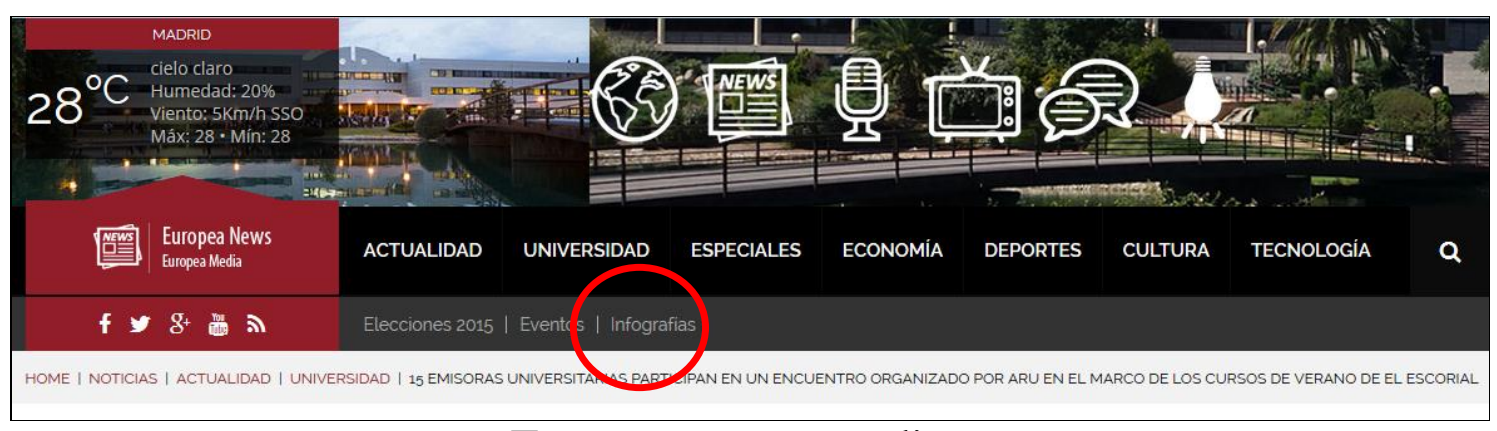

Fuente: europeamedia.es

Una vez que hemos accedido a este espacio podemos comprobar cómo existe realmente un proyecto en el que se contempla la infografía informativa como un potente género periodístico. Incluso, al seleccionar el botón y redirigirnos a la página que contiene las informaciones infográficas nos encontramos con uno de los trabajos dedicado precisamente a las radios universitarias en Internet en España y donde podemos también encontrar, de alguna forma centralizada, la información sobre aquellas.

Con motivo del Congreso Internacional de Medios Universitarios (2014), vemos esta infografía elaborada para EuropeaMedia en la que ofrece información sobre las radios universitarias. Se trata de un mapa interactivo con la localización e información de cada una. El mapa interactivo es por definición una infografía.

La autora, María Perdomo, nos ofrece una infografía interactiva en todo el sentido de la palabra. Al navegar con las flechas derecha e izquierda vamos teniendo acceso a una breve reseña de cada una de las que denomina "Radio universitaria (sic.) más populares de España". A la izquierda de la infografía encontramos el mapa que va situando cada una de las emisoras sobre la geografía española, a lo que añade una breve primera reseña respecto al nacimiento de la primera emisora universitaria, en La Laguna, Tenerife, en 1987. 
Imagen 2: Página de infografía: Infografía sobre las radios universitarias

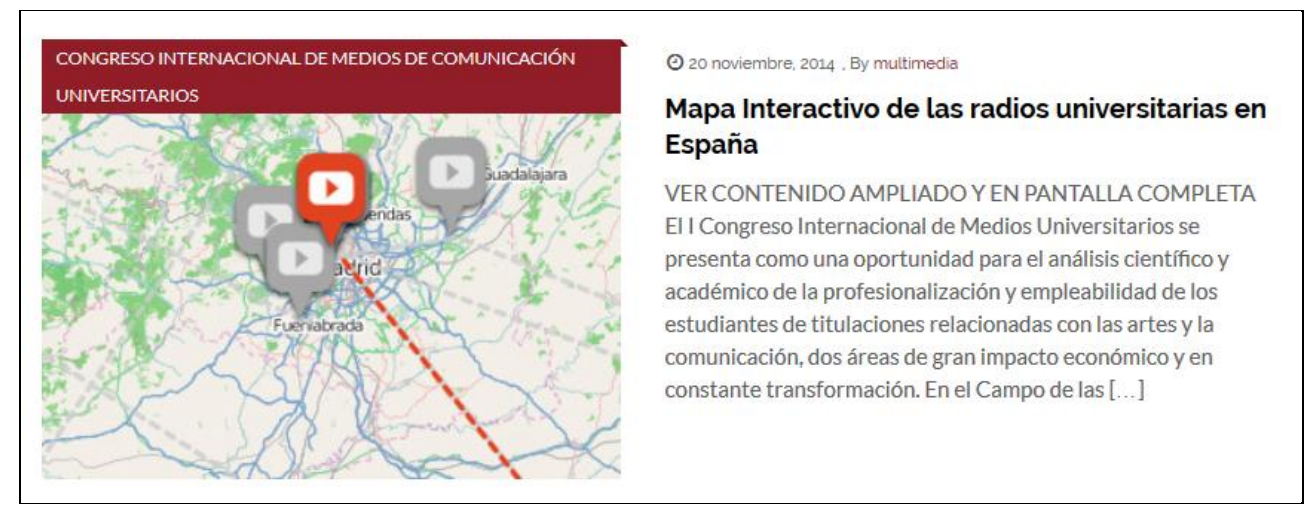

Fuente: europeamedia.es

De esta forma nos ofrece información sobre todas las radios asociadas a ARU (Asociación de Radios Universitarias), comenzando por la antedicha de La Laguna y finalizando, con un orden cronológico, en InfoRadio de la Universidad Complutense de Madrid:

- RADIO UNIVERSIDAD (Universidad de Salamanca, 1995) hoy Radio USAL-: Su diseño web está realizado por el Servicio de Producción e Innovación Digital de la universidad. Aunque en principio no incluye infografía como en el caso de la Europea de Madrid, podemos decir que el diseño web utiliza las técnicas de la información y diseño gráfico web de Internet con gran despliegue de medios y una efectividad comparable a la de una radio de carácter abierto y profesional.

- CUAC FM (Universidad de A Coruña, 1995). Con un diseño más agresivo, muy cuidado. Aunque inicialmente dependía de la universidad, en la actualidad se gestiona por medio de una asociación juvenil independiente fundada con ese objetivo, convirtiéndose en una emisora autogestionada, pero siempre de ámbito universitario.

- ONDAS (Universidad de León, 1997). Se trata de una Asociación Radiofónica ONDAS emite en TICS desde 1998. Con muy escaso diseño gráfico, simplemente funcional, no hay despliegue gráfico de ningún tipo. Su único objetivo es ofrecer la posibilidad de escuchar la radio con tres calidades distintas. Ese escaso esfuerzo gráfico evita que muchos de los posibles receptores se integren en la audiencia. 
Imagen 3: Información infográfica sobre radios universitarias

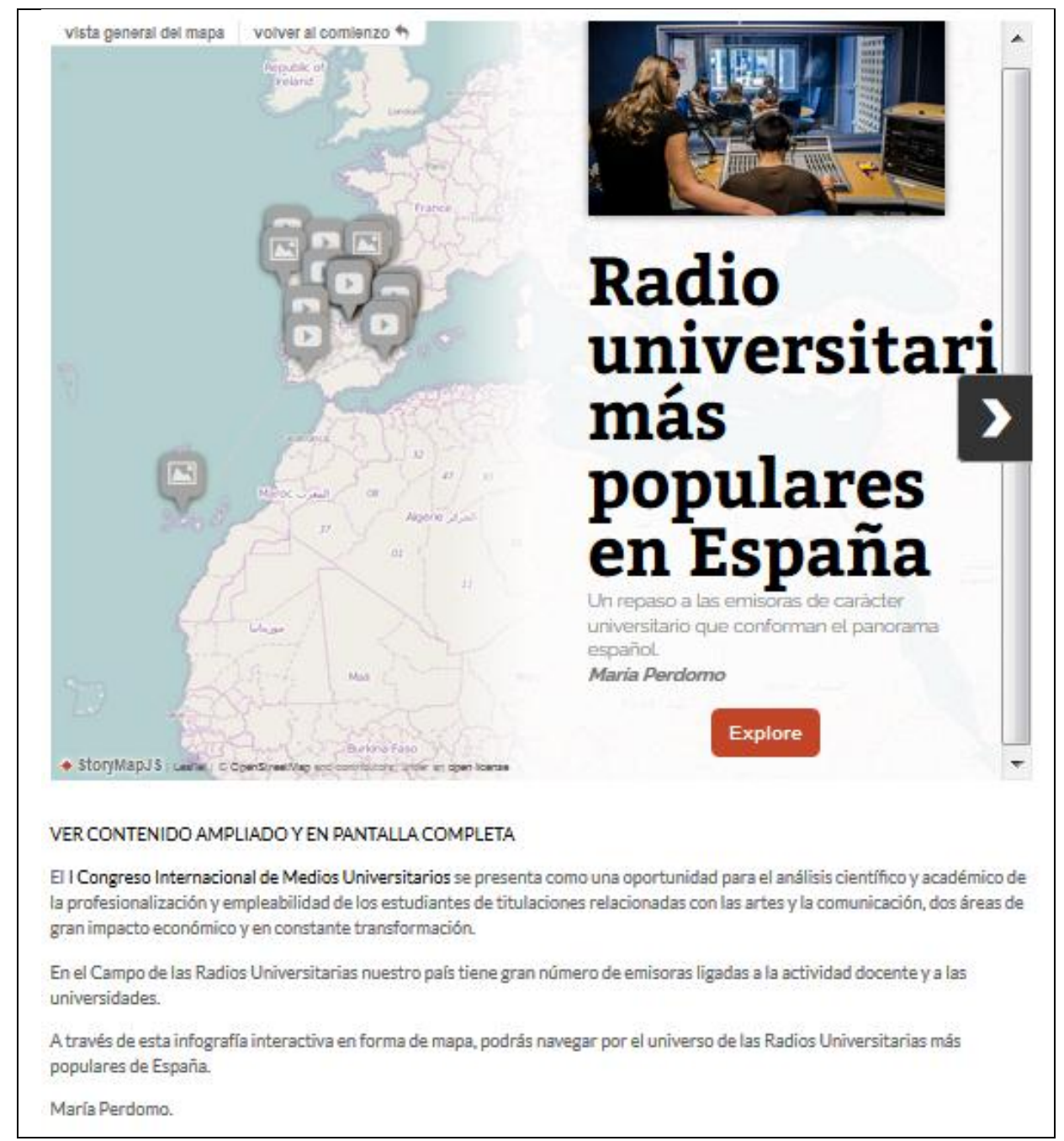

Fuente: europeamedia.es

- 98.3 RADIO UNIVERSIDAD DE NAVARRA (Universidad de Navarra, 1999). Emisora de la Facultad de Comunicación que, precisamente, declara entre sus objetivos el antes señalado respecto a los medios de comunicación universitarios en general: "Potenciar destrezas prácticas para el futuro desempeño profesional". Tiene un cuidado diseño web, aunque no aparece la infografía, probablemente por tratarse de un medio de comunicación audiovisual. Se han ocupado, sin embargo, de la infografía con la organización en la Facultad de Comunicación de la "Cumbre mundial de la Infografía" y la entrega de los Premios Internacionales Malofiej de Infografía. 
- EUROPEAMEDIA (Universidad Europea de Madrid 2000). Integra todos los medios periodísticos de la Universidad en Internet: Europea News (periódico digital); Europea Radio; Europea TV; y Europea Ads (agencia de publicidad de la propia universidad).

- ONDA EXPANSIVA (Universidad Politécnica de Madrid). Onda Expansiva Radio F1 es una emisora perteneciente a la Facultad de Informática de la UPM. Su diseño, al igual que el de la Universidad de León, es muy básico, debido probablemente a que priman otros objetivos distintos del periodístico al tratarse de un proyecto de la Facultad de Informática. Sin embargo es un proyecto ambicioso que emite 24 horas diarias.

- UPV RADIO (Universidad Politécnica de Valencia, 2002). También de la Facultad de Informática. Al igual que la anterior el diseño gráfico web escasea, aunque está un poco más trabajado no invita a la permanencia en la página.

- ONDA CAMPUS (Universidad de Extremadura, 2004), Radio Institucional de la Universidad de Extremadura. Diseño muy desigual.

- VOX UJI RADIO (Universidad Jaime I, 2004). El diseño gráfico de esta web descansa sobre una plantilla de blog. Aunque este tipo de diseño puede ser muy impactante, no deja de depender del trabajo externo realizado por las empresas que distribuyen plantillas para blogs.

- RADIO AL PILÓN (Universidad de La Rioja, 2001). Emisora dependiente de la Asociación Universitaria UniRioja, con muy escaso diseño web que sin duda no proporcionará oyentes.

- RADIO URJC (Universidad Rey Juan Carlos, 2009). Aunque empieza sus emisiones en 2005 no es hasta el año 2009 cuando se regularizan sus trabajos. Tiene un amplio despliegue de medios debido también a las dimensiones de esta universidad pública de Madrid, y cuenta con dos instalaciones, una en Fuenlabrada y otra en Vicálvaro. Muy buen despliegue gráfico en el que se nota la ambición del proyecto respecto al cuidado del diseño gráfico web y la generación de audiencias. Se echa en falta algo más de despliegue multimedia, no existiendo, por ejemplo, ninguna 
infografía que coadyuve a la ampliación y generación de nueva comunicación en las informaciones tratadas.

- RADIO UMH (Universidad Miguel Hernández de Elche, 2007). Con un buen despliegue de diseño gráfico web, su diseño está en manos del Servicio de Alojamiento web, es decir de los Servicios Informáticos de la propia Universidad. Ello le hace tener un gran atractivo y la posibilidad de obtener nuevos receptores gracias a un diseño gráfico ambicioso.

- RADIO CEU VALENCIA (Universidad Cardenal Herrera CEU). Emisora a cargo de los alumnos de Periodismo, Comunicación Audiovisual y Publicidad y Relaciones Públicas de la universidad. Tiene un buen despliegue gráfico, sin embargo adolece de la escasez de información al hacer coincidir su funcionamiento con la entrada en régimen del curso académico. Es decir, en periodos no lectivos deja de funcionar, de forma que la falta de continuidad hace también perder posibles oyentes.

- ONCEU RADIO (Universidad CEU San Pablo, 2009/2010). Emisora de la Facultad de Ciencias de la Comunicación creada para que los estudiantes aporten sus perspectivas informativas a la comunicación. También está desactualizada en periodo no lectivo.

- RUAH (Universidad de Alcalá de Henares, 2011). Es una web con plantilla de blog y por lo tanto diseñada por la empresa distribuidora, lo que no impide su objetivo, pero sí lo desvaloriza.

- IRADIO UCAM (Universidad Católica San Antonio de Murcia, 2010). Tiene un diseño atractivo aunque parece, porque no está declarado, una plantilla blog.

- INFORADIO (Universidad Complutense de Madrid, 2010) Este proyecto es la continuación de la antigua Radio Complutense. Es la radio de la Facultad de Ciencias de la Información de la UCM elaborada por los alumnos. Su diseño web está realizado con tecnología blog, de forma que a pesar de su fuerte difusión, el depender del diseño externalizado puede perjudicar la posible entrada de un mayor número de audiencia. 
Imagen 4: Páginas web de algunas radios universitarias
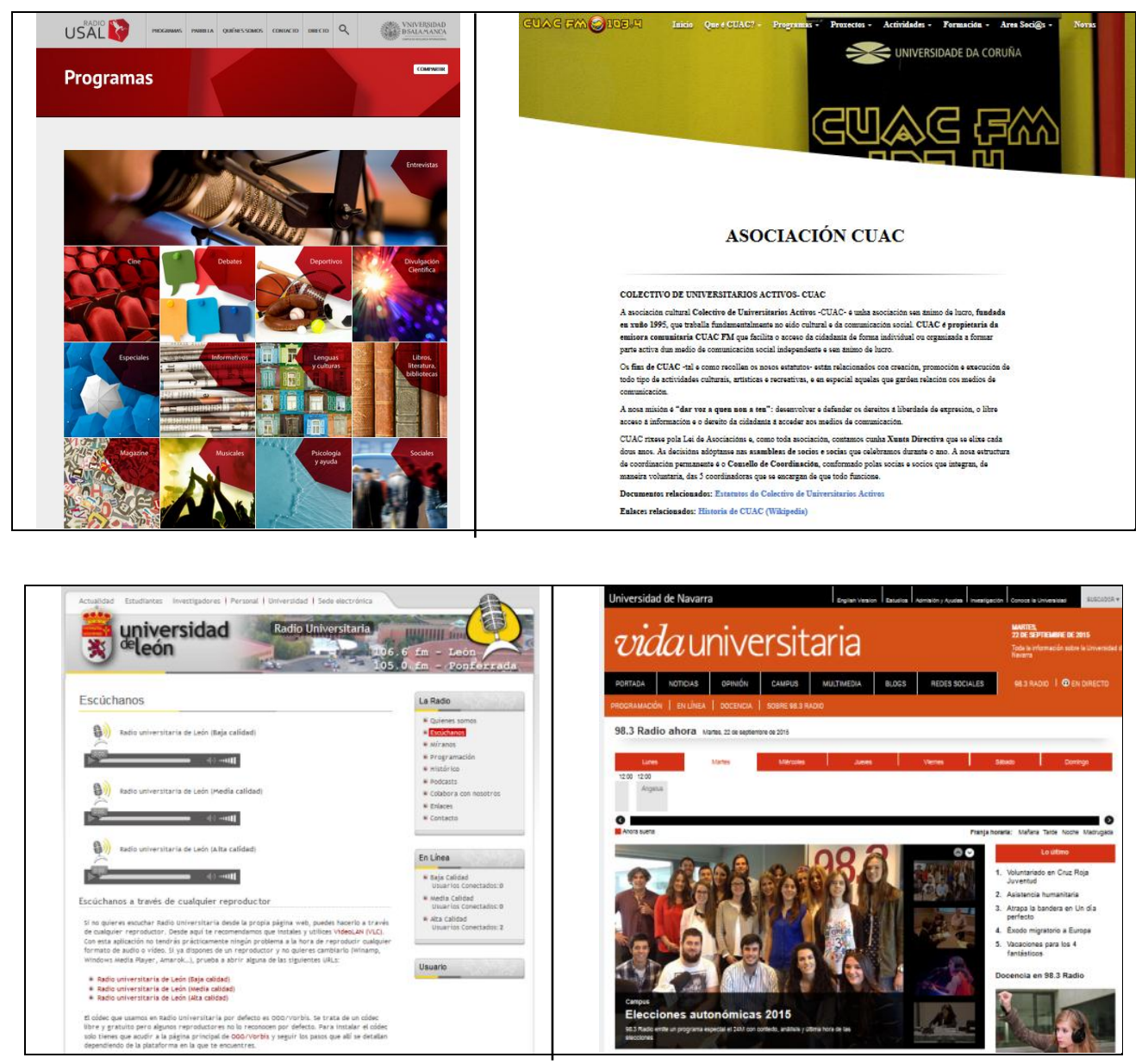

Páginas web de entrada de diversas radios universitarias: Universidad de Salamanca, de A Coruña, de León y de Navarra.

Fuentes: radio.usal.es; cuacfm.org; servicios.unileon.es/radio-universitaria; www.unav.edu/web/vida-universitaria/983radio.

\section{Conclusiones}

El diseño gráfico aplicado a las web de las radios universitarias es desigual en cuanto a su apariencia. Podemos establecer una escala en función del mismo. En la parte más baja situaríamos a las radios en las que el diseño gráfico prácticamente no existe, dentro de la consideración de una cierta retórica del diseño gráfico. En este apartado podemos situar, de entre las radios universitarias analizadas, las dos creadas y puestas en marcha por las respectivas Facultades de Informática de la Universidad Politécnica de Madrid y la Universidad Politécnica de Valencia, Onda Expansiva y UPV Radio, respectivamente. En las mismas circunstancias se encuentra la de la 
Universidad de León, Ondas, que si bien su proyecto no pertenece a una Facultad de Informática como es el caso de las anteriores, adolece de falta de preocupación por cualquier aspecto que no sea eminentemente radiofónico. Estas radios tendrán mayor dificultad en la consecución de niveles de audiencia aceptables, o por lo menos sus cifras es muy probable que no se vean incrementadas gracias a las visitas a las respectivas páginas web, su misión por tanto es meramente funcional.

Subiendo en la escala, de menos a más diseño, situamos a las emisoras de radio universitarias que utilizan diseños web de páginas extraídos de plantillas creadas al efecto por servidores de blogs. En este caso, aunque se trata de trabajos muy personales, el diseño está en manos externas y, por tanto, es un trabajo más de selección de una solución aceptable para nuestros intereses que de un acto voluntario de construcción de una solución gráfica para un proyecto determinado. En este caso puede ocurrir que nuestra solución gráfica deje fuera algunas de las funcionalidades que, como cibermedio, hayamos proyectado. En este ámbito se sitúan ya una cuantas de las páginas web de las radios universitarias que hemos estudiado. Su elección dependerá siempre, además de los recursos económicos citados, de la capacidad del proyecto de abordar el diseño gráfico web como una de las necesidades prioritarias de nuestro cibermedio.

Eso es precisamente lo que hacen las páginas que eligen una tercera opción, cual es la creación de una página ad hoc realizada por un diseñador o grupo de diseño para dar satisfacción a todas las necesidades de un proyecto global de una radio universitaria, o de un portal de medios universitarios entre los que se encuentre la radio. Esto último está referido sin duda a la página de la Universidad Europea de Madrid, donde se integran de forma eficiente los diversos medios de comunicación, tanto escritos como audiovisuales, que conforman la "clínica de medios". En este sentido se hace patente, normalmente de forma más acusada en alguna universidad privada como el citado caso, el aprovechamiento de los recursos tecnológicos de los centros docentes para la mejora de los proyectos. Es decir, desde un departamento NTIC de las propias universidades pueden desarrollarse proyectos de diseño gráfico para cibermedios muy efectivos. Otro sería el caso de la externalización de este servicio de 
diseño, pero comprar fuera una tarea como ésta priva de la posibilidad evidente de mejorar la enseñanza no sólo de las nuevas tecnologías sino también de la capacidad de pensamiento narrativo gráfico de los estudiantes que las proyectan.

En general hemos comprobado que el diseño gráfico web no es una prioridad en la mayoría de los cibermedios, y de las radios universitarias en particular. El trabajo radiofónico prima sobre el gráfico. Sin embargo es necesario la adecuación de éste último para la consecución de una mayor efectividad en la comunicación. También comprobamos la falta de integración en muchas ocasiones de esos cibermedios en la propia estructura web de las páginas universitarias, de forma que las radios se pierden en el marasmo de ofertas de las grandes páginas gráficas de la mayoría de universidades. Es encomiable el trabajo realizado por la propia Asociación de Radios Universitarias, ARU, en el sentido de promoción de este tipo de medios. Esta asociación debería animar a la puesta en común de una hoja de ruta gráfica para ayudar a la mayor efectividad de este tipo de medios, tanto en su aspecto docente, de práctica para los alumnos, como en su dimensión como medios de comunicación integrados en el mercado. 


\section{Bibliografía}

Acosta, K. et al. (2014): "Radio cultural: estudio del consumo que los estudiantes y trabajadores de la Universidad de Colima tienen de Universo 94.9", en Interpretextos 11.

Aguaded, J.I. y Martín-Pena, D. (2013): "Educomunicación y radios universitarias: panorama internacional y perspectivas futuras", en Revista Latinoamericana de Comunicación Chasqui, 124, pp.6370 .

Aguaded, J.I. y Contreras, P. (2011) (Coords.): La radio universitaria como servicio público. Modelos de programación. En J. I. Aguaded, y P. Contreras, La radio universitaria como servicio público para una ciudadanía democrática. La Coruña: Netbiblo.

Aguaded, J.I. y Contreras, P. (2011) (Coords.): La radio universitaria como servicio público para una ciudadanía democrática. A Coruña: Netbiblo.

ANECA (2004): Libro Blanco. Títulos de grado en comunicación. Agencia Nacional de Evaluación de la Calidad y Acreditación. ANECA. España.

Benavides, E. (2012): El sistema operativo Android en la radio universitaria: la implicación de los estudiantes. La experiencia de Radio Universidad de Almería. En C. Espino, y D. MartínPena (Eds.), Las radios universitarias, más allá de la radio. Las TIC como recursos de interacción radiofónica. Barcelona: UOC.

Blanco Castilla, E. (2007): "La utilización de la radio como herramienta didáctica. Una propuesta de aplicación" en FISEC-Estrategias, 6. Bogotá (Colombia): Universidad Sergio Arboleda.

Boud, D. (1993): Using Experience for Learning. Bristol, England: Open University Press. 
Cairo, A. (2004): Cómo la infografía interactiva cambió nuestras vidas. Malofiej 11. Pamplona: Index Book.

Caldevilla Domínguez, D. (2011): Radio por Internet: los Creative Commons como eje vertebrador para radio clubes de aficionados. En M.A. Ortiz Sobrino y N. López Vidales (Coords.), Radio 3.0 Una nueva radio para una nueva era. Madrid: Fragua.

Calvo, E. y Padilla, G. (2011). Radio 3.0. Éxito durmiente, en M.A. Ortiz Sobrino y N. López Vidales (Coords.). Radio 3.0 Una nueva radio para una nueva era. Madrid: Fragua, 281-300.

Casajús, L. (2014): Radios universitarias y redes sociales. Análisis de la gestión de contenidos de la radio universitaria española en las redes sociales. Tesis Doctoral. Castellón: Universitat Jaume I.

Casajús, L. y Vázquez, M. (2014): “Jóvenes prosumidores en la Radio Universitaria 2.0: Un perfil en construcción”, en Revista Edmetic, 3(1), pp.87-111.

Casajús, L. (2011): "Radio universitaria en América Latina: Escenario y perspectivas". En J.I. Aguaded, y P. Contreras Pulido (2011) (Coords.), La radio universitaria como servicio público para una ciudadanía democrática. A Coruña: Netbiblo.

Ceballos, G.; Portillo, D. y Arellano, A. (2012): ¿Y qué consumen los jóvenes?, Un estudio sobre la percepción y prácticas culturales en estudiantes del nivel superior de la Universidad de Colima. Colima, México: Universidad de Colima.

Cebrián Herreros, M. (2001): La radio en la convergencia multimedia. Madrid: Gedisa.

Coffey, A.J. (2012): “Teaching Students to Serve Niche Audiences: A Case of Study in Spanish Language News", en Electronic News, 6(2), pp.81-91. 
Contreras Pulido, P. y Parejo Cuellar, M. (2013) (Coords.): Más Ciencia. Cómo trabajar la divulgación científica desde las Radios Universitarias. Salamanca, España: Comunicación Social.

Contreras, P. (2012): La voz de los presos en la radio universitaria: puentes con la ciudadanía. La experiencia de UniRadio, Universidad de Huelva. En C. Espino y D. Martín-Pena (Eds.), Las radios universitarias, más allá de la radio. Las TIC como recursos de interacción radiofónica. Barcelona: Editorial UOC.

Cordeiro, P. (2012): "Radio becoming r@dio: Convergence, interactivity and broadcasting trends in perspective", en Participations, 9 (2), 4, pp.92-510.

Correyero, B.; García, I.M. y Robles, M.C. (2013): “La divulgación científica de los proyectos de innovación docente vinculados a las radios universitarias". En P. Contreras y M. Parejo, (Coords.). Más Ciencia. Cómo trabajar la divulgación científica desde las radios universitarias. Salamanca: Comunicación Social.

Dido, J. C. (2008): "Radios Universitarias: realidad y perspectivas", en Congreso REDCOM: Conectados, hipersegmentados y desinformados en la era de la globalización. Universidad Católica de Salta.

Duarte, P. (2014): Estudantes no FM Português. En D. Martín-Pena y M.A. Ortiz Sobrino (Eds.), Las Radios Universitarias en América y Europa. Madrid: Fragua.

Esteve, F. (2009): "Bolonia y las TIC: de la docencia 1.0 al aprendizaje 2.0", en La Cuestión Universitaria, 5, pp.59-68.

Espino, C. y Martín-Pena, D. (2012) (Eds.): Las radios universitarias, más allá de la radio. Las TIC como recursos de interacción radiofónica. Barcelona. Editorial UOC.

Espino, C. y Marín-Pena, D. (2012): "Las TIC y las radios universitarias: hacia una nueva comunicación". En C. Espino, y D. Martín-Pena (Eds.), Las radios universitarias, más allá de la radio. Las TIC como recursos de interacción radiofónica. Barcelona: UOC. 
Faus, A. (1991) (Ed.): Radio y Universidad. Treinta años de Radio en la Facultad de Ciencias de la Información de la Universidad de Navarra. Pamplona: Servicio de Publicaciones Universidad de Navarra, S.A.

Faus, A. (1973). La Radio. Madrid: Guadiana.

Fernández, B. (2014): "La radio ante el desafío de las nuevas audiencias", en Razón y Palabra 87.

Fernández Baeza, I. y Busón Buesa, C. (2012): Las plataformas digitales y uso de contenidos audiovisuales. La experiencia de UNED Radio. En C. Espino, y D. Martín-Pena (Eds.), Las radios universitarias, más allá de la radio. Las TIC como recursos de interacción radiofónica. Barcelona: UOC.

Fidalgo Díez, D. (2009): "Las radios universitarias en España: Transformación al mundo digital”, en Telos 80, pp.124-137.

Gallego, J.I. (2010): "La distribución de contenidos de audio. Relaciones entre podcasting, radio y movilidad". Telos, 92.

Gallo, I. (2014): “La democratización de los medios estuvo presente en el Foro Libertad de expresión, comunicación y radios universitarias", en Agencia N22.

Gamonal Arroyo, R. (2011): "Retórica aplicada a la enseñanza del diseño gráfico. Operaciones para la creatividad", en Revista Icono14, Año 9 Esp., pp.410-422.

García Gotor, D. (2015): RadioUnizar.es: Análisis y gestión de la información en una radio universitaria. TFG. Zaragoza: Facultad de Filosofía y Letras. Universidad de Zaragoza.

García, I.M.; Robles, M.C. y Correyero, B. (2014): "Propuestas metodológicas para incentivar el uso de la radio en la docencia en Comunicación: La experiencia de iradio UCAM", en Revista Historia y Comunicación Social, vol. No 19, pp.631-644.

González Conde, M. J. (2003): “Ámbitos de actuación de la radio educativa y su integración en el contexto escolar", en Red 
Digital: Revista de Tecnologías de la información y comunicación educativas, $\mathrm{n}^{\circ} 4$.

Hernández, R.; Fernández, C. y Baptista, P. (2010). Metodología de la investigación. México: McGRAW-HILL.

Hurtado, C. (2007): "En busca de la nueva radio", en Enlaces: Revista Del CES Felipe II, 7.

IAB México (2015): "Estudio de consumo de medios y dispositivos entre internautas mexicanos". Disponible en: http://iabmexico.com/consumo-medios-y-dispositivosmexicanos

IFT (2016): “Infraestructura de Radio y Televisión. Estaciones autorizadas al 14 de Agosto de 2015". Disponible en http://www.ift.org.mx/sites/default/files/contenidogeneral/i ndustria/cuadroestadisticodedistribuciondeestacionesagosto2 015.pdf

Lamas, E. (2003): Gestión integral de la radio comunitaria. Centro de Competencia en Comunicación para América Latina \& Fundación Ebert Stiftung. Quito: Promefes.

LOC (2013): Ley Orgánica de Comunicación. Quito: LEXIS.

LOES (2010): Ley Orgánica de Educación Superior. Quito: LEXIS.

López Vidales, N. y Gómez Rubio, L. (2015): "La radio generalista española, ¿pensada para los jóvenes de hoy?, en Formación, perfil profesional y consumo de medios de los alumnos en Comunicación", en Formación, perfil profesional y consumo de medios de alumnos en Comunicación, Fernando Peinado Miguel (Coord.). Cuadernos Artesanos de Comunicación, 77. La Laguna (Tenerife): Latina.

López Vidales, N y Gómez, L. (2014): “Claves de la desafección juvenil hacia la radio generalista española", en Actas del VI 
Congreso Internacional Latina de Comunicación Social, Universidad de La Laguna.

López Vidales, N. y González Aldea, P. (2014): “Audioblogs y Tvblogs, herramientas para el aprendizaje colaborativo en Periodismo", en Revista Comunicar, 42.

Marta-Lazo, C. y Segura Anaya, A. (2014): Análisis de los usos de redes sociales en las emisoras universitarias españolas. En J.E. Gonzalvez Vallés (Coord.), Redes sociales y lo 2.0 y 3.0. Madrid: Visión Libros.

Marta-Lazo, C. y Segura Anaya, A. (2014): Despliegue de la radio universitaria española en la era de Internet. En D. MartínPena y M.A. Ortiz Sobrino (Eds.), Las Radios Universitarias en América y Europa. Madrid: Fragua.

Marta-Lazo, C. y Martín-Pena, D. (2014): “Investigación sobre radio universitaria: presente, pasado y futuro", en Revista Edmetic, 3(1), pp. 8-25.

Marta-Lazo, C. y Segura-Anaya, A. (2014): "Radios universitarias y redes sociales: Modelos de gestión y perfiles de usuario", en Historia y Comunicación Social, 19, pp.341-354.

Marta-Lazo, C. y Martín-Pena, D. (2014): “Antecedentes, estado de la cuestión y prospectiva de las radios universitarias", en Revista Edmetic, 3(1), pp.2-7.

Marta-Lazo, C. y Segura Anaya, A. y Martín, J.C. (2013): Divulgación científica en Radio.Unizar: podcast e innovación: En clave de ciencia. En. P. Contreras, y M. Parejo, (Coords.), Más Ciencia. Cómo trabajar la divulgación científica desde las Radios Universitarias. Salamanca, España: Comunicación Social.

Marta-Lazo, C. y Ortiz Sobrino, M.A. (2013): “Gestión de los fondos documentales en Radio Nacional de España", en Elprofesional de la información, 22, 5. 
Marta-Lazo, C. y Segura Anaya, A. (2012): “Emisoras universitarias españolas en la Web 3.0: programas y contenidos". En C Espino Narváez y D Martín-Pena (eds.). Las radios universitarias, más allá de la radio. Barcelona: Editorial UOC, pp. 103-124.

Marta-Lazo, C. y Segura Anaya, A. (2011): La radio educativa en la era del dial infinito. En M. Gértrudix, F. Gértrudix Barrio y F. García García (Coords.), Actas II Congreso Internacional Sociedad Digital: espacios para la interactividad y la inmersión, 8. Madrid: Icono 14.

Martí, J.M. et al. (2010): "La crisis del consumo radiofónico juvenil en Cataluña”, en Quaderns del CAC 34, vol. XIII (1), pp.69-79.

Martín-Pena, D. y Aguaded, J. (2016): “La radio universitaria en España: comunicación alternativa de servicio público para la formación”, en Comunicación y Sociedad. N²5, pp.237-265.

Martín-Pena, D. y Aguaded Gómez, J.I. (2015): Participação e interatividade nas rádios universitárias espanholas. En M.J. Brites, A. Jorge y S. Correia (eds.), Metodologias Participativas: Os media e a educação. Portugal: LabCom Books.

Martín-Pena, D., Marta-Lazo, C. y Ortiz Sobrino, M.A. (2015): “De las primeras experiencias radiofónicas universitarias en Latinoamérica y España al trabajo asociativo y colaborativo", en Revista Faro, 1(21), pp.81-94.

Martín-Pena, D. y Segura Anaya, A. (2015): “Las radios universitarias en España: Equipos de trabajo, participación y función social", en Formación, perfil profesional y consumo de medios de los alumnos en Comunicación", en Formación, perfil profesional y consumo de medios de alumnos en Comunicación, Fernando Peinado Miguel (Coord.). Cuadernos Artesanos de Comunicación, 77. La Laguna (Tenerife): Latina.

Martín-Pena, D. y Ortiz Sobrino, M.A. (2014) (Eds.): Las Radios Universitarias en América y Europa. Madrid: Editorial Fragua. 
Martín-Pena, D. y Contreras Pulido, P. (2014): Las radios universitarias en España: inicios, evolución y panorama actual. En D. Martín-Pena y M.A. Ortiz Sobrino (Eds.), Las Radios Universitarias en América y Europa. Madrid: Fragua.

Martín-Pena, D. y Espino Narváez, C. (2014): “Contenido, estructura y función social en la programación de radio universitaria española", en Revista Edmetic, 3 (1), pp.26-43.

Martín-Pena, D. y Aguaded, J.I. (2013): La Asociación de Radios Universitarias como eje dinamizador de intercambios para la divulgación científica. En. P. Contreras, y M. Parejo, (Coords.), Más Ciencia. Cómo trabajar la divulgación científica desde las Radios Universitarias. Salamanca, España: Comunicación Social.

Martín-Pena, D. (2013): Radios universitarias en España: plataformas de comunicación interactiva y redes de colaboración. Tesis Doctoral. Huelva: Universidad de Huelva.

Martínez, L. (2005): "El periodista en transformación en el ciberespacio: la reivindicación del periodista como periodificador en la Red”, en Razón y Palabra, n42.

Martínez Arias, A. y Martínez Arias S. (2013): "Evolución de la radio global y competencia en Internet. El caso de Radio Exterior de España", en Estudios sobre el Mensaje Periodístico, Vol. 19, Núm. 1, pp.487-504.

Martínez Arias, S. (2012) "Periódicos universitarios en Internet. Los diarios de alumnos como herramienta docente en el nuevo entorno tecnológico", en Revista de Comunicación de la SEECI, Año XV (29), pp.17-30.

Martínez Costa, M.P., Moreno, E. y Amoedo, A. (2012): "La radio generalista en la red: un nuevo modelo para la radio tradicional", en Anagramas, 10(20): 165-180.

Martínez Rodrigo, E. y Sánchez Martín, L. (2015): “Comunicación y redes sociales”, en Icono14. Vol.13, 2. pp. 1-5. 
McMillan, S. (2009): Exploring models of interactivity from multiple research traditions: users, documents, and systems. Tennessee, EE.UU: University of Tennessee Pbl.

Meseguer Conesa, Á. (2009): La radio del siglo XXI, un medio interactivo. Euroeditions. Fundación Europea para la Sociedad de la Información y la Administración Electrónica.

Merrill, S.A. (2008): College Radio Survivability: Emerging Business Models and the Challenges of Technological Convergence, Thesis.

Michavila, F. (2009): La innovación educativa. Oportunidades y barreras, en Arbor, Ciencia, Pensamiento y Cultura, pp.3-8.

Moreno, E.; Martínez Costa, M.P. y Amoedo. A. (2009): "Radio and the Web: Communication Strategies of Spanish Radio Networks on the Web (2006-2008)", en Observatorio OBS* Journal, 3(3), pp.121-137.

Ortiz Sobrino, M.A., Salgado Santamaría, C. y Cavadas Gormaz, M.J. (2014a): "Las radios universitarias españolas en la convergencia digital". En J. Sierra (Coord.), Miscelánea sobre el entorno audiovisual 2014. Madrid: Fragua.

Ortiz Sobrino, M.A., Salgado Santamaría, C. y Cavadas Gormaz, M.J. (2014b): "University Radios in Spain as training centers of new broadcasters", en VII Colloque International du GRER, Estrasburgo.

Ortiz Sobrino, M.A., Rodríguez Barba, D. y Cheval, J.J. (2014): “La radio universitaria en el siglo XXI: perspectiva hispanofrancesa", en Revista EdMetic, 1, 3, pp.61-86.

Ortiz Sobrino, M.A. (2011): La radio española en el umbral de la Web 3.0. En M.A. Ortiz Sobrino y N. López Vidales (Coords.), Radio 3.0 Una nueva radio para una nueva era. Madrid: Fragua.

Parejo, M. y Martín-Pena, D. (2014): El papel de la Radio Universitaria como transmisora del conocimiento científico. De la producción individual al trabajo cooperativo: El 
proyecto 'Semillas de Ciencia. En D. Martín-Pena y M.A. Ortiz Sobrino (Eds.), Las Radios Universitarias en América y Europa. Madrid: Fragua.

Parejo, M. y Martín-Pena, D. (2011): OndaCampus Radio: Integradora y formadora. En J.I. Aguaded Gómez y P. Contreras Pulido (Coords.), La radio universitaria como servicio público para una ciudadanía democrática. A Coruña: Netbiblo.

Parra, D. (2008): "De Internet 0 a Web 3.0: un reto epistemológico para la comunidad universitaria", en Anälisi 36, pp.65-78.

Perona Páez, J.J. (2012): Las emisoras universitarias en el contexto digital: programación, nuevos medios y hábitos de Escucha. En C. Espino, y D. Martín-Pena (Eds.), Las radios universitarias, más allá de la radio. Las TIC como recursos de interacción radiofónica. Barcelona: UOC.

Piñeiro-Otero, T. (2015): "La mediamorfosis de la radio local. Una perspectiva desde el contexto de la Eurorregión Galicia Norte de Portugal", en Quaderns del CAC, 41, pp. 35-45.

Piñeiro-Otero, T. (2012): "Los podcast en la educación superior. Hacia un paradigma de formación intersticial", en Revista Iberoamericana de Educación, 58 (1), 1-12.

Prata, N. (2008): Webradio: Novos Géneros, Novas Formas de Interacção. Disertación doctoral. Belo Horizonte, Brasil: Universidade Federal de Minas Gerais.

Quintana, R. (2001): "El lenguaje de la radio y sus posibilidades educativas", en Revista Comunicar, 17, pp.97-101.

Reig, D. y Vílchez, L. F. (2013): Los jóvenes en la era de la hiperconectividad: tendencias, claves y miradas. Fundación Telefónica y Fundación Encuentro.

Rincón, O. (1997): “La radio en la Universidad Javeriana”, en Artículos de Fondo. 
Rivera, M.J. (1993): "El mensaje radiofónico: El uso de la radio en la escuela". En R. Aparici (Coord.), La Revolución de los Medios Audiovisuales. Madrid: Ediciones de la Torre.

Rocha, C. (2008): Radio escolar: comunicación, conflictos y ciudadanías. Bogotá: Uniminuto.

Rodero Antón, E. (2008): "Educar a través de la radio", en Signo y Pensamiento, vol. 27, 52, pp.97-109.

Rodero Antón, E. y Sánchez, Ch. (2007): "Radiografía de la radio en España”, en Revista Latina de Comunicación Social, 62.

Rugeles Contreras, P.A., Mora González, B., Metaute Paniagua, P. y Díaz, J.A. (2014): "El trabajo colaborativo en la educación superior mediada por las tecnologías de información y comunicación". En Global Conference on Business and Finance Proceedings, vol. 9 nº1, pp. 1551-1559.

Salmerón, H., Rodríguez, S. y Gutiérrez C. (2010): “Metodologías que optimizan la comunicación en entornos de aprendizaje virtual", en Comunicar, no 34, pp.163-171.

Sariol, J. (2007). "La Radio Universitaria desde una perspectiva docente", en Mesa de Trabajo.

Sauls, S. (2000): The culture of American college radio. Ames: Iowa State University.

Segura, A. (2014): "Divulgación científica en las radios universitarias españolas", en Revista Edmetic, 3(1), pp.44-60.

Sellas, T. (2012): A two-dimensional approach to the study of podcasting in Spanish talk radio stations, en The Radio Journal, 10 (1), pp.7-22.

Sierra Sánchez, J. y Cabezuelo Lorenzo, F. (2010) (Coords.): Competencias y perfiles profesionales en los estudios de Ciencias de la Comunicación. Fragua: Madrid. 
Teixeira, M., Perona Páez, J.J. y Daher, M. (2010): A rádio web universitária como modalidade educativa audiovisual em contexto digital. Os casos da Espanha e de Portugal. En N. Pretto y S. Tosta (orgs.), Do MEB à WEB. O Rádio na Educação. Belo Horizonte: Autêntica.

Teixeira, M. y Da Silva, B. (2009): Rádio web: Educaçao, comunicaçao e cibercultura no universo académico portugués. En P. Dias e A.J. Osório (orgs.), Challenges 2009: actas da Conferência Internacional de TIC na Educação. Braga: Universidade do Minho.

Ten, A. (2015): La audiencia social en las radios universitarias. TFG de Grado de Periodismo. Madrid: Facultad de Ciencias de la Información, Universidad Complutense de Madrid.

Torregrosa, J. F. (2006): Los medios audiovisuales en la educación. Sevilla: Alfar.

Universidad Colima (2015): "Numeralia 2015". Disponible en http://portal.ucol.mx/content/micrositios/186/ file/estadisti $\mathrm{ca} /$ numeralia/numeralia2015.pdf

Valero Sancho, J.L. (2008): “Tipología del grafismo informativo", en Estudios sobre el Mensaje Periodístico, no 14, pp. 631-648.

Vázquez Guerrero, M. (2014): "World Radio Challenge: el más alegre acto de visibilización de la radio universitaria", en Blog Radio y Universidad, entrada del 9 de septiembre. [Mensaje de un blog].

Vázquez Guerrero, M. y Chamizo, F. (2014): La radio Universitaria en México: Diversidad y contraste. En D. Martín-Pena y M.A. Ortiz Sobrino (Eds.), Las Radios Universitarias en América y Europa. Madrid: Fragua.

Vázquez, M. (2012): La Radio universitaria en México y España: estudio de la participación y formación de los jóvenes. Tesis doctoral. Barcelona: Universitat Pompeu Fabra. 
Vilar, J. et al., (1988): El Sonido de la radio. Ensayo teórico y práctico sobre producción radiofónica. México: UAM-X, IMER, y Plaza y Janés.

Yaguana, H. y Aguiló, J. M. (2014): La radio universitaria ecuatoriana, un nuevo reto para un nuevo tiempo. En D. Martín-Pena y M.A. Ortiz Sobrino (Eds.), Las Radios Universitarias en América y Europa. Madrid: Fragua.

Yaguana, H. y Delgado, W. (2014): 85 años de la radiodifusión en Ecuador. Quito, Ecuador: Quipus, CIESPAL. 


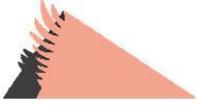 \\ Los autores}

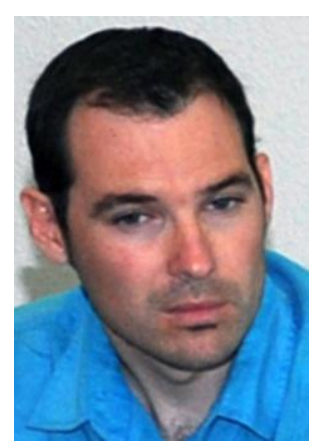

Daniel Martín Pena, Doctor en Comunicación y Educación por la Universidad de Huelva. Personal Científico Investigador de la Universidad de Extremadura. Miembro del Grupo de Investigación ARDOPA. Presidente de la Asociación de Radios Universitarias de España (ARU) y Director de la RadioTv de la Universidad de Extremadura (OndaCampus). Ha impartido conferencias sobre radios universitarias en Colombia, Argentina e Italia. Ha sido editor de dos libros sobre radios universitarias: Las radios universitarias, más allá de la radio. Las TIC como recursos de interacción radiofónica, de la Editorial UOC y Radios Universitarias en América y Europa, de la editorial Fragua.

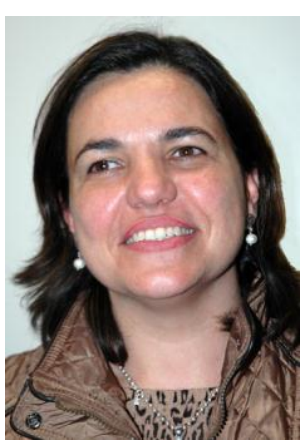

Carmen Marta-Lazo, Profesora Titular de Comunicación Audiovisual y Publicidad y Coordinadora del Grado de Periodismo de la Universidad de Zaragoza. Doctora en Ciencias de la Información por la Universidad Complutense de Madrid. Es Directora de Radio.Unizar e Investigadora Principal del Grupo de Investigación en Comunicación e Información Digital (GICID).

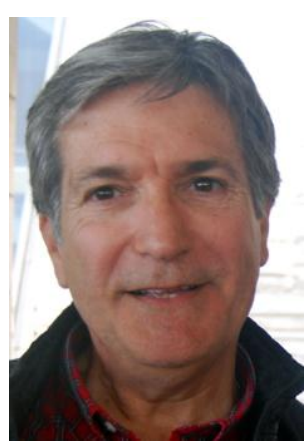

Miguel Ángel Ortiz-Sobrino, Doctor en Ciencias de la Información por la UCM. Licenciado en Periodismo y en Ciencias de la Imagen Visual y Auditiva. Es Máster Oficial en Humanidades por la Universidad Francisco de Vitoria y Diplomado en Investigación de Medios por A.I.M.C. Imparte docencia en el área de Empresa Informativa en la UCM y es Delegado para Medialab/InfoRadio de la Facultad de Ciencias de la Información de la misma Universidad. Miembro de MediaCom UCM. Director entre el año 2000 y 2009 del Instituto Oficial de Radio y Televisión. También ha sido director 
adjunto de Radio Televisión Madrid y jefe de Programas de Onda Madrid.

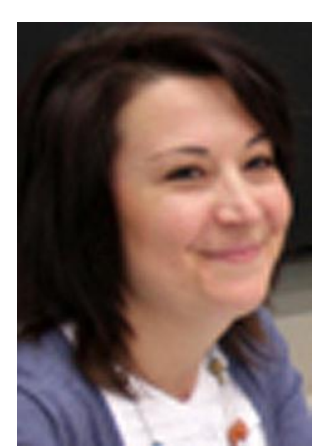

Elsa Moreno Moreno, Profesora Contratada Doctor del Departamento de Proyectos Periodísticos de la Universidad de Navarra. En la actualidad, imparte las asignaturas Creatividad Sonora y Radiofónica, Radio Especializada y Comunicación Radiofónica. Sus líneas de investigación abordan la innovación radiofónica y la creatividad sonora en la convergencia digital, el desarrollo de la radio española en Internet y las redes sociales, así como la evolución de los modelos de programación (oferta-producto) y los modelos de negocio de la industria radiofónica en Europa y Estados Unidos.

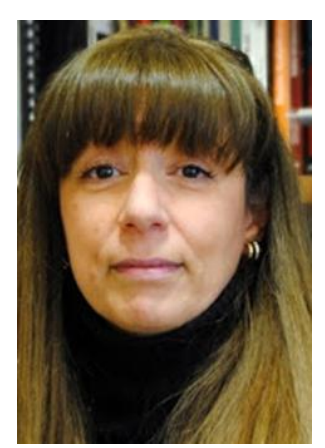

Nereida López Vidales, Profesora Titular del Grado en Periodismo de la Universidad de Valladolid con dos tramos de investigación reconocidos por la CNEAI. Licenciada en Periodismo, Doctora en Ciencias Políticas y Sociología por la UPV y Magister en Producción Radiofónica. Desde 1997 compagina el periodismo profesional con la docencia universitaria. Ha publicado diversos artículos científicos y diez libros. Sus líneas de investigación académica se centran en la tecnología de los medios audiovisuales, la evolución de los perfiles profesionales, las tendencias de consumo mediático, la cultura digital y la creación de nuevos contenidos de entretenimiento para el ocio digital. Directora y fundadora del Observatorio del ocio y el entretenimiento digital (Ocendi).

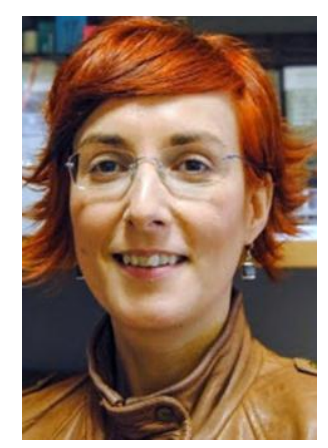

Leire Gómez Rubio, Profesora del Grado en Periodismo y del Máster en Investigación de la Comunicación como Agente Histórico-Social en la Universidad de Valladolid. Licenciada en Periodismo y en Publicidad y Relaciones Públicas por la UPV/EHU, durante varios años ha trabajado en prensa escrita, televisión y gabinetes de comunicación. Sus líneas de investigación se centran especialmente en contenidos, formatos $\mathrm{y}$ audiencias en radio $\mathrm{y}$ 
televisión, así como en nuevas tendencias en consumo audiovisual y medios de comunicación locales. Es autora de varios artículos científicos y coautora del libro Radio Informativa. Guía didáctica de iniciación al medio.

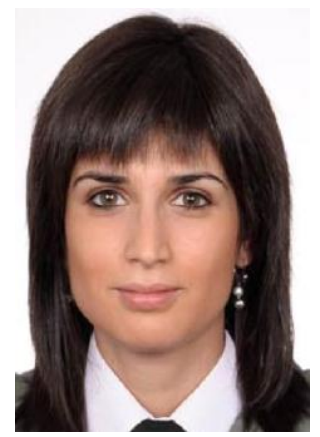

Marta Hernando Lera, Licenciada en Periodismo y Máster en Investigación de la comunicación como Agente Histórico-Social por la Universidad de Valladolid. En este momento, realiza su tesis doctoral sobre la ficción radiofónica en España en la actualidad dirigida por la profesora Nereida López Vidales.

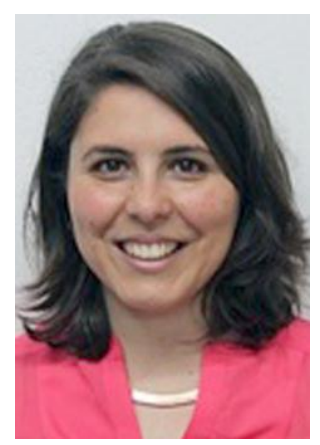

Teresa Piñeiro-Otero, Doctora por la Universidade de Vigo y profesora en la Universidade da Coruña, donde imparte Ambientación sonora y musical en el Grado de comunicación audiovisual. Ha orientado su investigación al medio radiofónico, especialmente desde la perspectiva de su adaptación a la plataforma web y móvil, así como a las nuevas manifestaciones sonoras en la Red. En esta línea ha desarrollado estancias de investigación en la Universidade de Aveiro y en la Universidade de Minho.

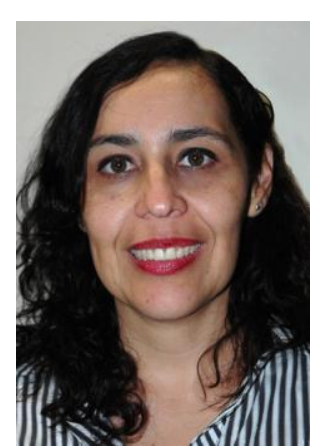

Marina Vázquez-Guerrero, Doctora en Comunicación Pública por la Universidad Pompeu Fabra de Barcelona. Profesora-investigadora de tiempo completo en la escuela de Mercadotecnia y del doctorado en Ciencias Sociales de la Universidad de Colima, México. Perfil PRODEC y miembro del cuerpo académico 59. Experta en temas de periodismo cultural, radio universitaria, formación a través de los medios y jóvenes en España y México con publicaciones nacionales e internacionales. Es editora del blog: La radio universitaria. Los múltiples rostros de la radio universitaria iberoamericana: http://radioyuniversidad.wordpress.com. 
Arturo García Lezama; René López Chagoya y Jorge Andrés Velasco, Licenciados en Publicidad y Relaciones Públicas de la Universidad de Colima.

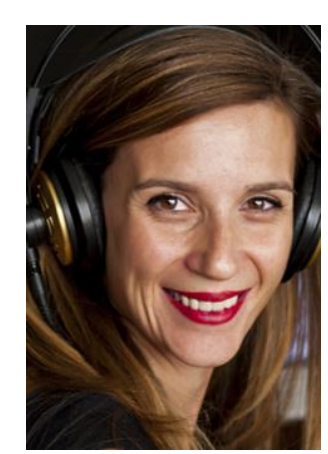

Regina Pinto-Zúñiga, Doctora en Ciencias de la Comunicación por la Universidad de Málaga. Profesora de Formación Profesional de la especialidad de Imagen y Sonido de la Junta de Andalucía. Profesional de los medios de televisión y radio. Ponente de materia radiofónica en distintas universidades Españolas. Integrante de la Comisión de Asesoramiento, Formación y Consultoría de la Asociación de Radios Universitarias de España.

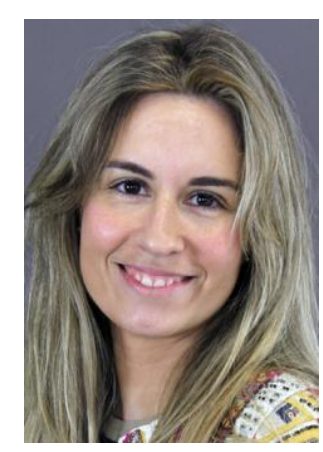

Macarena Parejo Cuéllar, Doctora en Comunicación Audiovisual, Licenciada en Comunicación Audiovisual y Graduada en Periodismo. Trabaja en el Servicio de Difusión de la Cultura Científica dependiente del Gabinete de Información y Comunicación y el Vicerrectorado de Investigación, Transferencia e Innovación de la Universidad de Extremadura. En el año 2013 codirigió el libro +Ciencia. Cómo trabajar la divulgación científica desde las Radios Universitarias promovido por la Asociación de Radios Universitarias (ARU).

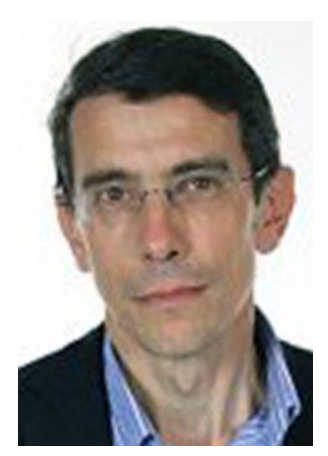

Agustín Vivas Moreno, Profesor Titular de Archivística en la Facultad de Ciencias de la Documentación y la Comunicación de la Universidad de Extremadura. Acreditado como Catedrático de Universidad desde 2012. Doctor en Documentación. Licenciado en Historia y Documentación. Premio Extraordinario de tesis doctoral. Es Director del Centro de Documentación de Estudios de Lectura y Escritura de dicha universidad. Asimismo es representante de la UEx en la Red Internacional de Universidades Lectoras. Ha impartido conferencias y cursos invitados, entre otros lugares, en Brasil, México, EE.UU., Rusia, o Italia. Ha sido investigador principal de 17 proyectos o contratos de investigación. En la actualidad, es director 
del Gabinete de Información y Comunicación de la Universidad de Extremadura.

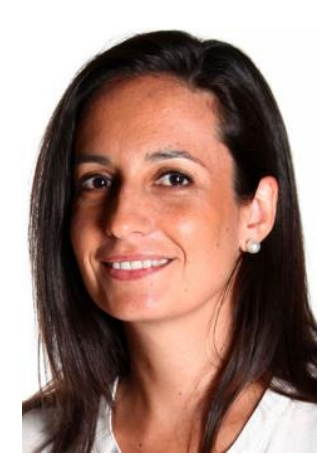

$\mathbf{M}^{\mathbf{a}}$ Carmen Robles, Licenciada en Periodismo y en Publicidad y Relaciones Públicas por la Universidad Católica San Antonio de Murcia. Es profesora del Departamento de Comunicación Audiovisual de la UCAM donde imparte las asignaturas Inteligencia emocional y psicología de la Comunicación, Comunicación oral, Programas informativos y Doblaje Audiovisual. En la actualidad está realizando su tesis doctoral sobre la evolución de la industria de la música en España. Desde 2009 es coordinadora del proyecto de radio universitaria de la UCAM (iradio). Actualmente forma parte de la Comisión Sectorial de Asesoramiento y formación así como de la de Investigación de la Asociación de Radios Universitarias (ARU). Es miembro del Grupo de Investigación Digitalac de la UCAM dentro del cual es investigadora del Proyecto de Innovación docente en comunicación de la Facultad de Comunicación.

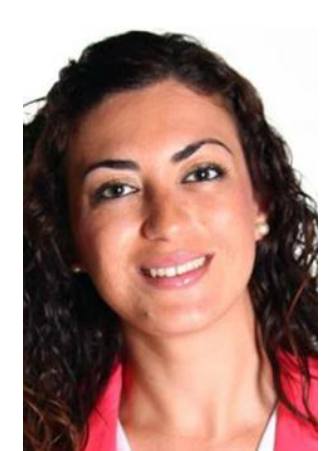

Isabel María García, Licenciada en Periodismo por la Universidad Católica San Antonio de Murcia. Es profesora del Departamento de Comunicación Audiovisual de la UCAM donde imparte las asignaturas Redacción Audiovisual, Información en televisión y Programas informativos. En la actualidad está realizando su tesis doctoral sobre la calidad de los informativos de televisión. Desde 2009 es coordinadora del proyecto de radio universitaria de la UCAM (iradio). Actualmente forma parte de la Comisión Sectorial de Asesoramiento y formación de la Asociación de Radios Universitarias (ARU). Es miembro del Grupo de Investigación Digitalac de la UCAM dentro del cual es investigadora del Proyecto de Innovación docente en comunicación de la Facultad de Comunicación. 


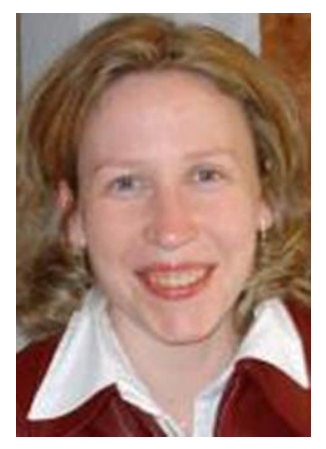

Beatriz Correyero, Doctora en Periodismo y Especialista en Producción Radiofónica por la Universidad Complutense de Madrid. Desde 2012 es Vicedecana del Grado en Periodismo de la Universidad Católica San Antonio (UCAM). Ha colaborado en los procesos de adaptación al Espacio Europeo de Educación Superior de los Grados en Periodismo, Comunicación Audiovisual y Publicidad y Relaciones Públicas de dicha universidad. Desde hace diez años imparte la asignatura de Información en radio. Es también profesora de Taller de Periodismo multimedia y responsable de la asignatura de Practicum. Ha publicado diversos artículos y capítulos de libros sobre innovación docente en comunicación. Actualmente es miembro del Grupo de Investigación Digitalac de la UCAM dentro del cual ha sido coordinadora del Proyecto de Innovación docente en comunicación de la Facultad de Comunicación.

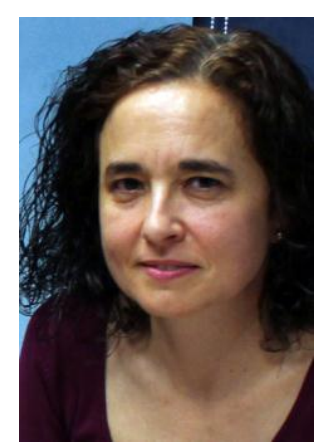

M. Carmen Ponce López, Profesora de Periodismo Radiofónico en la Universidad Miguel Hernández de Elche. Licenciada en Ciencias de la Información por la Universidad Complutense de Madrid. Ha desarrollado su carrera profesional en radio, televisión, prensa y gabinetes de comunicación. Actualmente, compagina la docencia en el Grado de Periodismo con el desarrollo de Proyectos de Innovación Docente en Radio UMH. Miembro del Grupo de Investigación Observatorio de Comunicación Audiovisual y Publicidad (OCAP). Está realizando su tesis doctoral sobre la formación de los estudiantes en las radios universitarias. Vocal del Consejo de Dirección de la Asociación de Radios Universitarias de España (ARU).

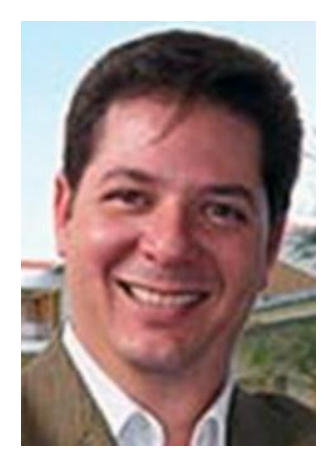

Juan Manuel Aguiló, Ingeniero Electrónico por la Universidad de Oriente, Santiago de Cuba, Cuba. Master en Diseño de Sistemas Electrónicos por la Universidad Martha Abreu, Las Villas, Cuba. Diplomado en sonido para radio, tv y cine. Trabajó en HCJB World Radio y en otras emisoras de Radio y TV tanto en la parte técnica como en producción y brindando asesorías técnicas y de contenido. Docente 
de producción radial y de materias vinculadas al sonido en algunas universidades del país. Es presidente de la Red de Radios Universitarias del Ecuador.

Santiago María Martínez Arias, Doctor en RRII por la UCM. Trabaja como asesor de Contenidos y Producción del canal temático CLASSICA, y es profesor de la Facultad de CC de la Información de la UCM y de la Facultad de Comunicación de la UCJC. Inició su actividad profesional trabajando como corresponsal en Europa Central y Oriental para "El Independiente", colaborando también con otros medios audiovisuales y escritos, y siendo testigo directo de las transformaciones democratizadoras en los países europeos bajo la influencia soviética. 